\title{
Quality Assurance of ARM Program Climate Research Facility Data
}

March 2008

\section{R. A. Peppler, K. E. Kehoe, K. L. Sonntag}

Cooperative Institute for Mesoscale Meteorological Studies/University of Oklahoma

\section{P. Bahrmann, S. J. Richardson}

Pennsylvania State University

S. W. Christensen, R. A. McCord

Oak Ridge National Laboratory

K. J. Doty, R. Wagener

Brookhaven National Laboratory

R. C. Eagan, J. C. Liljegren, B. W. Orr, D. L. Sisterson

Argonne National Laboratory

T. D. Halter, N. N. Keck, C. N. Long, M. C. Macduff, J. H. Mather, R. C. Perez, J. W. Voyles Pacific Northwest National Laboratory

M. D. Ivey

Sandia National Laboratories

S. T. Moore

Mission Research and Technical Services

\section{K. L. Nitschke, B. D. Perkins}

Los Alamos National Laboratory

D. D. Turner

University of Wisconsin

Work supported by the U.S. Department of Energy,

Office of Science, Office of Biological and Environmental Research 


\section{DISCLAIMER}

This report was prepared as an account of work sponsored by the U.S. Government. Neither the United States nor any agency thereof, nor any of their employees, makes any warranty, express or implied, or assumes any legal liability or responsibility for the accuracy, completeness, or usefulness of any information, apparatus, product, or process disclosed, or represents that its use would not infringe privately owned rights. Reference herein to any specific commercial product, process, or service by trade name, trademark, manufacturer, or otherwise, does not necessarily constitute or imply its endorsement, recommendation, or favoring by the U.S. Government or any agency thereof. The views and opinions of authors expressed herein do not necessarily state or reflect those of the U.S. Government or any agency thereof. 


\section{Contents}

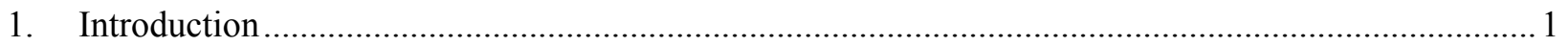

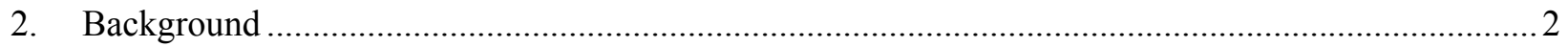

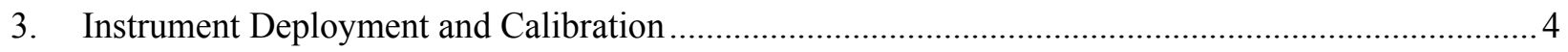

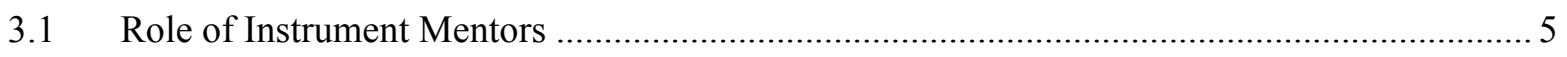

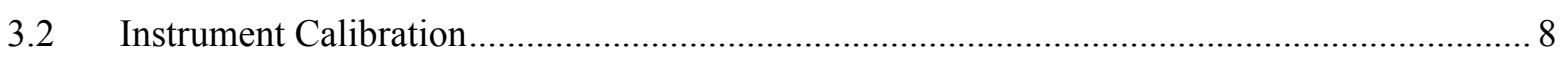

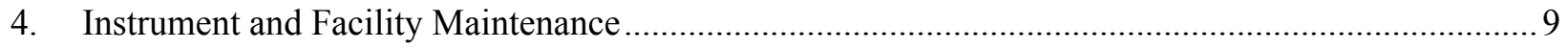

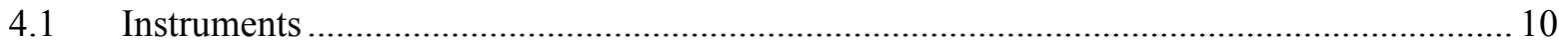

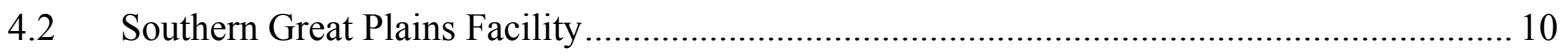

4.3 Tropical Western Pacific Facility and ARM Program Mobile Facility................................ 13

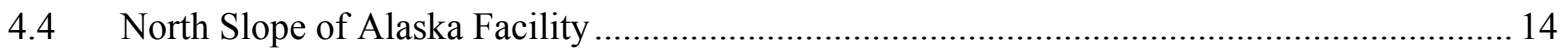

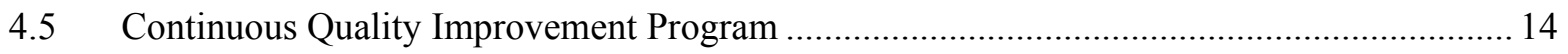

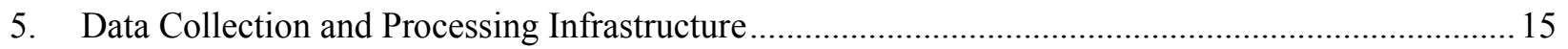

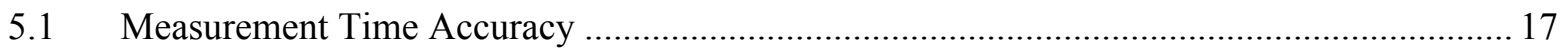

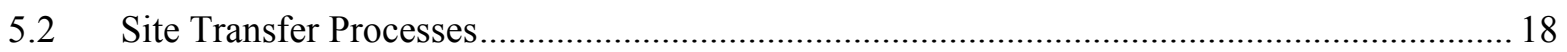

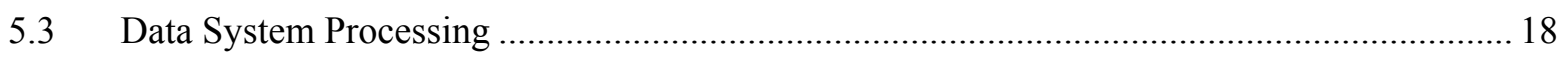

6. Evolution of ARM Program Data Stream Inspection and Assessment ........................................... 18

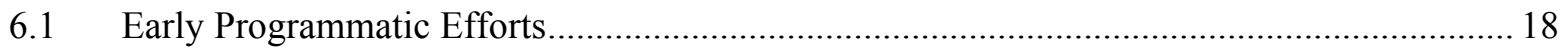

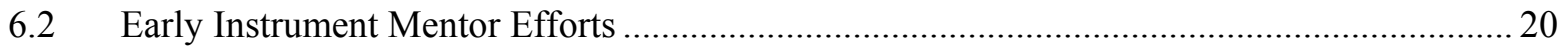

6.3 Early Southern Great Plains Efforts .................................................................................. 20

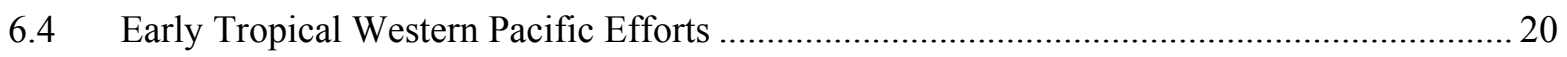

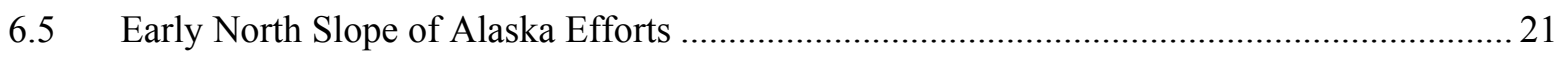

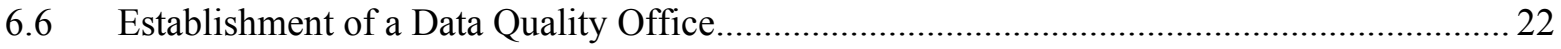

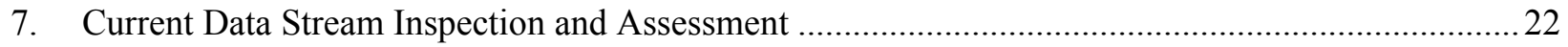

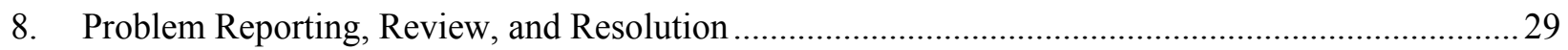




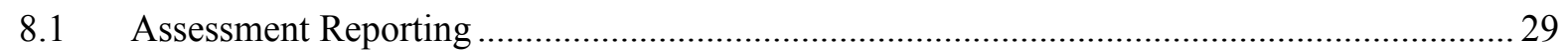

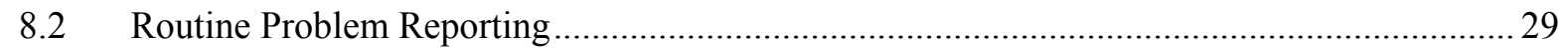

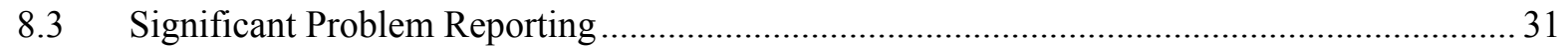

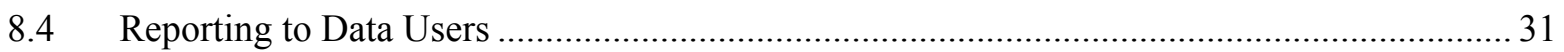

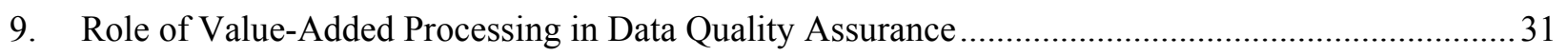

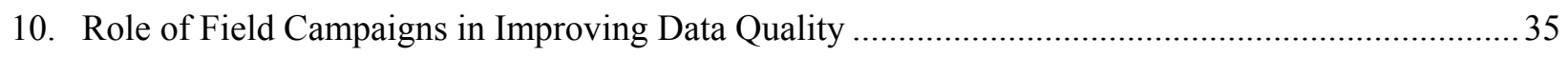

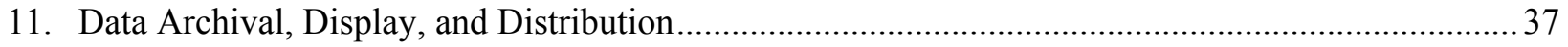

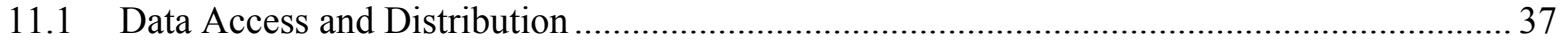

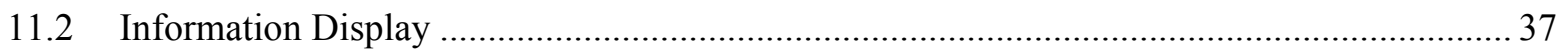

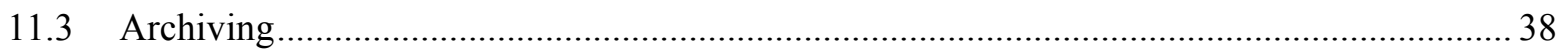

11.4 Metadata for Displaying Information About Data …...................................................... 41

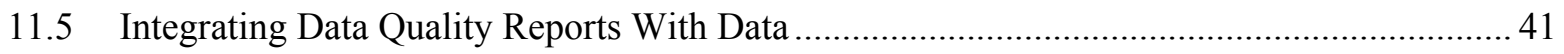

11.6 Quality Assurance Procedures for File Processing............................................................... 41

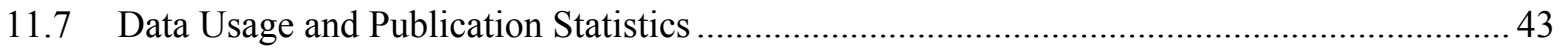

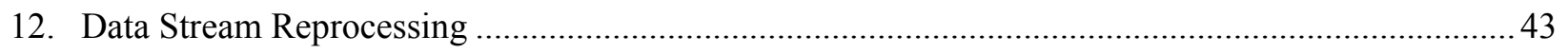

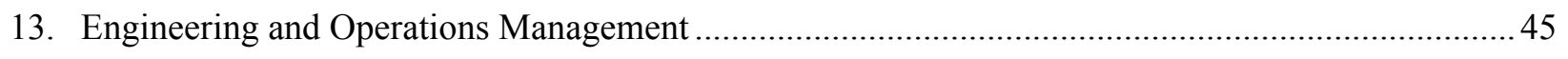

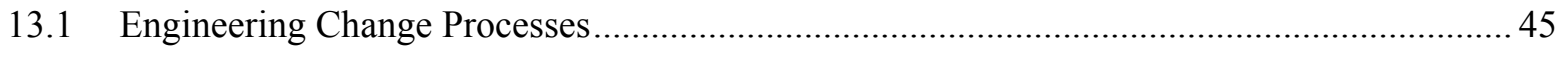

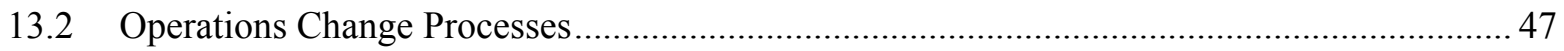

14. Future Directions in ACRF Data Quality Assurance .................................................................. 47

14.1 Using Historical ACRF Measurements to Improve Working Quality Control Limits

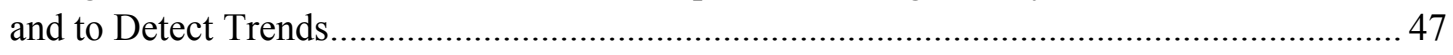

14.2 A New Data Model for Providing Data and Statistics to Users .........................................50

14.3 Storing and Organizing Documentation on Measurements for Data Quality Purposes .......... 51

14.4 Automated Data Stream Quality Processing Modules ….................................................... 53

14.5 Operations Status System Database ............................................................................ 54

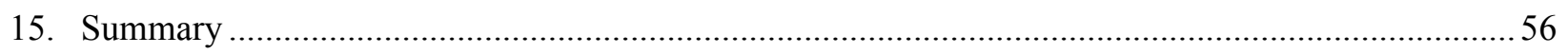

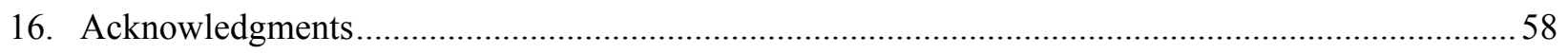

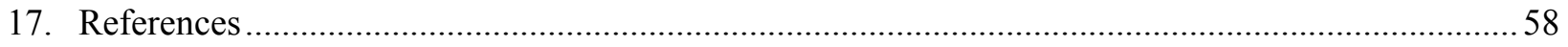




\section{Figures}

1. ARM Climate Research Facility measurement locations............................................................. 4

2. The ACRF Radiometer Calibration Facility located at Lamont, Oklahoma .................................. 9

3. Southern Great Plains extended facilities service routes.............................................................. 11

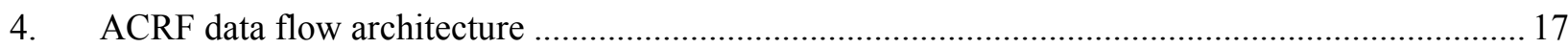

5. Data System View processing page used by site operators to view and monitor current collection and ingest status.

6. Daily color table of automated quality control check results for Tropical Western Pacific Manus Island site for May 1-11, 2007, for a radiometer suite that measures downwelling shortwave radiation.

7. Hourly color table of automated quality control check results for one day at the Tropical Western Pacific Manus Island site corresponding to the example in Figure 6

8. Diagnostic plot of some downwelling shortwave radiation variables on May 7, 2007, at the Tropical Western Pacific Manus Island site corresponding to the example in Figures 6 and 7........26

9. Plot browser time sequence of downwelling radiation plots for May 5-8, 2007, corresponding to the example in Figures 6-8 for the Tropical Western Pacific Manus Island site

10. NCVweb zoom-in on the hours 0200-1000 UTC of the shortwave direct normal measurement on May 7, 2007, corresponding to the example in Figures 6-9, showing values denoted in Figure 7 that violated a minimum test.

11. Data Quality Problem Report 1701 identifying degraded Vaisala Ceilometer backscatter data at SGP boundary facility 6 in Purcell, Oklahoma, that ultimately were caused by a dirty window ..... 30

12. Data Quality Report D070219.1 issued to data users to alert them to the issue described in Figure 11

13. Example plots from several instruments as generated in the ARM Data Archive Thumbnail Browser, a user-customizable interface capable of concurrently displaying multiple measurements from multiple instruments

14. Example color table display obtained from the Data Archive Data Browser for data from a Surface Meteorological Observation Station

15. The ACRF engineering and operations change process flow

16. Statistical analysis system block diagram, running from left to right and top to bottom.......

17. Upwelling longwave radiation exhibits a strong seasonal dependence, as seen in the timeseries and frequency distribution plots

18. Multi-modal distributions signify trend shifts that may warrant investigation of possible data quality issues..... 
19. A data quality Twiki example of a Total Sky Imager shadowband correctly shading the sun at local solar noon; local solar noon is an optimal time to check the alignment of the shadowband....52

20. Proposed revision to the data quality flag processing path, allowing for additional and/or more sophisticated automated data quality processing at the end of a 24-hour data collection cycle........53

21. Operations Status System database schema in summarized form.................................................... 55

\section{Tables}

1. ARM Climate Research Facility instruments and their deployment locations ............................... 6

2. Level at which 95 percent cumulative frequency of agreement was reached between ARM Southern Great Plains Climate Research Facility radiometer measurements ................................. 33

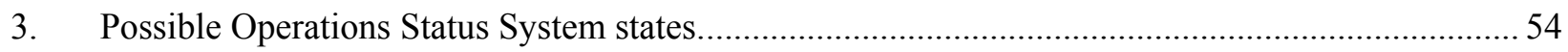




\section{Introduction}

This report documents key aspects of the Atmospheric Radiation Measurement (ARM) Climate Research Facility (ACRF) data quality assurance program as it existed in 2008. The performance of ACRF instruments, sites, and data systems is measured in terms of the availability, usability, and accessibility of the data to a user. First, the data must be available to users; that is, the data must be collected by instrument systems, processed, and delivered to a central repository in a timely manner. Second, the data must be usable; that is, the data must be inspected and deemed of sufficient quality for scientific research purposes, and data users must be able to readily tell where there are known problems in the data. Finally, the data must be accessible; that is, data users must be able to easily find, obtain, and work with the data from the central repository.

The processes described in this report include instrument deployment and calibration; instrument and facility maintenance; data collection and processing infrastructure; data stream inspection and assessment; the roles of value-added data processing and field campaigns in specifying data quality and characterizing the basic measurement; data archival, display, and distribution; data stream reprocessing; and engineering and operations management processes and procedures. Future directions in ACRF data quality assurance also are presented.

Instruments deployed at ACRF sites have been selected to satisfy specific measurement requirements identified by the ARM-funded Science Team as necessary to achieve the scientific goals of the program, which include improving the treatment of clouds and atmospheric radiation within general circulation models. These instruments are maintained by mentors who are experts in their fielding and operation. ACRF site operators and technicians further maintain instruments and sites through preventative and corrective maintenance, collecting and storing information on field procedures and the metadata describing the results of their efforts. In addition, they assist instrument mentors in performing bench and on-site calibration checks. A data collection and processing infrastructure efficiently transmits the data generated by field instruments to a central distribution point. Through several iterations and significant efforts to establish internet connectivity to each field site, the ACRF data system has developed an efficient and integrated data flow.

Data collected by field instrumentation then must be characterized such that users can readily identify the location of known problems. Data quality inspection and assessment activities have included the development of comprehensive tools and protocols as devised by instrument mentors, site scientists, and data quality analysts, and their consistent application across ACRF sites. The quality of ACRF instrument-level measurements has been further improved through the processing and analysis of higherorder, value-added data products. These products provide more sophisticated interpretations of measurement-level information than are possible through routine data quality analysis. The many field campaigns conducted at ACRF sites over the years have included application of observational strategies and instrument comparisons aimed specifically at better characterizing key measurements; these efforts have led to improved measurement accuracy and characterization of key ACRF instruments.

To be useful to the user community, data must not only be of high quality but also must be easily accessible and sufficiently easy to work with. A data archive efficiently stores and provides access to the 
data collected by field instrumentation; it presents intuitive, specific, and complete quality information for all data files. While all of the above is occurring, other processes are at work to make sure that the best data possible is made available to the user community. Data stream reprocessing helps ensure that known, correctable problems are removed, producing a more consistent data format across sites and time to increase the usability of data. In addition, engineering and operations management processes help optimize the performance of all systems and make sure that the application of changes is performed in a structured, documented manner. Future directions in ACRF data quality assurance should lead to more process automation, quicker problem detection, improved tracking of systems, and ultimately better data products for the end user.

A comprehensive, end-to-end data quality assurance program is essential for producing a high-quality research dataset. The processes developed during the more than 15 years of the ARM Program offer a framework for use by other instrumentation-diverse data-collection networks. These networks are described here to highlight the myriad aspects that go into conducting a successful data collection and dissemination program.

\section{Background}

The value of any measurement is dependent on the accuracy and precision with which it represents the physical quantity being measured. Instrument calibration is only one aspect of measurement accuracy, especially for long-term field measurement activities where exposure to the elements adds a host of possible adverse influences on the instruments fielded. Thus, continuous data quality evaluation is necessary when operating long-term automated weather and climate measurement networks. To be most useful for scientific research purposes, a comprehensive, end-to-end quality assurance program, from instrument siting, to calibration and maintenance, through data quality control and well-documented dissemination, is essential.

The amount of attention paid to data quality assurance in the recent (since 1990) meteorological literature attests to these concerns. The review here is limited to automated data collection networks and those in the United States; the grey literature has many other examples. Quality assurance programs for data collected by automated networks have been described in the recent literature by Ohmura et al. (1998) for the Baseline Surface Radiation Network; Shafer et al. (2000) for the Oklahoma Mesonet; Augustine et al. (2000) for the National Oceanic and Atmospheric Administration's (NOAA's) Surface Radiation Budget Network (SURFRAD); and Schroeder et al. (2005) for the West Texas Mesonet.

Specific aspects of the data quality assurance process for automated networks have been documented and include the following publications:

- Meyer and Hubbard (1992) on standards and best practices for automated weather stations

- Meek and Hatfield (1994) on screening rules for hourly and daily data values from individual stations

- Hollinger and Peppler (1995) on the importance of site characterization and documentation

- Tucker (1997) on the variation in characteristics of mesonets, their meteorological implications, and the need for the establishment of standards

- Fiebrich and Crawford (2001) on the impact of unique meteorological events on automated quality assurance systems 
- Martinez et al. (2004) on the value of a dedicated quality assurance meteorologist

- Martinez et al. (2005) on the importance of weather station metadata

- Fiebrich et al. (2006) on the value of routine preventative instrument and site maintenance, equipment rotation, and vegetation control.

Other recent work has focused on the quality assurance of data from particular instruments and includes the following publications:

- Weber et al. (1993) on the quality control of profiler measurements of winds and radar acoustic sounding system temperatures for the NOAA Wind Profiler Demonstration Network

- Richardson (1995) on the calibration of humidity and temperature sensors for the Oklahoma Mesonet

- Fiebrich et al. (2003) on the limitations of sensors used to measure skin temperature in the Oklahoma Mesonet

- Lambert et al. (2003) on the data quality of 915-MHz wind profilers operated by the U.S. Air Force

- Burns et al. (2003) on techniques developed for improving the relative accuracy of longwave radiation measurements made by pyrgeometers during the Cooperative Atmosphere-Surface Exchange Study (CASES-99) experiment.

As these efforts show, much effort is undertaken to ensure that collected data are of the highest quality possible, for not only the immediate purposes of the particular network, but also for future data-mining and research endeavors. A recent community workshop sponsored by the U.S. Weather Research Program on the design and development of a multifunctional, comprehensive mesoscale observing system for integrated forecasting efforts has emphasized the importance of data standards and attention to data quality as part of an integrated, end-to-end solution (Dabberdt et al. 2005). End-to-end data quality assurance has been in practice by the ARM Program since 1992.

As a brief review, programmatic planning for the ARM Program began in the fall of 1989 after the U.S. Global Change Research Program (CEES 1990) identified the influence of clouds and the role of cloud radiative feedback as a highest priority research concern as part of its identification of the scientific issues surrounding climate and hydrological systems. An initial description of the ARM Program was published in 1990 (U.S. Department of Energy 1990) and the identification, recommendation, and justification for site locales took place shortly thereafter (U.S. Department of Energy 1991). The programmatic and scientific objectives of the program, along with a description of the design of a cloud and radiation testbed, were detailed by Stokes and Schwartz (1994). Data collection has taken place at the ACRF Southern Great Plains (SGP) site since late 1992 (e.g., see Peppler et al. 1999), at its Tropical Western Pacific (TWP) locale since 1996 (e.g., see Mather et al. 1998), and at its NSA facility since 1997 (e.g., see Stamnes et al. 1999). A ten-year retrospective of the ARM Program climate observatory and its science can be found in Ackerman and Stokes (2003). Figure 1 shows the locations of the three fixed ACRF sites. 


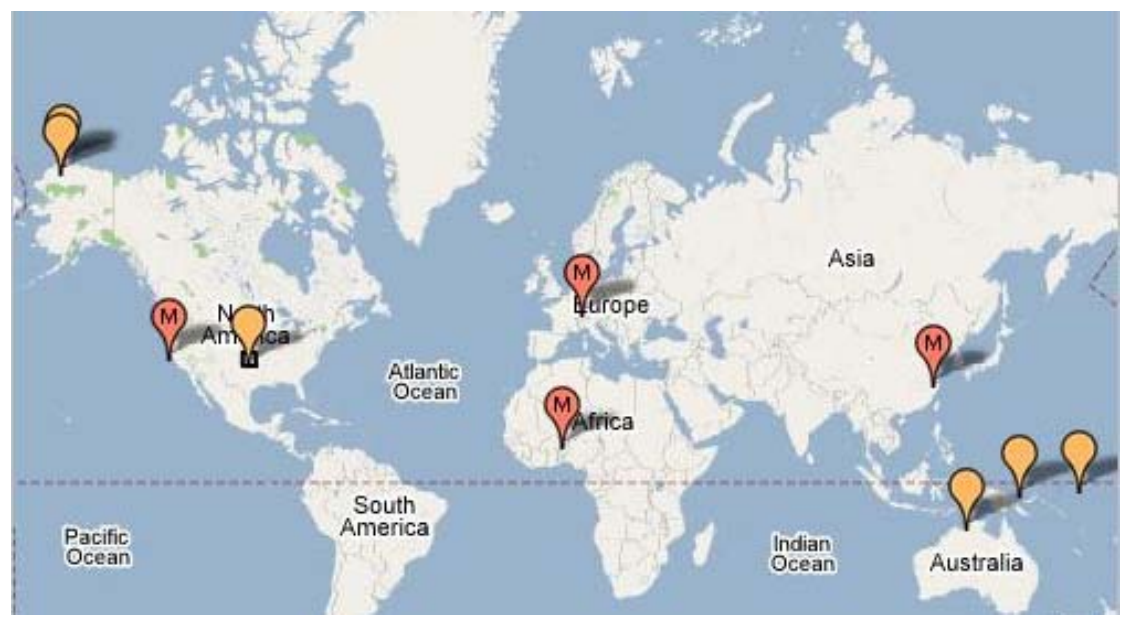

Figure 1: ARM Climate Research Facility measurement locations. Gold markers represent fixed-site locations in the North Slope of Alaska, Southern Great Plains of the United States, and Tropical Western Pacific. Red markers with "M" denote past (California; Niger), present (Germany) and future (China) mobile facility deployments.

In 2004, the ARM Program's climate research facilities and its infrastructure were designated a national user facility, broadening the scope of the data collection and facility activities. The ARM Climate Research Facility, or ACRF, sites provide a unique asset for the study of global climate change to a broad national and international research community having the potential to contribute to a wide range of interdisciplinary science, including meteorology, atmospheric aerosols, hydrology, ecology, oceanography, and satellite validation.

One of the stated goals of ACRF is to provide data and information not only to meet the science goals of the ARM Program but also to provide for the needs of climate science community at large. As such, ACRF sites contain a broad spectrum of instrumentation not often seen in weather and climate observing networks, presenting unique challenges and opportunities with respect to data quality assurance. Thus, the importance of creating a high quality dataset has extended beyond the immediate scientific success of the ARM Program to the legacy needs of the broader climate science community.

Some data quality research has been conducted and reported on particular aspects of ACRF data. This research includes in situ moisture sensor comparisons conducted during an ACRF field campaign focusing on water vapor measurement (Richardson et al. 2000), evaluation of retrievals of column water vapor and liquid water amounts from microwave radiometers (Ivanova et al. 2002), and the detection of a dry bias in radiosonde data (Turner et al. 2003). No comprehensive description of the ACRF's data quality assurance program has been assembled until now.

\section{Instrument Deployment and Calibration}

Instruments initially deployed by the ARM Program were selected to satisfy specific measurement requirements identified by the ARM-funded Science Team as necessary to achieve the scientific objectives of the program (see Stokes and Schwarz [1994] for a thorough description of the ARM Program's scientific objectives). ACRF sites now house numerous instrument platforms, including 
radiometer suites that measure solar and terrestrial radiation; tower-mounted instruments that measure wind, temperature, and humidity; sub-surface sensors that measure soil moisture and thermal properties; a host of cloud-observing instruments that measure cloud extent and are used to infer microphysical properties; and instruments for observing atmospheric aerosols. For the most part, instruments have been obtained from commercial manufacturers for their mature design, operational reliability, ease of maintenance, availability of spare parts, and cost. Because not all programmatic measurement requirements could be met using commercially available equipment, research instruments developed by others have been hardened for autonomous, long-term field operation through a program-funded instrument development program (e.g., atmospheric emitted radiance interferometer, micro-pulse lidar) or have been designed specifically for the program (e.g., Raman lidar, millimeter cloud radar).

\subsection{Role of Instrument Mentors}

For each instrument, an instrument mentor - the technical point of contact assigned to the instrument develops a fundamental statement or baseline of expectations of the performance of each instrument. Data quality ultimately depends on how closely a measurement conforms to an expectation; without an expectation, an accurate assessment of quality is not possible. The mentor documents the expected performance of the instrument on an instrument web page in terms of accuracy, precision, and response time, so that data users can determine the suitability of the measurements for their scientific application. This information can be found at the ARM Program web page (http://www.arm.gov/) within a handbook for each instrument. Each handbook includes information on the current understanding of each measurement system, its quirks and limitations, and describes common problems encountered or inherent to the measurement. Table 1 lists ACRF instruments and their deployment locations, past and present.

The mentor initiates the deployment process by preparing the technical specifications for procurement (in cooperation with relevant ARM-funded Science Team members and other experts), participates in the evaluation of technical proposals from prospective suppliers, and carries out acceptance testing to ensure that performance expectations are met. During deployment, the mentor works closely with other functional teams within the ACRF infrastructure, including Site Operations, the Data System, the Data Archive, and the Data Quality Office to ensure a coordinated installation.

The mentor provides Site Operations with detailed guidance to prepare for installing the instrument in the field (leading to a pre-deployment readiness review) and the documentation and training needed to permit on-site technicians to operate, maintain, diagnose, and repair the instrument (leading to an operational readiness review). The mentor provides Data System personnel with information needed to collect the data from the instrument system (e.g., the size, naming convention, and frequency of the data files) and a comprehensive description of the data and supporting metadata to permit them to be ingested by the data system and converted to self-documenting NetCDF-formatted data files. The ingest process may include the application of calibration parameters to convert the measured values to the International System of Units (SI) or other processing (e.g., retrieval algorithms) that aids the data user or the data quality analyst. Simple limits checking (minimum value, maximum value, maximum rate of change) specified by the mentor is applied as well during ingest and the results included in the NetCDF files. 
Table 1: ARM Climate Research Facility instruments (past and present) and their deployment locations. $(N S A=$ North Slope of Alaska; SGP $=$ Southern Great Plains; TWP $=$ Tropical Western Pacific; AMF $=$ ARM Mobile Facility; $\mathrm{BF}=$ boundary facility; $\mathrm{CF}=$ Central Facility; $\mathrm{EF}=$ extended facility; IF = intermediate facility; FKB = Heselbach/Black Forest, Germany; NIM = Niamey, Niger; PYE = Point Reyes, California. * indicates current deployment as of publication; \# indicates discontinued deployment as of publication; \& indicates present and past AMF deployment as of publication.)

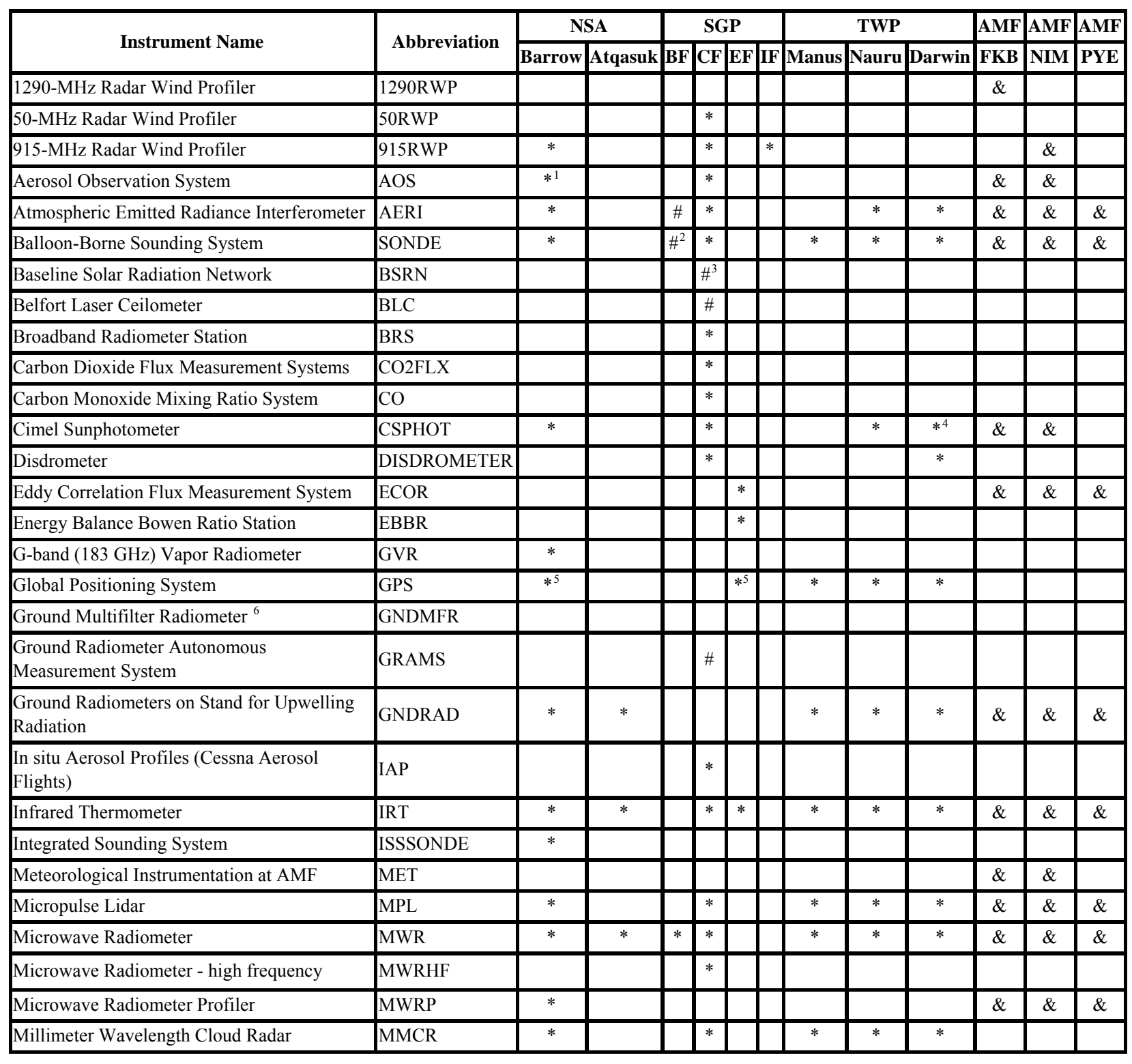

1 The AOS at NSA Barrow is identical to those at SGP and AMF but is operated by NOAA/ESRL/GMD

${ }^{2}$ Occasionally, radiosondes are launched from the SGP BF sites during field campaigns

${ }^{3}$ The BSRN station was renamed BRS

${ }^{4}$ The CSPHOT at TWP Darwin is operated by Ross Mitchell of CSIRO.

${ }^{5}$ GPS instruments at NSA and SGP are operated by SuomiNet

${ }^{6}$ Downward pointing MFRs exist on SGP CF TWR (25-m level) and on SGP CF SMOS (10-m level) and are named mfr25m and $\mathrm{mfr} 10 \mathrm{~m}$ 


\begin{tabular}{|c|c|c|c|c|c|c|c|c|c|c|c|c|}
\hline Mini Sound Detection and Ranging & SODAR & & & & & & & & & & & \\
\hline Multifilter Radiometer & MFR & $*$ & $*$ & & $*$ & & & & & & & \\
\hline $\begin{array}{l}\text { Multifilter Radiometer and Infrared } \\
\text { Thermometer }\end{array}$ & MFRIRT & & & & $*$ & & & & & & & \\
\hline Multifilter Rotating Shadowband Radiometer & MFRSR & * & $*$ & & $*$ & $*$ & $*$ & * & * & & $\&$ & $\&$ \\
\hline Narrow Field of View Zenith Radiometer & NFOV & & & & $*$ & & & & & & & $\&$ \\
\hline Normal Incidence Multifilter Radiometer & NIMFR & * & $*$ & & & & & & & & & \\
\hline Precipitation Network & PRECNET & & & & & & & & & & & \\
\hline $\begin{array}{l}\text { Precision Carbon Dioxide Mixing Ratio } \\
\text { System }\end{array}$ & PGS & & & & * & & & & & & & \\
\hline Radiation Measurements at AMF & RAD & & & & & & & & & & $\&^{1}$ & \\
\hline Raman Lidar & RL & & & & * & & & & & & & \\
\hline Rotating Shadowband Spectral Radiometer & RSS & & & & $*$ & & & & & & & \\
\hline $\begin{array}{l}\text { SGP Surface Conditions Observations by Site } \\
\text { Technicians }\end{array}$ & SURFLOG & & & & $*$ & & & & & & & \\
\hline Shortwave Spectrometer & SWS & & & & * & & & & & & & \\
\hline $\begin{array}{l}\text { Sky Radiometers on Stand for Downwelling } \\
\text { Radiation }\end{array}$ & SKYRAD & * & $*$ & & & & * & $*$ & $*$ & $\&$ & \& & $\&$ \\
\hline Soil Water and Temperatures System & SWATS & & & & & $*$ & & & & & & \\
\hline $\begin{array}{l}\text { Solar and Infrared Radiation Observation } \\
\text { Station Instruments }\end{array}$ & SIROS & & & & * & $*$ & & & & & & \\
\hline Solar and Infrared Radiation Station & SIRS & & & & $*$ & $*$ & & & & & & \\
\hline Surface Meteorological Instruments for TWP & SMET & & & & & & * & $*$ & * & & & $\&$ \\
\hline $\begin{array}{l}\text { Surface Meteorological Observation System } \\
\text { Instruments for SGP }\end{array}$ & SMOS & & & & & $*$ & & & & & & \\
\hline $\begin{array}{l}\text { Surface Temperature and Humidity Reference } \\
\text { System for Sondes }\end{array}$ & SURTHREF & & & & $*$ & & & & & & & \\
\hline $\begin{array}{l}\text { Surface and Tower Meteorological } \\
\text { Instrumentation at NSA }\end{array}$ & METTWR & $*$ & * & & & & & & & & & \\
\hline $\begin{array}{l}\text { Temperature, Humidity, Wind and Pressure } \\
\text { Sensors }\end{array}$ & THWAPS & & & $*$ & * & & & & & & & \\
\hline Time-Lapsed Cloud Video & TLCV & & & & \# & & & & & & & \\
\hline Tipping Bucket Rain Gauge & RAIN & & & & $*$ & & * & * & $*$ & & & \\
\hline Total Precipitation Sensor & TPS & * & & & & & & & & & & \\
\hline Total Sky Imager & TSI & * & & & * & & * & * & * & $\&$ & $\&$ & $\&$ \\
\hline Tower Camera & TWRCAM & $*$ & $*$ & & & & & & & $\&$ & $\&$ & $\&$ \\
\hline Tower Temperature and Humidity Sensors & TWR & & & & $*$ & & & & & & & \\
\hline Vaisala Ceilometer & VCEIL & $*$ & $*$ & $*$ & $*$ & & * & $*$ & * & $\&$ & $\&$ & $\&$ \\
\hline W-Band (95 GHz) ARM Cloud Radar & WACR & & & & $*$ & & & & & $\&$ & $\&$ & \\
\hline Whole Sky Imager & WSI & $\#$ & $\#$ & & \# & & \# & \# & \# & & & \\
\hline
\end{tabular}

\footnotetext{
${ }^{1}$ Deployed at the AMF Niamey Ancillary Facility at Banizoumbou, Niger
} 
The mentor provides Data Quality Office personnel with detailed guidance for inspecting the data to identify anomalies, their likely root cause, and appropriate remedial actions to resolve the problem. Depending on the instrument, the mentor also may provide the Data Quality Office with algorithms that permit more sophisticated checking of the data to identify more subtle problems. Finally, the mentor provides the Data Archive with descriptive metadata about the measurement that allows data users to locate particular data by their attributes.

Instrument mentor quality assurance responsibilities begin with a beta release of data streams. The mentor determines whether the technical specifications of the instrument are being met by the initial data collection, and then performs an initial evaluation of the flagging limits. When the instrument mentor is satisfied that the instrument is functioning properly, the data are formally released to the scientific community and routine data inspection is handed off to Data Quality Office analysts. The mentor remains as a technical consultant to assist the Data Quality Office when unexpected or unrecognized problems arise, and the mentor retains key roles in both problem resolution and problem reporting. As the technical authority on the instrument, the mentor has the final word on data quality issues and accordingly is responsible for writing data quality reports (DQRs) that are seen by data users. However, data quality assurance is a team effort, and the opinions of site scientists, site operators, and Data Quality Office staff figure into such assessments.

Another key instrument mentor role in quality assurance is a focus on longer-term instrument performance characteristics. Whereas the shorter-term efforts of the Data Quality Office are focused on quickly identifying and addressing new data anomalies, the longer-term efforts of the mentor look for subtle trends in data quality over time. The results of this analysis may necessitate the need for instrument recalibration, a change in maintenance practices, a component replacement, or a system upgrade to address unfavorable data trends. The results of such analysis are documented in a monthly report for each instrument.

\subsection{Instrument Calibration}

The calibration of instruments before they are fielded and the calibration checks performed once instruments are operational represent crucial components of the instrument deployment and quality assurance processes. As an example, the ARM Program requires accurate measurement of solar radiation from radiometers used in ground-based networks and airborne instrument platforms. Such measurements are needed to improve the mathematical description of radiative transfer processes simulated in global circulation models. In particular, the evaluation of the so-called 'excess absorption' by clouds and radiative transfer models for clear skies is highly dependent on accurate surface measurements of downwelling solar radiation. More than 100 pyranometers and pyrheliometers have been acquired for measuring shortwave solar irradiance. Here we describe how radiometer calibration is addressed.

To meet the radiometer calibration need, a Radiometer Calibration Facility (RCF) was established in 1997 at the SGP Central Facility, under the guidance of the National Renewable Energy Laboratory (NREL). In support of this need, The RCF provided calibrations of all broadband shortwave radiometers traceable to the World Radiometric Reference maintained by the Physikalisch-Meteorologisches Observatorium Davos/World Radiation Center (PMOD/WRC) in Switzerland (Figure 2). The RCF is comprised of a 45-foot trailer and two elevated decks. The facility houses calibration electronics and a data acquisition 
system, a repair laboratory for radiometer technicians, storage for the reference cavity radiometers and spare radiometers, and a broadband longwave radiometer calibration blackbody (Reda et al. 2005). One of the elevated decks includes mounting spaces equipped with hail shields for up to 50 radiometers. Another elevated deck surrounds four Brutsag solar trackers, which are mounted on concrete piers independent of the deck, and can accommodate eight normal incidence pyrheliometers each. The RCF is designed to simultaneously calibrate up to 100 radiometers in outdoor conditions similar to those the instrument can experience during routine field operations. All broadband shortwave radiometers are calibrated annually at the RCF in two Broadband Outdoor Radiometer Calibration (BORCAL) events, an activity that began in September 1997. During a BORCAL event, the electrically self-calibrating, absolute cavity radiometers are used to calibrate pyrheliometers and pyranometers for measuring the direct normal and total hemispheric shortwave irradiances, respectively. Procedurally, spares are calibrated and swapped with half of the radiometers in the field; then, the radiometers brought in are calibrated and swapped with the remaining half in the field, which then become spares awaiting calibration the following year. Calibration results are processed and reviewed for validity by the broadband radiometer instrument mentor and associates at NREL. The calibration of broadband longwave radiometers is based on exposures to temperature-controlled blackbodies and outdoor comparisons with standard pyrgeometers, and is consistent with the World Meteorological Organization's Baseline Surface Radiation Network (BSRN) calibration protocol. A pyrgeometer blackbody calibration system was installed at the RCF in April 2002.

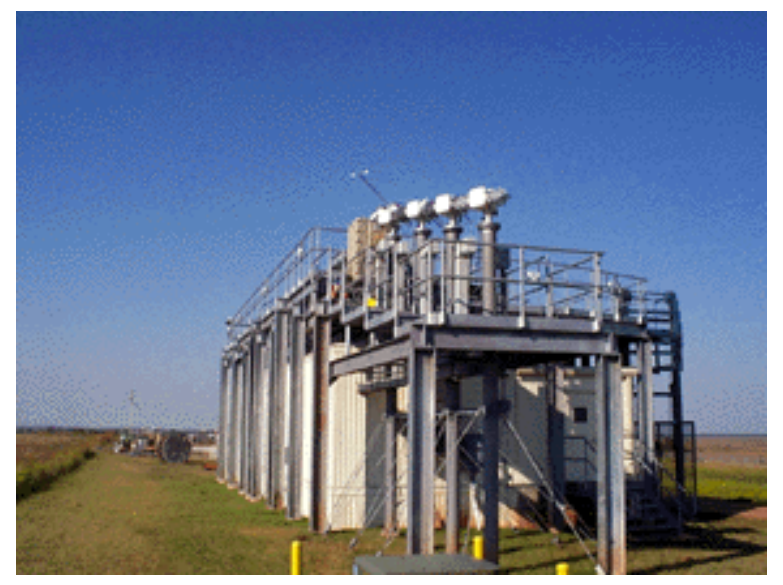

Figure 2: The ACRF Radiometer Calibration Facility located at Lamont, Oklahoma.

\section{Instrument and Facility Maintenance}

ACRF site operators and technicians conduct preventative and corrective instrument and site maintenance, and collect and store information on field procedures and the metadata describing the results of their application. An early description of the maintenance system developed for the SGP site, since expanded to other sites, can be found in Sisterson et al. (1999). 


\subsection{Instruments}

The instrument maintenance process consists of a cycle of structured activities that result in a continuous effort, with the primary objectives of ensuring instrument reliability and performance, robust data quality, all the while achieving cost efficiencies. Building a maintenance capability to service a wide variety of instrument types at diverse locations requires many support elements. Fundamental to this task is recruiting capable local technicians. Instrument mentors and vendors supply the documentation and training needed to permit technicians to operate and maintain the instrumentation. Instrument mentors and vendors also provide diagnostic support and repair coordination as needed once instruments are in the field. These interactions have resulted in the transfer of fundamental knowledge to the technician level. Most activities require a consistent, repeatable maintenance effort, so that maintenance procedures have been developed at the appropriate skill level for the various level of personnel involved, evolving into a substantial library of both paper and electronic procedures. It is beyond the scope of this report to provide detail on the myriad maintenance procedures used at the ACRF sites.

A reliable instrument maintenance capability requires efficient, timely procedures for procuring parts and services to repair failed components. Basic ordering agreements and support contracts have been established with local service companies and instrument vendors to allow parts, supplies, tools, test equipment, instrument sensor repairs, and spare components and assemblies to be obtained quickly. The implementation in 1998 of an electronics repair laboratory at the SGP Central Facility, which serves all ACRF sites, has enabled more on-site repairs of equipment and resulted in reduced instrument downtime related to off-site shipping and repair and in substantial cost savings.

\subsection{Southern Great Plains Facility}

Maintaining a high level of data quality requires periodic on-site maintenance as instruments and elements of the site infrastructure need to be repaired or replaced. Preventative maintenance is performed on a routine basis at the SGP Central Facility and at its 24 extended facilities, 4 boundary facilities, and 3 intermediate facilities. Most Central Facility instruments receive preventative maintenance daily, five days per week, except for holidays. Because of the expanse of the SGP locale in Oklahoma and Kansas, preventative maintenance is performed on a bi-weekly schedule at all other sites.

For the extended facilities, each week two 2-person field technician teams embarks on a multi-site road trip. One week, the two teams service sites in the northern half of the domain and the following week they service the southern half, with the schedule repeated continuously. Sites are divided to make the most efficient use of time and resources. Figure 3 shows the biweekly extended facility maintenance travel routes.

Preparation for an extended facility maintenance trip consists of completing a detailed pre-departure inspection checklist for preventative maintenance, loading spare parts and test equipment, and receiving a briefing on the work orders to be completed during the week's trip. Upon arrival at a site, the team performs checks on all site instruments and communication equipment. A detailed, instrument-specific checklist for each of the instruments is annotated through use of a field-hardened laptop computer and menu-driven, drop-down, preformatted response areas for each checklist item. For some instruments, the laptops are connected directly to the instrument data loggers so that real-time sensor voltages and 


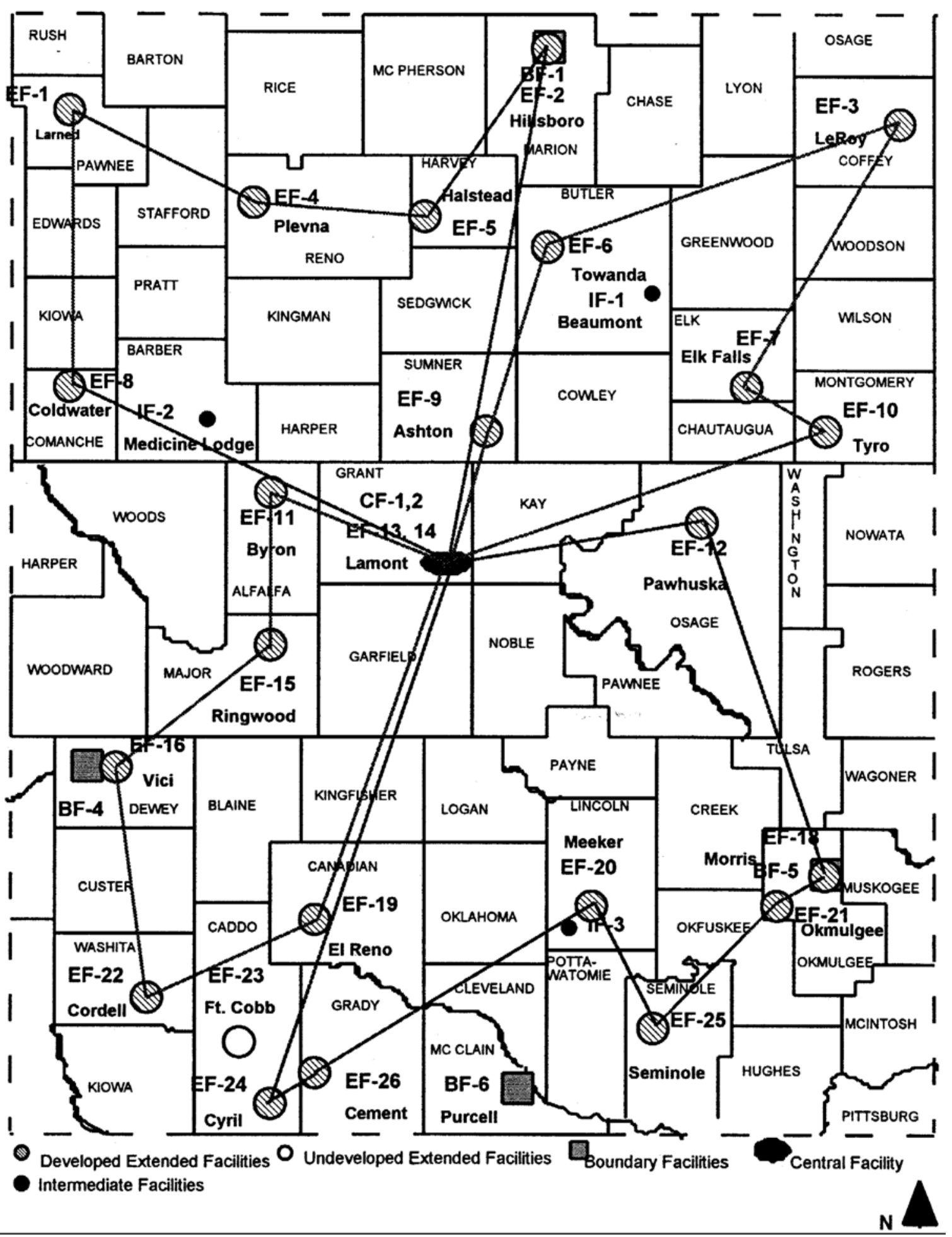

Figure 3: Southern Great Plains extended facilities service routes. Approximate scale: 50 kilometers (31 miles) per inch. 
measurement values can be recorded. If the observed values fall outside an expected range, the applicable data base field is marked as an observed problem and troubleshooting begins. Detail is then provided on the suspected root cause of the failure, along with the name of the specific component that failed or caused the problem.

Pre-trip identified problems (such as by a data quality analyst or instrument mentor) are addressed via a work order that specifies a corrective maintenance procedure and a checklist report also housed in the laptop. The corrective maintenance report contains the date, time, and location of the problem; the affected instrument; a problem description; the problem resolution or action taken at the site; and whether the action resolved the problem. If necessary, technicians download instrument data stored on instrument loggers during the past two weeks. This 'sneakernet' data represents a backup dataset used to fill gaps when data were not successfully collected remotely by the site's data system. When all scheduled maintenance work, grounds reports (e.g., vegetation conditions and heights, and a safety inspection), and sneakernet data gathering are completed, the team notifies the Central Facility operator that maintenance at the site is complete and it departs for the next site on the maintenance route.

During any given week of extended facility maintenance, a team typically completes about 75 preventative maintenance checklists for instruments and site equipment and about 25 corrective maintenance actions. On average, field technician maintenance teams are at a site for one to two hours. The need to complete a route sometimes prevents a team from making all needed repairs before moving on to the next site. In such cases, actions can be postponed until the next regular visit or a field team can be dispatched for emergency repairs; the latter is scheduled by the SGP operations manager based on available resources and the priority of the repair.

Similar biweekly strategies provide maintenance at boundary and intermediate facility sites and will not be detailed here. A more frequent daily preventative maintenance schedule is implemented at the Central Facility because of its co-location to site operations offices and the greater complexity of its instruments. Some instruments require minimal effort, such as the filling of liquid nitrogen coolant, cleaning of domes, or minor adjustments for alignment or shading. More complex systems - such as the Raman lidar, millimeter cloud radar, and aerosol observing system - receive daily inspection and, in some cases, require considerable monitoring effort. The Raman lidar is unique in that its operational status is normally checked several times a day during operation. If the instrument is not running, a manual startup procedure is performed when sky conditions permit laser alignment. An uninterruptible power supply provides constant power to the system so that it can operate continuously through power bumps or outages lasting nearly 60 minutes. Technicians perform more than 100 preventative maintenance procedures on Central Facility instruments during a typical work week, with each procedure generating a report. Developmental and guest scientist instruments residing at the Central Facility also receive preventative maintenance. Corrective maintenance activities at the Central Facility vary from week to week, with the weekly time expended on them varying from 15 minutes to several days.

Because of the large number of instruments and resulting maintenance records generated at the SGP site, a fully integrated web-based system called the Operations Management Information System was developed. After successful deployment at the SGP, this system was adapted to all ACRF sites. This access-restricted, security-protected system provides for rapid exchange of all manner of operational data and information needed by ACRF infrastructure personnel involved in data quality assurance. 


\subsection{Tropical Western Pacific Facility and ARM Program Mobile Facility}

Two of the three TWP data collection sites, Manus Island and the Republic of Nauru, are in remote locations that significantly complicate on-site maintenance activity. Thus, the model for maintenance activity at these sites is different from that for SGP sites and requires a multi-tiered approach. Trained local staff in combination with a team of ACRF technicians based at Los Alamos National Laboratory (LANL) visit the site periodically to perform on-site maintenance. The LANL team is responsible for shipping equipment to and from the sites, coordinating site visits, and communicating frequently with onsite staff. At Manus and Nauru, on-site staff drawn from the local community provide basic training in instrumentation and observations. They capably perform an assortment of system checks on a periodic basis, including daily inspection of instruments, and communicate as necessary with LANL staff. Many maintenance activities, however, require specially trained technicians.

From 1996 to 2001, the Regional Service Team (RESET) based at Sandia National Laboratories in Albuquerque, New Mexico, handled technical site maintenance. RESET visited Manus and Nauru several times per year to replace or repair instruments and infrastructure components. The relative infrequency of visits to Manus and Nauru meant that some instrument repairs took a considerable amount of time to accomplish. When an instrument experienced a problem, it often took one visit to diagnose the problem and a second visit to perform the required maintenance, resulting in significant periods of degraded or missing data. Complex active remote sensors such as the millimeter cloud radar and micropulse lidar were most susceptible to these delays.

In 2002, the ACRF TWP entered into a collaborative arrangement with Australia's Bureau of Meteorology to conduct this maintenance. This arrangement also included installation of a third site in Darwin, adjacent to the local Bureau observation facility. Because it is significantly easier to travel to Manus and Nauru from Darwin than from the United States, this change has made it possible to visit Manus and Nauru more frequently. Although delays still occur in addressing instrument issues at these remote sites, the relative proximity of the Bureau team has led to a general decrease in the time required for repairs and to a resultant improvement in data availability and quality.

In 2004, a mobile platform was designed and integrated into the ACRF measurement suite to address a lack of data in undersampled yet climatically important regions of the world. The ARM Mobile Facility (AMF), with a suite of instruments similar to those at Manus and Nauru, was initially deployed in March 2005 for six months at Point Reyes, California; then deployed for 13 months near Niamey, Niger, in West Africa; and for nine months in the Village of Heselbach in the Black Forest region of Germany. Due to the relatively short duration of AMF deployments and the effort required to support them, responsive technical support was deemed essential to ensure that instrument downtime was minimized and data quality was optimized. Thus, the support functions of LANL and Bureau staff were extended to include the AMF, including the full-time, on-site technical support.

A Site Operations Center located in Darwin now provides the TWP and AMF on-site technicians with primary technical support assistance. Center technical-team members rotate through these sites as required and participate in planned routine maintenance visits of the TWP sites. The Center utilizes electronics workshop expertise at the SGP Central Facility and the expertise of instrument mentors to reinforce technical competencies. The similarity of instruments, infrastructure, and processes of the TWP 
and AMF sites, coupled with the experiential familiarity of the Center's technical team with each site, has enabled efficient operations and cross-site integration. During an AMF deployment, the on-site technician is wholly responsible for the daily operation of the site, with the exception of balloon-borne sounding operations that are undertaken by locally contracted staff. With regular instrument inspections and on-site data analysis, the on-site AMF technician often can address instrument and data quality issues before they are seen as data quality evidence. As the sole custodian of the mobile site, this technician has developed a well-established sense of ownership, as shown by a resultant increase in operational performance. The combination of resident technician and well-developed support infrastructure and processes has resulted in AMF deployments exceeding data availability and quality targets.

\subsection{North Slope of Alaska Facility}

Preventive and corrective maintenance for instruments and facilities at the NSA facility can be challenging, particularly during winter months. North Slope facilities are remote, and Arctic conditions in mid-winter often limit outdoor activities. Identification of problems, corrective actions, and scheduled preventive maintenance occurs through collaboration among local on-site observers, Data Quality Office staff, the North Slope site scientist team, instrument mentors, and a Rapid Response Team at the University of Alaska in Fairbanks.

North Slope facilities include a primary site in Barrow, maintained by two full-time staff, and a smaller secondary site in Atqasuk, staffed by one part-time operator. At Barrow, operators perform daily workweek maintenance procedures on all permanent instruments, as well as daily or weekly procedures as specified for visiting instruments. At Atqasuk, maintenance procedures are performed three times per week. The preventive maintenance procedures are described in a preventive maintenance manual located at each site. The operator records results and notes from these regular checks in a database. These forms are maintained in an Operations Management Information System on a server at Fairbanks.

When a problem is observed, a description and possible action are forwarded via email or phone call to the site operator and a problem report is filed. The local operator then performs corrective maintenance; instrument mentors via remote access to instrument computers can accomplish some corrective maintenance procedures remotely. Corrective actions also are tracked and stored in the Operations Management Information System.

\subsection{Continuous Quality Improvement Program}

A Continuous Quality Improvement Program has been implemented at the SGP and North Slope facilities and may be implemented at the TWP sites. It consists of a cycle of planning, implementation, proficiency checking, and analysis that is carried out through periodic on-site audits by the site scientist, the site operations safety officer, the site instrumentation and facilities manager, and the ACRF environmental safety and health coordinator. The diversity in background of this team allows it to examine the sites and their instruments from several perspectives. Audits include inspections and observations of site grounds, instruments, equipment, maintenance procedures, technician proficiency, and other work quality measures. Data collected during these audits are analyzed, and improvements in the work process are developed and inserted into the planning process for eventual implementation. Continued audits and 
checks provide feedback to the quality cycle by assessing the effects of the improvements. Rotating audits during different seasons help capture information on exposure to seasonal extremes.

Since the SGP Continuous Quality Improvement Program was implemented in spring 2000, the number of problems noted during on-site audits has dropped because of improvements to maintenance procedures and technician training. This has resulted in an overall improvement in data quality by improving data availability and by heading off potential instrument and site problems before they have a chance to affect data quality. The first North Slope audit took place during summer 2006.

\section{Data Collection and Processing Infrastructure}

An early glimpse at how data collection and processing was accomplished can be found in Gracio et al. (1996). Much has changed since then, driven largely by technology. Here, we provide an overview of the present data collection and processing infrastructure, given in more detail by Macduff and Eagan (2004, 2005). The basic focus of this infrastructure is to efficiently transport data generated by instruments from the field to a central distribution point. The remoteness of most of the sites and the diversity of instruments deployed add to the complexity of the solution. Network access to sites often is limited, which significantly impacts options for data flow architecture and management. Through several iterations and significant efforts to establish Internet connectivity to each site, an efficient and integrated data flow has evolved. Network and computing infrastructure now are able to centrally process data from all sites on an hourly basis and to make daily updates available for data users. This is accomplished using satellite networking, specialized data movement processes, and a tight configuration management process.

The data collected from all ACRF sites are processed at the Data Management Facility at Pacific Northwest National Laboratory, which is the central point for raw data processing, before being transferred to the Data Archive at Oak Ridge National Laboratory, where processed data are made publicly available. Data from other non-program sources are collected, processed, and made available to the ARM Science Team at the External Data Center at Brookhaven National Laboratory. The Data Management Facility is able to monitor the individual site data systems through a graphical user interface called Data System View (http://c1.dmf.arm.gov/ds/dsview/), which provides an overview of site instrument collection and ingest status and detailed messages and access to system resources.

All measurement sites now are connected to the Internet. The SGP Central Facility has a T1 link to an Energy Sciences Network (ESNet) peering point at Oak Ridge. Other measurement facilities within the SGP domain use a continuous, low-speed (20-50 Kbps) satellite link or a landline modem dial-up to a local Internet Service Provider (ISP). At Manus and Nauru in the TWP, the network connection is accomplished with satellite ground stations that support 256-Kbps outbound and 64-Kbps inbound channels. The Darwin facility has a 512-Kbps frame relay link with an Australian service provider. At Barrow in the NSA domain, the site shares a satellite-based T1 link that is partially funded by the National Science Foundation. The Atqasuk facility there uses a symmetrical 64-Kbps satellite link through a commercial ISP. The variety in types of infrastructure is a result of identifying the most appropriate available technology that will support the data transfer requirements of the facility in the most cost-effective manner. In practice, the network infrastructure has, at some locations, changed over time to meet changing needs and to take advantage of current technologies. Before achieving complete Internet connectivity, some data were transmitted on removable media. This had a significant impact on the efficiencies of the entire data flow process. Simple activities such as upgrading software or debugging problems were more time consuming. 
Ubiquitous Internet connectivity has enabled the program to develop the data flow architecture illustrated in Figure 4. The ACRF data flow process acquires the measurement data at the remote sites, processes the measurements into a form that is usable by the scientific and educational communities, performs quality analyses of the dataset, and archives the data in a manner that enables ease of accessibility by users worldwide. The data flow process includes the following functional steps performed at various physical locations:

- Collect measurement data at remote measurement facilities

- Verify measurement time accuracy

- Transfer measurement data to the Data Management Facility

- Ingest data into a common, standardized format

- Perform quality analysis of the data

- Perform supplemental processing, which results in value-added products (VAPs)

- Reprocess measurements as necessary to correct errors or otherwise ensure a complete and representative dataset

- Acquire and process non-program data products that are of interest to the ARM Program-funded scientific community

- Transfer raw and processed measurements to the Data Archive

- Ensure the long-term availability of the data at the Archive

- Make the measurements publicly available to a worldwide user community in a largely transparent process.

Access controls are in place to ensure that the remote sites are operated in a continuous, highly-reliable manner. The data flow architecture is logically implemented by routing all Internet traffic to the measurement facilities through a Virtual Private Network (VPN) Server Network (VSN) located at Argonne National Laboratory. The VSN implements VPNs with each of the measurement facilities. This architecture has several interesting features that include the following:

- Internet routing that effectively remains unchanged when ISPs for local measurement facilities change due to budget, technological, or other reasons

- Firewalls implemented in a common, central, and easily accessible location by authorized administrators

- Undesirable traffic that can be filtered before it traverses (often expensive) satellite infra-structure

- Traffic monitoring and analysis that can be performed at a common, central location.

For reasons of performance and redundancy, the Data Management Facility also implements a set of VPNs within each measurement location. These VPNs are the primary paths of data flow between measurement facilities and the Data Management Facility. Significant features of the data flow process are described below. 


\section{ARM Climate Research Facility Data Flow Architecture}

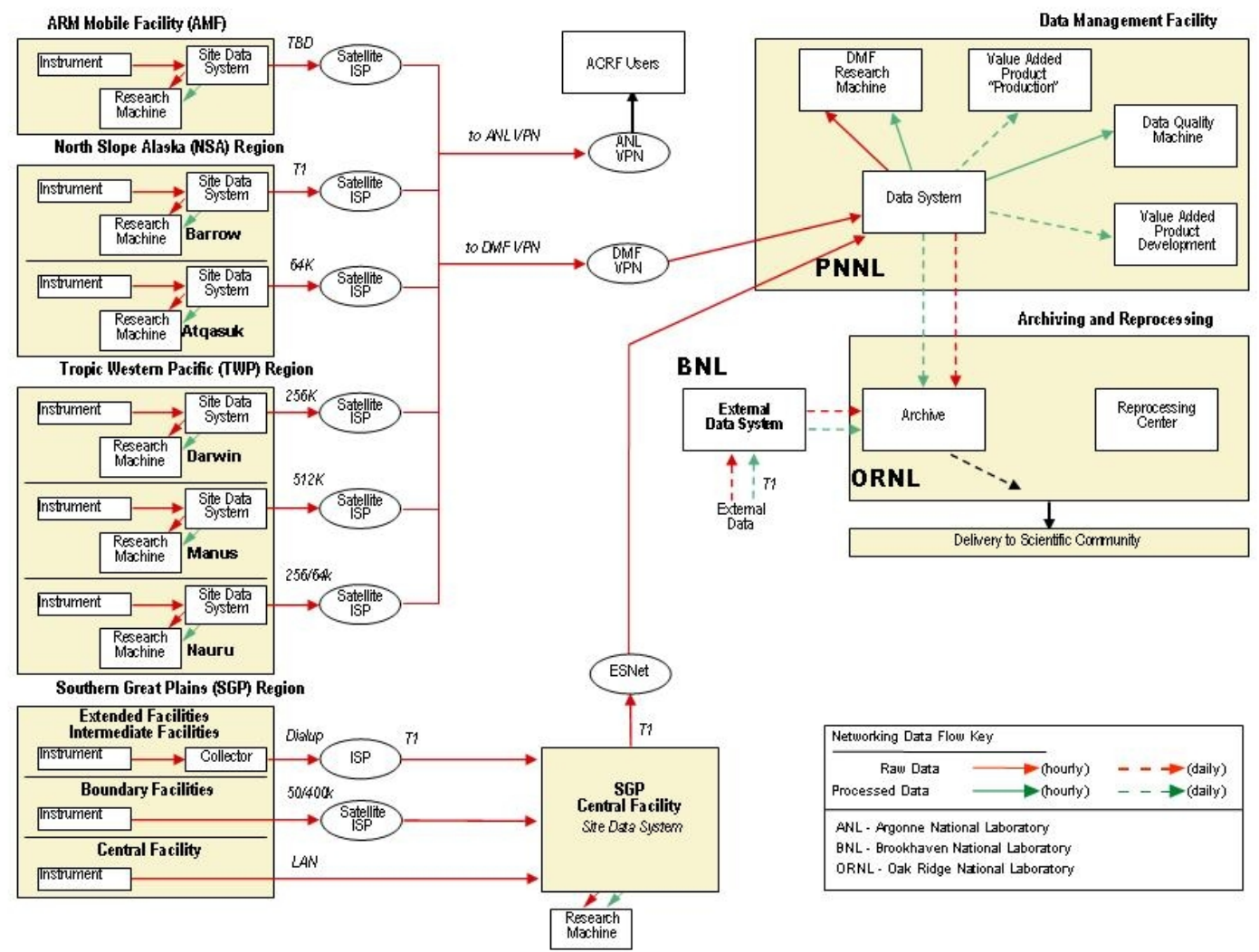

Figure 4: ACRF data flow architecture.

\subsection{Measurement Time Accuracy}

A critical characteristic of measurements is the accurate synchronization of the measurement time stamp with a universally recognized time reference. The ACRF data system uses the Network Time Protocol (ntp; Internet Engineering Task Force Request for Comment 1059, 1119, and 1305) to maintain accurate time synchronization. Each measurement facility and the Data Management Facility have a commercially available Global Positioning System (GPS) network time reference. Solaris and Linux systems used within the data infrastructure include a daemon (ntpd) that implements the ntp. Windows systems use an open-source application, Dimension-4. Instrumentation that is not network connected but uses an RS-232 or equivalent interface has its internal clock compared to that of the GPS reference by the Linux collector system, which uploads the data from the device. In this case, the instrument clock time is reset when the time difference exceeds twice the instrument clock resolution. Even though ntp daemons are installed on all systems, synchronization occasionally fails. Therefore, at each collection time, the collector system uses a perl implementation of ntptrace to verify that the instrument currently being collected from has a running ntpd and that it is synchronized with the GPS reference within two seconds. 


\subsection{Site Transfer Processes}

Moving data in a reliable manner is one of the essential functions of the data system. The greatest risk of data loss or corruption occurs in the transfer of files across wide area networks (WAN). To mitigate this risk, a Site Transfer Suite (STS) was developed. This software uses File Transfer Protocol (FTP) to send data between the sites and the Data Management Facility. STS uses MD5 checksums to validate the successful transfer of data. The checksums are transmitted twice, with each validated on the receiving host, ensuring the integrity of the data. Files that fail checks are automatically resent. While data integrity is the first concern of the STS, the limited bandwidth to some sites presents additional challenges. It is operationally important to know the state of the remote sites as well as that of each instrument. If a backlog of one instrument is allowed to dominate file transfers, it will prevent efficient management of the sites and of data flow. The STS provides configuration options that include prioritizing data and using multiple threads for different datasets. This ensures that essential operational information is sent first. It also allows larger datasets to be sent as the lowest priority, ensuring that most data products are delivered in a timely manner. In general, all hourly data are shipped from each site to the Data Management Facility within 20 minutes. The STS has served as the backbone of inter-site data movement for over 12 years. While WAN networks have increased in reliability during this period, the potential for data mishaps is still significant and the use of STS provides appropriate and necessary assurances.

\subsection{Data System Processing}

The automated processing of data occurs hourly at the Data Management Facility. This primarily is comprised of the ingesting of data into NetCDF format and applying aforementioned quality limits tests. To manage the processing of the data system, several components are used, including a postgres database (DSDB) and the Data System View web interface. The database is replicated throughout the data system to ensure consistency in data flow and is used to track process status. These statuses are displayed by Data System View, which is used by Data Management Facility operators to monitor processing (Figure 5). Such tools provide simple views of data throughput that help catch problems early in the quality assurance system.

\section{Evolution of ARM Program Data Stream Inspection and Assessment}

\subsection{Early Programmatic Efforts}

Initial data quality inspection and assessment was made through the development of self-consistency checks for individual data streams (Blough 1992) and quality measurement experiments (Miller et al. 1994) that compared multiple data streams. Self-consistency checking involved not only simple range and rate-of-change tests, but also automated statistical assessment of individual data streams for internal anomalies to detect outliers and identify instrument failure, creating flags to notify data users and instrument operators. Some statistical assessment was done using a Bayesian dynamic linear model. Early applications of these were made for the detection of moisture on radiometer domes and for the detection of signal attenuation, side-lobe leakage, birds, and other interference on wind profilers. 


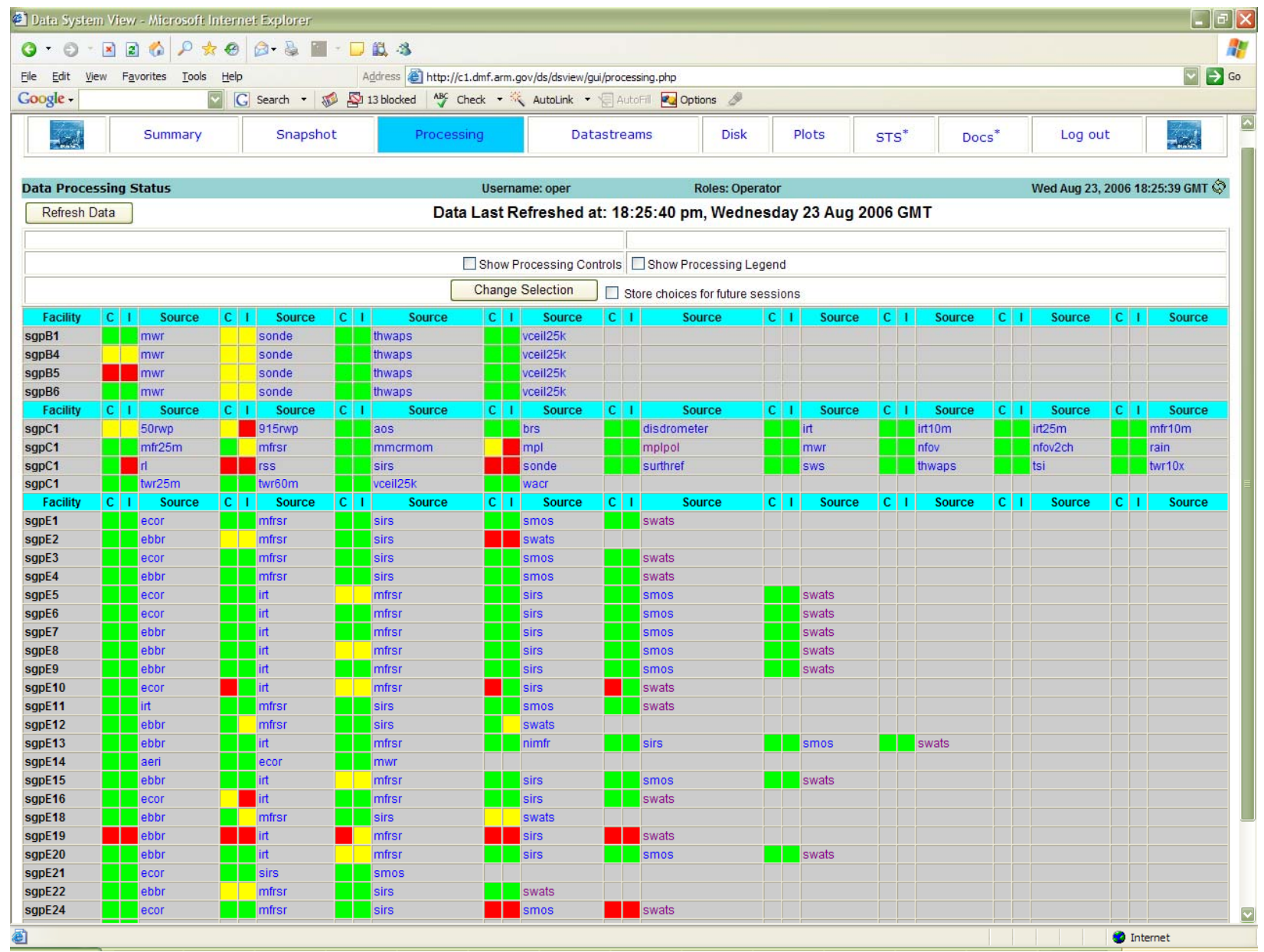

Figure 5: Data System View processing page used by site operators to view and monitor current collection and ingest status. Sites are labeled in black and instruments in blue. Columns labeled with "C" denote collection status and columns labeled with "I" denote ingest status. This page allows site operators the ability to enable and disable instrument collection and ingest processes.

The quality measurement experiment concept was developed to compare multiple data streams against a set of expectations as to the outcome of the comparison, such as the hypothesis of an experiment. The multiple data streams that served as inputs included: direct observations from instruments; measurements derived from multiple instrument observations and the subsequent application of algorithms; and model output. The idea behind this concept was that comparisons involving multiple data streams should reveal more information about quality than simple single data stream self-consistency checks could allow. As such, a major function of the quality measurement experiment was to identify data anomalies and to help analysts identify the root cause of exceptional behavior. The defined comparisons were typically made in the near real-time and processing was automated. The measurements produced were themselves treated as official ACRF data and were archived. As examples, one quality measurement experiment involved comparing vertically integrated water vapor from microwave radiometers with the output of a microwave radiometer instrument performance model that used thermodynamic profiles from sondes to drive the model. Another made hourly comparisons between infrared spectral radiances observed by a Fouriertransform interferometer and the output of a line-by-line radiative transfer model (Turner et al. 2004b). 
While within-file flagging continues today, dynamic linear models and quality measurement experiments are no longer processed, though many multi-measurement and instrument comparisons are still made.

\subsection{Early Instrument Mentor Efforts}

Substantial effort was expended in day-to-day quality control early in the program by instrument mentors, as described earlier in Section 3. In short, mentors played a crucial role by independently monitoring the data for their assigned instruments using various homegrown analysis and interpretive techniques, reporting their findings on potential problems, and suggesting solutions to site operators. Instrument mentors were the first line of defense in data quality assessment and problem diagnosis and solution.

\subsection{Early Southern Great Plains Efforts}

SGP site scientists at the University of Oklahoma, after the broadening of the World Wide Web in the mid-1990s, assisted instrument mentors by developing methods to facilitate the graphical display of data and the results of within-file limits checking (Splitt 1996; Peppler and Splitt 1997). The idea behind these diagnostics was to make them available for viewing by instrument mentors and site operators as soon as the data became available (at that time, two days after collection), regardless of the physical location of the viewer. Among the earliest diagnostic aides developed were comparisons between hemispheric broadband solar irradiances and modeled clear sky estimates, and the respective comparisons of shortwave albedo estimates and broadband longwave observations from multiple sites. Interpretive guidance for plots was developed to aid site scientist analysts and an email reporting system was developed for alerting site operators and instrument mentors about problems. Instrument mentors remained fully engaged in near real-time data inspection and assessment activities.

\subsection{Early Tropical Western Pacific Efforts}

Efforts to display and assess TWP were made by site scientists then at Pennsylvania State University as data collection commenced later in the 1990s. This locale presented interesting complications that require some description here. Its first site was installed at Manus Island in October 1996. It included the core instruments then found at the SGP Central Facility site, including broadband radiometers, a micropulse lidar, and a radiosonde system. However, unlike sites in Oklahoma and Kansas, the available bandwidth connecting Manus to the Data Management Facility was extremely limited. The only satellite communications available were via InmarSat-C for very limited system queries, InmarSat-B for voice communication, and a GOES data channel. The latter provided the only near real-time data transfer, which amounted to packets of approximately $1 \mathrm{~kb}$ each hour. The remainder of the data were recorded to tape and mailed to the United States, with typical delays of several months between raw data collection and their processing at the Data Management Facility. This delivery delay was the norm until an enhanced VSAT satellite communications system was installed in late 2002, making near-real time delivery possible for most data.

During the period of delayed data delivery from the TWP sites, examination of the data by site scientists occurred in two stages. The first stage was to identify potential maintenance issues and was directed at site operations staff. The second stage involved a more detailed review of the data and was directed more toward the science-user community. To address the operations requirement, a compact data status 
message was constructed that included hourly statistics from most of the instruments along with environmental parameters such as the temperature of the instrument enclosures. These messages were sent via the GOES satellite each hour. Each day, plots of these hourly data were generated and posted on a web site at Pennsylvania State University. Initially, this process was carried out by the site scientists but was eventually transitioned to site operations. The plots proved useful for identifying gross errors in the data, which fed back to operations team technicians, allowing them to plan repair visits.

Once the full dataset was delivered to the Data Management Facility, the site scientists produced daily quick looks of these data and performed diagnostic tests, including closure of the solar direct and diffuse components, the net radiative flux, and comparison of the integrated radiosonde water vapor with the vapor derived from the microwave radiometer. Data gaps also were cataloged, which led to uncovering problems with data loggers on several occasions. When operation began at Manus, data were examined prior to release. Once the full dataset was received, the data were examined, and the site scientist office produced a report describing any issues with the data. This report was submitted to the Data Management Facility, though there was not a mechanism at the time to include all of this information to data users. Most of the information was subsequently converted to reports suitable for distribution to users. The procedure of reviewing the data prior to release ended at approximately the time when the second site was installed at Nauru in November 1998. With two sites running, it became impractical to review all of the data prior to release.

During this early phase of operation at the tropical ACRF sites, the site scientist team took a lead role in the examination of the data collected; the initial review of the data was done by a site scientist. When a question regarding a specific instrument arose, the site scientist typically contacted the appropriate instrument mentor and worked with the mentor to solve the problem. On the other hand, if the source of a problem was known or suspected by the site scientist team, site operators were contacted to work toward a problem solution. This model of putting the site scientist on the front line of data review had distinct advantages as well as disadvantages. The system had the advantage that the site scientist team had a strong vested interest in the instruments at the site, and looking at multiple instruments provided a holistic view that was useful for problem solving because data from more than one instrument could provide clues regarding the source of a problem. However, this system was inefficient and time consuming, limiting site scientist time for other important activities like promotion of the data to the science community, planning, and implementing field campaigns. With the implementation of a Data Quality Office in 2000, the role of site scientist in reviewing data quality gradually but dramatically changed.

\subsection{Early North Slope of Alaska Efforts}

At the NSA, still another model was used. Site scientists and site operators jointly subjected data to a systematic program of quality checks (e.g., Delamere et al. 1999). Data streams were visually inspected on a daily basis; from these visual inspections, metadata documenting the overall quality of the data streams were generated. Such inspections facilitated detection of instrument malfunction as the Barrow site was spinning up in 1998. A web-based archive of quick look images was developed to facilitate visual inspection; it was developed and maintained by the site scientists at the Geophysical Institute of the University of Alaska, Fairbanks. These images were updated and made available daily. In addition to visual inspections, the site scientists interpreted within-file limits testing. Instrument mentors had relatively little involvement in quality assurance activities at this locale after instrument installation and official data release. 
North Slope site scientists and operators played a crucial role in discussions in 1999 and 2000 on how to better automate data quality checking and how to place this information and other metadata both within NetCDF data files and on the web. The program later adopted many of these ideas after the formation of the Data Quality Office.

\subsection{Establishment of a Data Quality Office}

While instrument mentor and site scientist and site operator efforts were crucial for detecting instrument malfunction and minimizing poor data quality, they tended to be unevenly developed and applied across the ACRF, sometimes leading to varying treatments of like measurements taken at different locations. A key finding of an ARM Program Infrastructure Review in 1999 stated, "although all groups were well intentioned, there was little coordination of their work. Rather, the effort was unfocused and inconsistent, leading to a general and anecdotal perception both inside and outside ARM that ARM data are less useful than might be expected." 1 A recommendation was made to consolidate and coordinate the program's data quality activities in one place, which evolved in July 2000 into the Data Quality Office at the University of Oklahoma.

The Data Quality Office has since coordinated the data quality assurance program, and has particularly helped develop comprehensive tools based on the best of what had been produced by the various contributors to data quality analysis. It has played a key role in establishing and ensuring consistent application of data quality protocols across ACRF sites and has broad authority across the ACRF infrastructure to help ensure that the collected data meet the standards required by ARM Program researchers. The next section documents the results of these efforts. Instrument mentors and site scientists still retain strong, complementary roles in the quality assurance process. Instrument mentors, as the technical authorities for the instruments, still provide in-depth instrument-specific perspectives on data quality and are responsible for helping resolve problems and identifying long-term data trends. Site scientists, as authorities on their locale and its scientific mission, provide a broad perspective on data quality spanning the full range of site instrumentation. They also oversee their site's problem resolution process and perform targeted research on topics related to site data quality issues. They also directly interact with the scientific community to plan and conduct field campaigns at their sites, which have at times identified previously unknown data quality issues (see Section 10).

\section{Current Data Stream Inspection and Assessment}

The Data Quality Office presently is charged with inspecting and assessing approximately 5,000 data fields on a daily to weekly basis. The objective of this activity is to quickly identify data anomalies and report them to site operators and instrument mentors so that corrective actions can be performed and thereby minimize the amount of unacceptable data collected. To perform this task the Data Quality Office has developed, using the technical guidance of instrument mentors and site scientists, automated tools and procedures for inspecting data, packaged into the Data Quality Health and Status (DQ HandS) system (http://dq.arm.gov/; see for example, Peppler et al. 2005). It facilitates inspection of ACRF data streams and initiates the problem resolution process, and is built around scripting languages that produce summaries of key parameters. ACRF network configuration allows the Data Quality Office to share a file

\footnotetext{
${ }^{1}$ ARM Infrastructure Review Committee Report, September 1999, p. 12.
} 
server with the Data Management Facility, where raw instrument data from the sites are processed and converted into NetCDF format, facilitating data quality processing. A DQ HandS prototype was created in the late 1990s as a way to monitor the results of a solar tracker algorithm written by SGP site scientists and was expanded to soil water and temperature system data there (Bahrmann and Schneider 1999); from there, it was formalized into a program-wide, web-based inspection and assessment tool.

Every hour, the latest available ingested data at the Data Management System is processed by DQ HandS to create a summary of the bit-packed integer quality control fields (limits tests) within a file. When these fields are not available for an instrument, the Data Quality Office works with instrument mentors to identify limits that can be incorporated directly within DQ HandS algorithms. A user interface provides options for selecting the site, data stream, and date range of interest for analysis. After selections are made, a color table showing limits-testing summaries by day is displayed, using a red/yellow/green color system that bins the data by the percentage passing the limits tests. Drilling down further provides a more detailed color-coded table by hour for each day, with a mouse-over capability displaying a pop-up window showing more detailed information on flagging results for a particular hour and measurement; statistics include the amount of failure (percentage of collected data) for each automated quality control test violated. Testing that results in flagging now includes internal data stream tests against a set of valid data ranges and comparison tests across data streams against like measurements from different instruments. Color tables are updated hourly as data arrive at the Data Management Facility, as are diagnostic plotting aides, which include cross-instrument comparisons. Visual inspection of these plots by data quality analysts helps identify data abnormalities not detectable by automated algorithms. These plots have color-coded backgrounds to indicate local sunlight conditions, helping analysts distinguish between night and day. Figure 6 shows a representative color table for TWP Manus Island for the first 11 days of May 2007 for a radiometer suite that measures downwelling radiation, while Figure 7 shows the corresponding hourly color table for one day (May 7). Figure 8 displays an example diagnostic plot for May 7. 


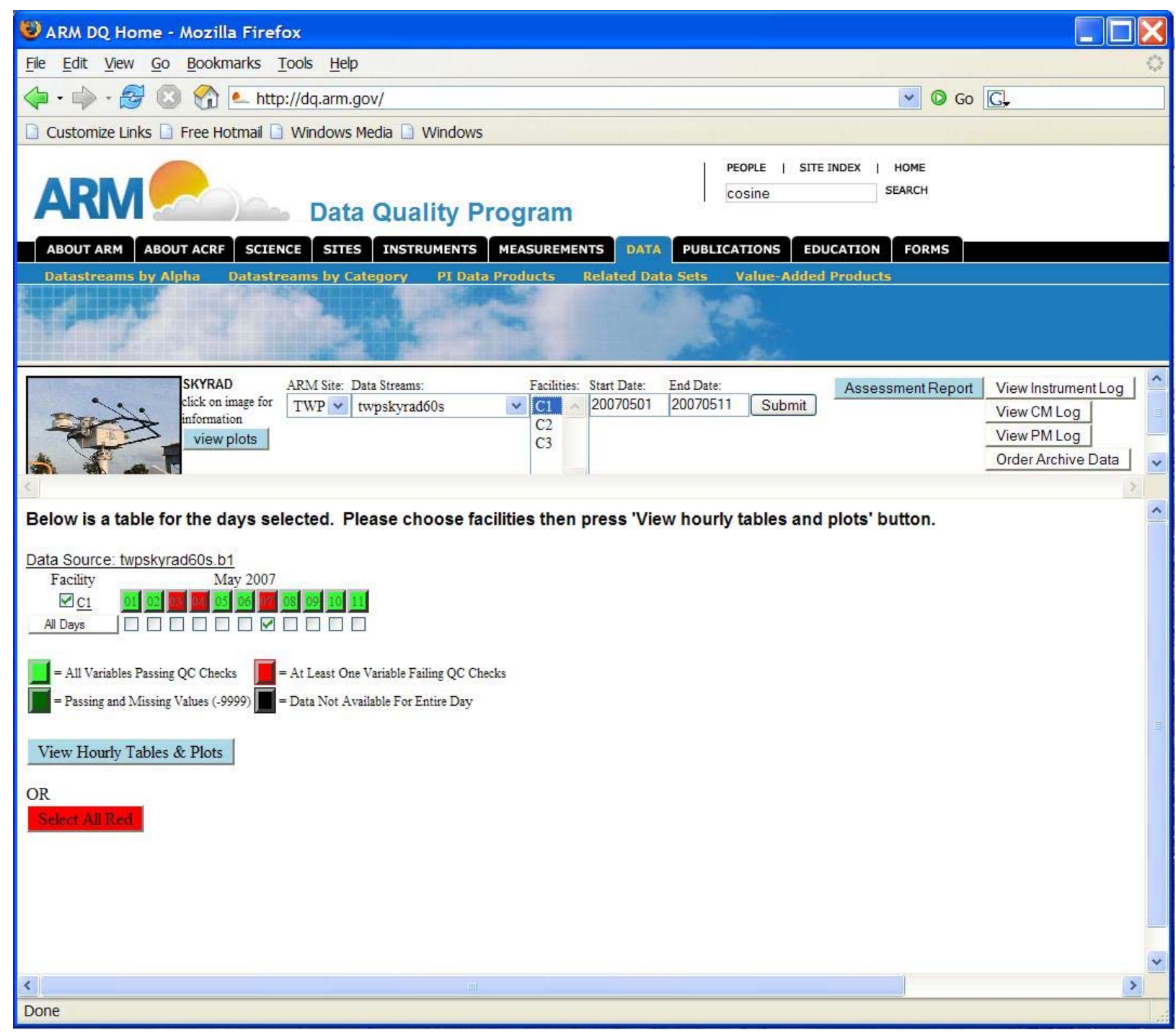

Figure 6: Daily color table of automated quality control check results for Tropical Western Pacific Manus Island site for May 1-11, 2007, for a radiometer suite that measures downwelling shortwave radiation. 


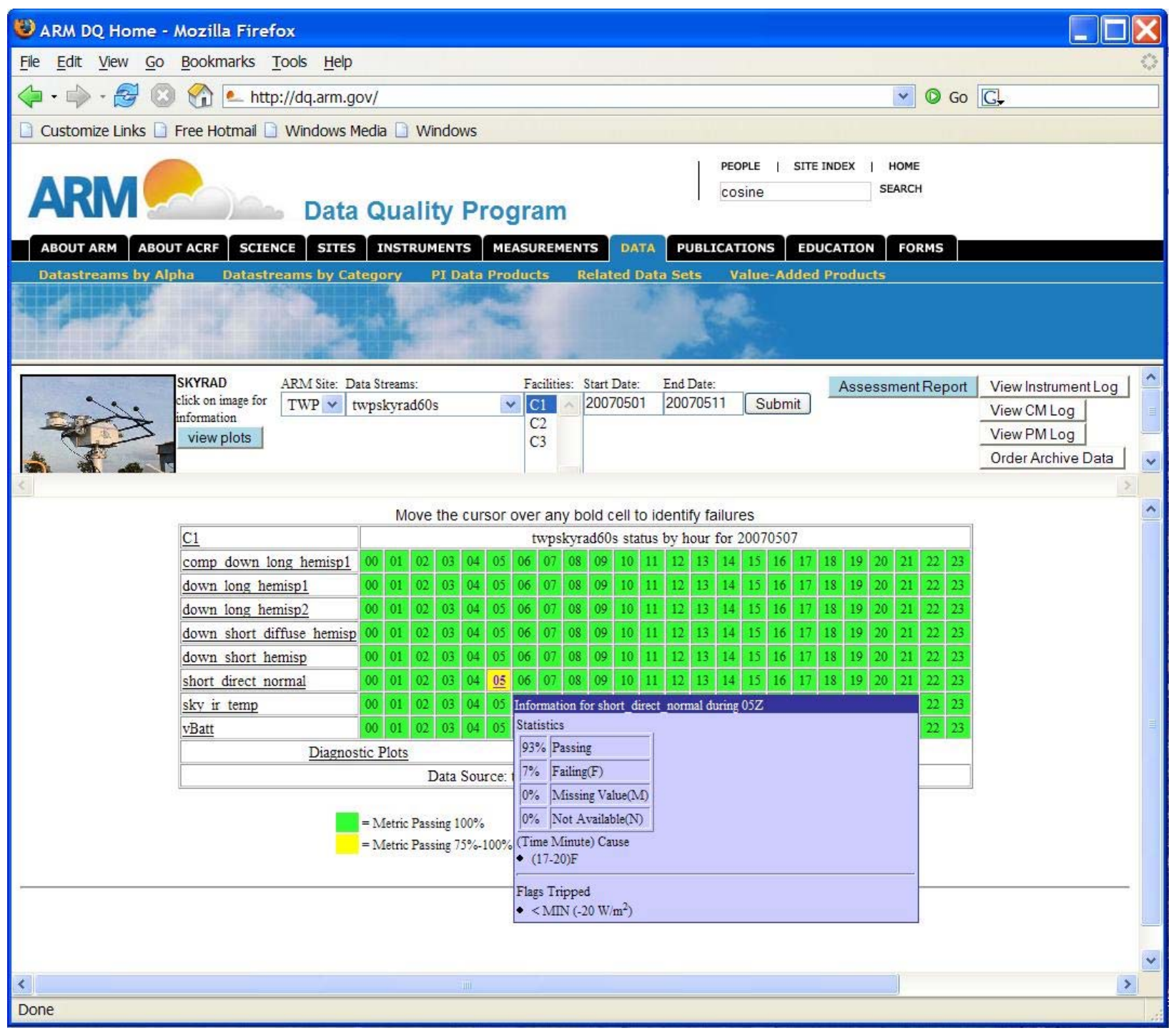

Figure 7: Hourly color table of automated quality control check results for one day (May 7, 2007) at the Tropical Western Pacific Manus Island site corresponding to the example in Figure 6. Blue pop-up window of flagging statistics is obtained by mousing over the yellow shaded box for 0500 UTC for the shortwave direct normal incidence measurement; here, $7 \%$ of the observations failed a minimum test. 


\section{ARM DQO Diagnostic Plots}
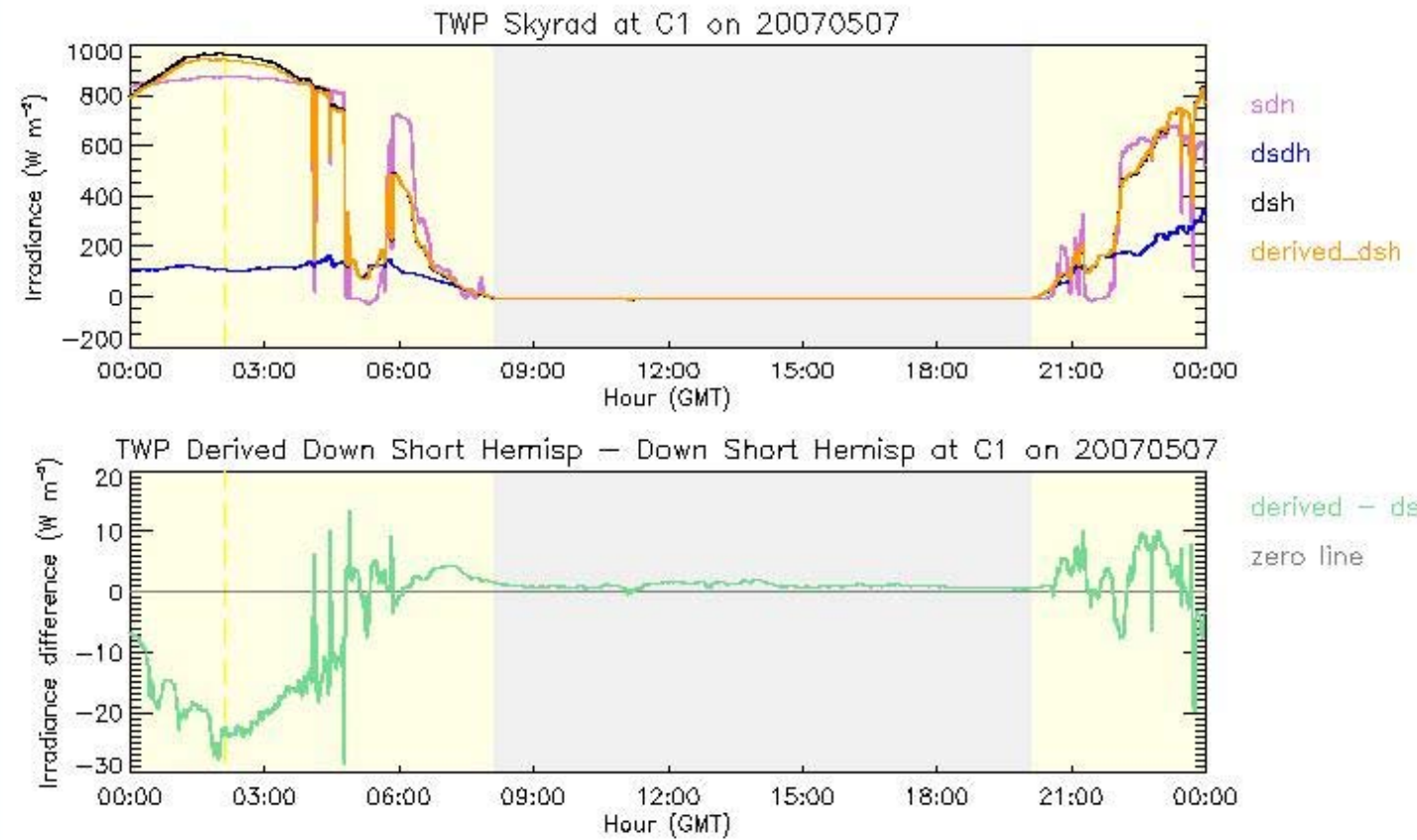

TWP Derived Down Short Hemisp / Down Short Hemisp at C1 on 20070507

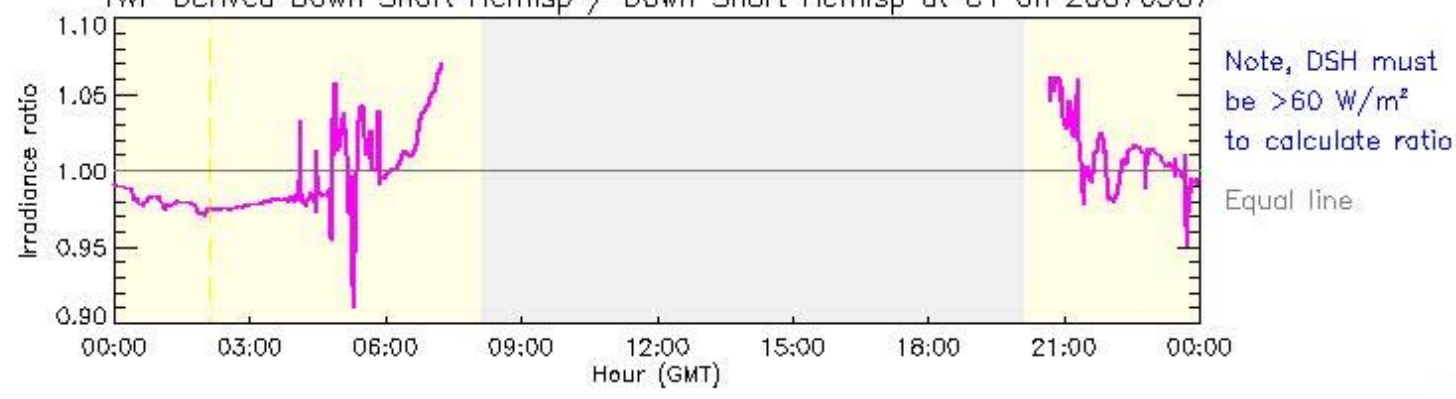

Done

Figure 8: Diagnostic plot of some downwelling shortwave radiation variables on May 7, 2007, at the Tropical Western Pacific Manus Island site corresponding to the example in Figures 6 and 7. 'sdn' is the shortwave direct normal component; 'dsdh' is downwelling shortwave diffuse hemispheric component, and 'dsh' is the downwelling shortwave hemispheric measurement. 'Derived' hemispheric is calculated by adding the diffuse radiation component (measured by a shaded pyranometer) to the direct normal radiation component (measured by a pyrheliometer) multiplied by the cosine of the zenith angle; it is then compared as a quality control check to the actual hemispheric measurement provided by an unshaded pyranometer (denoted as 'dsh'). The yellow vertical dashed line denotes local solar noon. 
A time sequence of daily plots, which can help analysts detect subtle trends in data, is available through a DQ HandS plot browser (http://plot.dmf.arm.gov/plotbrowser/). Analysts may select a site, an instrument, and a date range, and have the option to view the plot thumbnails for up to 30 days at a time. The thumbnail format facilitates the comparison of different instruments that measure like quantities. A user may filter thumbnail results by facility and plot type, and can step forward or backward in time while retaining current filter options. Figure 9 shows a time sequence of downwelling radiation thumbnails for Manus for May 5-8, 2007.

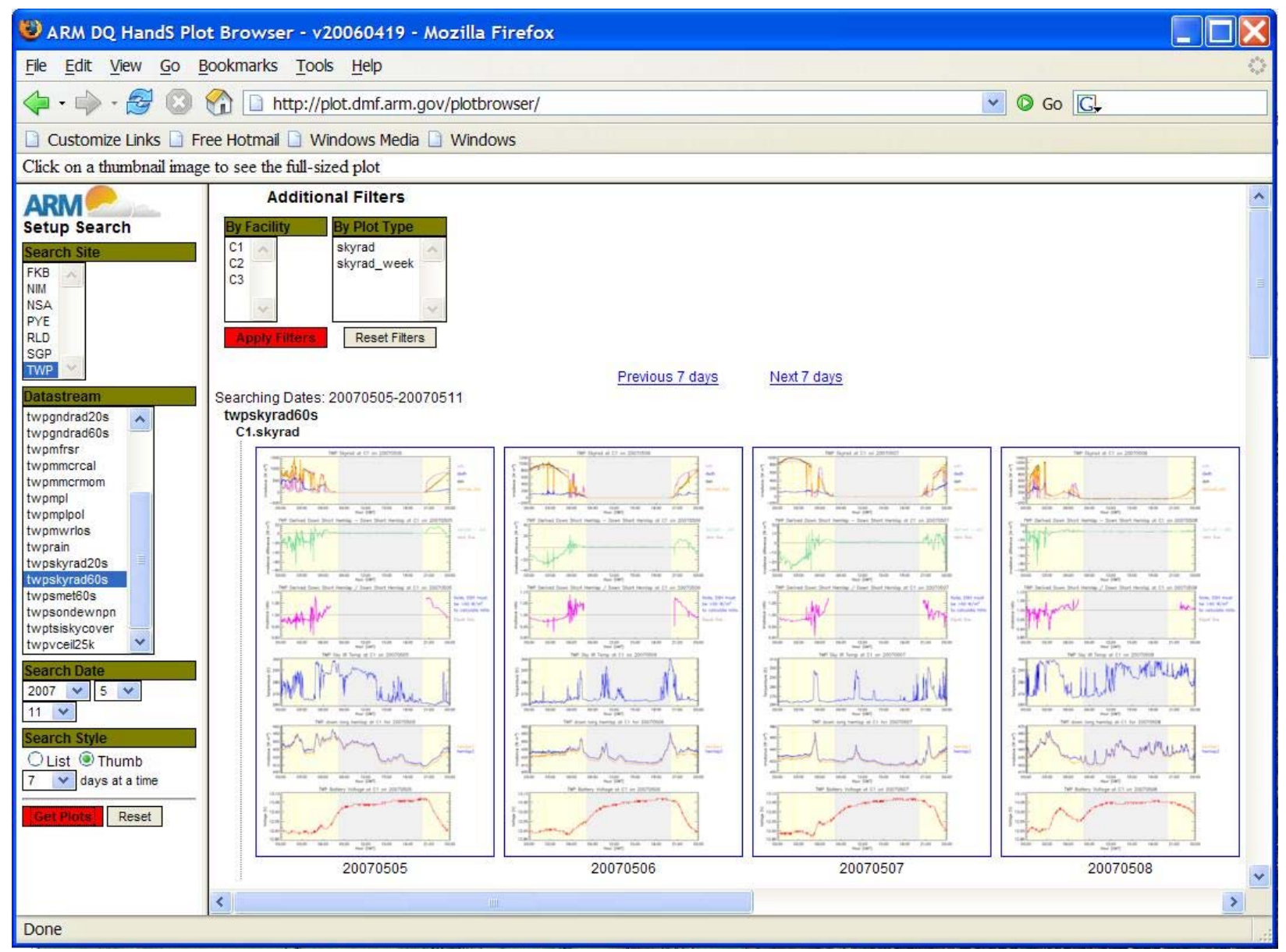

Figure 9: Plot browser time sequence of downwelling radiation plots for May 5-8, 2007, corresponding to the example in Figures 6-8 for the Tropical Western Pacific Manus Island site.

An interactive, web-based plotting tool called NCVweb also is available in DQ HandS; it allows analysts to easily view NetCDF data at the Data Management Facility (http://plot.dmf.arm.gov/ncvweb/ncvweb.cgi). Since it works by querying the metadata within each file of interest, the data quality analyst or data user does not need to be conversant in the NetCDF format. Key features include zooming in on data periods of interest (including less than one day) and plotting multiple data files at one time. Particular data fields of interest can be specified from pull down menus. Plots may consist of one or more independently plotted fields, multi-dimensional color-coded images such as radar spectra, or slices through a multidimensional array. For closer inspection, data values can be displayed in tabular form or 
downloaded in ASCII comma-delimited format for easy importation into other applications. Analysts can view file headers to obtain direct access to metadata or can obtain both a summary of data field descriptions and basic field statistics. Figure 10 shows a zoom in of shortwave direct normal measurement at Manus on May 7 for the hours 0200-1000 UTC, indicating a value that violated a minimum test.

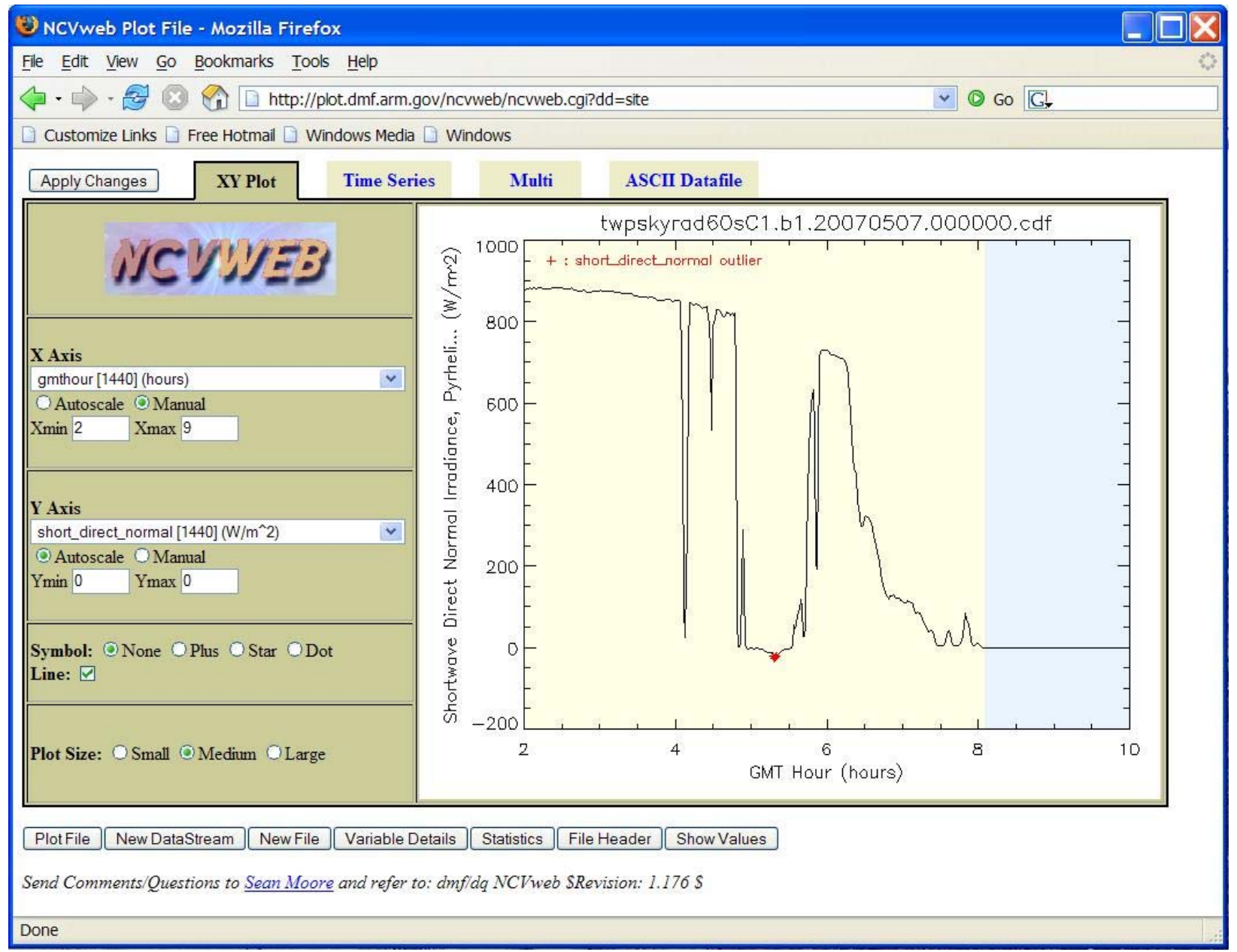

Figure 10: NCVweb zoom-in on the hours 0200-1000 UTC of the shortwave direct normal measurement on May 7, 2007, corresponding to the example in Figures 6-9, showing values (red asterisk) denoted in Figure 7 that violated a minimum test.

Supporting data are made available within DQ HandS to assist analysts in the data inspection and assessment process. Such information includes maintenance field reports from site technicians and data availability statistics from the Data Management Facility, plus links to basic information about instrument operation and limitations. The results of data inspections and assessments are issued weekly by the Data Quality Office analysts as assessment reports, while data anomalies requiring diagnostic or corrective action require the issuance of problem reports; these reporting mechanisms are described in the next section. 


\section{Problem Reporting, Review, and Resolution}

Data quality reporting mechanisms are based on searchable and accessible databases that allow the various pieces of information produced during the quality assurance process to be neatly conveyed to problem solvers in a timely manner. The technical design of this database system has evolved with generally available Internet technologies, and as of this writing consists of a Sybase database back end and various CGI scripting languages (PHP, PERL, JavaScript) running on an Apache web-server as the user-accessible front end. Access privileges are controlled by the user's role within the ACRF infrastructure as defined by entries within another database.

The system is divided into the following four linked subsystems, administered by Brookhaven National Laboratory, with the subsystems based on the nature of the problem:

1. Routine weekly assessments of data inspection results are documented through an assessment report system

2. Routine problems that can be addressed by site operators under the guidance of instrument mentors and site scientists are documented through a problem report system

3. Significant problems that require engineering effort or that could not be solved in a timely manner through the routine problem reporting system are documented through ACRF's Problem Identification Form (PIF)/Corrective Action Report (CAR) system

4. The resulting impact on data quality of either problem type is documented by the instrument mentor through the ACRF's DQR system, which is what is made available to the data user.

The complete history of problems, corrective actions, and reports on data quality is searchable, including criteria for submitter, time period, data stream name, instrument name, designated priority, and assignee. The database allows for the tracking of problem trends and helps identify problematic instrument systems that might require design modifications to make them more reliable and suitable for the continuous operations.

\subsection{Assessment Reporting}

To report results of data inspection and assessment, an assessment report is created by Data Quality Office analysts through an interface within DQ HandS. The site, instrument, and date range selections that the analyst has been viewing in DQ HandS automatically populate the report's fields, leaving the analysts only to type their findings into the form in simple text format. HTML tags can be added to highlight issues in bold or underline and hyperlinks can be inserted to provide access to data plots. The result is the email issuance of the report to instrument mentors, site scientists, and site operators. If a data anomaly is discovered during the inspection and assessment process, the assessment report interface provides the ability to pre-populate fields in a problem report (see next subsection). The complete assessment report history is accessible and searchable through web-based forms by report number, analyst name, date range, site, and instrument, and can be found at http://www.db.arm.gov/DQA/.

\subsection{Routine Problem Reporting}

The routine problem reporting subsystem allows Data Quality Office analysts a means to alert appropriate site operators, site scientists, and instrument mentors about a data anomaly. Instrument mentors and site 
scientists also can issue these reports. A powerful feature is its ability to capture the conversation that documents the progress and status of the diagnostic and corrective actions proposed and implemented. Once a problem has been identified and a problem report issued, the instrument mentor specifies a corrective action and site operators schedule and perform the proposed action. If additional diagnostic effort is necessary to address the issue, the report remains open until an alternative solution can be implemented. The report will not be closed until a corrective action has been deemed successful through the analysis of the quality of subsequent data. The site scientist, with assistance from the Data Quality Office manager, oversees the progress of problem resolution and each has the responsibility and authority to change problem status and make work assignments as necessary to resolve an issue in a timely manner. Figure 11 shows an example problem report for degraded SGP Vaisala Ceilometer backscatter data caused by a dirty window. If a problem cannot be resolved through this process within 30 days, the routine problem report is 'elevated' to PIF status (see next subsection), which brings it to the attention of key ACRF infrastructure personnel comprising the Problem Review Board. Routine problem reports can be accessed at http://www.db.arm.gov/DQPR/.

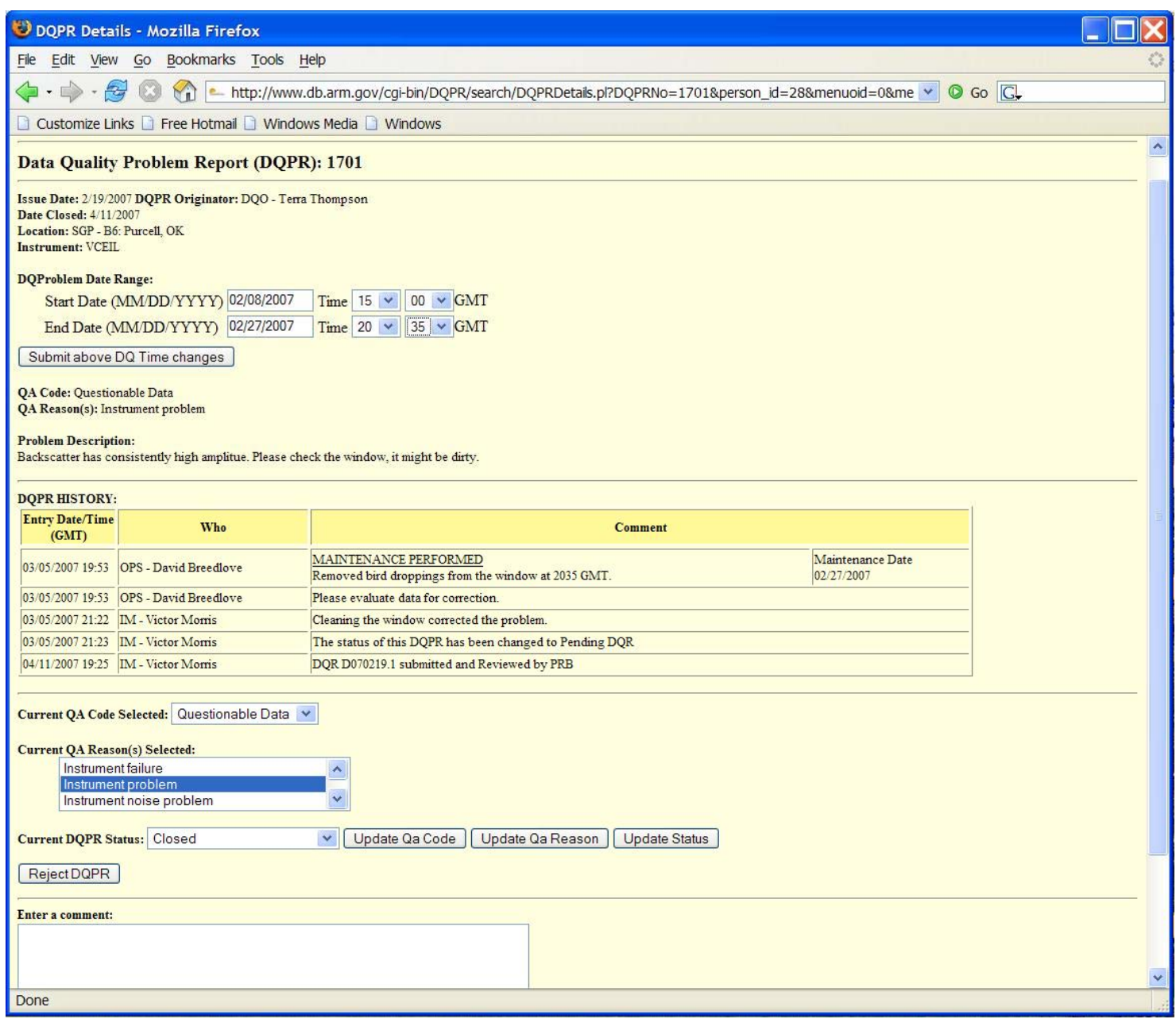

Figure 11: Data Quality Problem Report 1701 identifying degraded Vaisala Ceilometer backscatter data at SGP boundary facility 6 in Purcell, Oklahoma, that ultimately were caused by a dirty window. Comments reveal the series of steps taken to rectify and report on the problem. 


\subsection{Significant Problem Reporting}

A PIF may be submitted by anyone involved in the production or use of ACRF data, including ARM Science Team members and those outside of the ARM Program that may discover a data anomaly when analyzing data. As previously indicated, site scientists or the Data Quality Office manager can recommend that unsolved routine problems be elevated to PIF status, but sometimes problems are of such magnitude that they require the immediate attention of the ACRF Problem Review Board. This board consists of senior managers within ACRF infrastructure representing the Engineering, Operations, Instrument Team, Archive, External Data, Data System, and Data Quality Office groups. It meets once a week via conference call to review new problems and to track progress on old problems. To facilitate the discussion, an agenda of yet-to-be reviewed items from the PIF/CAR/DQR database is generated in advance of the call and the Problem Review Board manager prepares disposition recommendations. The board reviews each agenda item and assigns new PIFs to the most appropriate person that can take responsibility for its resolution. It also assigns a priority to the problem described and specifies an email distribution of people that need to know about it. The assignee is asked to determine an estimated date of completion.

The assignee then supervises and monitors problem resolution and submits attachments to the PIF that serve as progress reports toward correction of the problem. This person also is responsible for submitting a Corrective Action Report (CAR) when the problem has been resolved; the CAR closes out the problem resolution process with a description of what was done to correct the problem and triggers the issuance of a DQR (see next subsection) to the data user community. The PIF/CAR/DQR system can be accessed at http://www.db.arm.gov/PIFCARDQR2/.

\subsection{Reporting to Data Users}

Any issue having a bearing on the quality of the data is ultimately summarized by the instrument mentor in terms of the problem's severity, affected measurements, and period covered. If warranted, suggestions are provided to the data user on how to correct or replace affected data. Such descriptions are captured in a DQR that is distributed by the Data Archive to a data user whenever the affected data are ordered; it is also sent to those that previously ordered the affected data. These reports are worded such that they fully describe the nature of the problem without excessive jargon or unnecessary detail. The theory behind these reports is that they will provide end users with the information they need to make informed judgments on whether and how to use the data. Figure 12 shows the DQR corresponding to the routine problem report in Figure 11. The DQR system also can be accessed at http://www.db.arm.gov/PIFCARDQR2/.

\section{Role of Value-Added Processing in Data Quality Assurance}

Some of the scientific needs of the ARM Program are met through the combination of instrument-level data streams into VAPs. Despite the extensive instrumentation deployed at the ACRF sites, some quantities of interest are either impractical or impossible to measure directly or routinely. Although VAPs have filled this void and provided sophisticated interpretations of measurements (e.g., indications of cloud fraction from measurements of solar radiation and estimates of cloud microphysics from radar 
and lidar data), they evaluate measurements through the constraints of our understanding of physics (i.e., do the retrieved quantities make sense in the context of the surrounding physical situation?).

VAPs also have shed light on the quality of the data streams used as their input. An example of measurement improvement was accomplished through the Diffuse Correction (DiffCorr) VAP. Cess et al. (2000) found that some downwelling diffuse shortwave measurements made with shaded Eppleymodel precision spectral pyranometers (PSP) under clear-sky conditions fell below the physicallypossible limit of diffuse irradiance as produced by a model incorporating both Rayleigh (molecular) scattering and conventional clear-sky atmospheric absorption. Subsequent investigation by Dutton et al. (2001) and Philipona (2002) attributed the problem to infrared loss from the pyranometer detector causing anomalously low shortwave readings, with Dutton et al. (2001) suggesting a methodology for correcting the measurements using information from co-located longwave pyrgeometer instruments. In implementing the Dutton et al. (2001) methodology as a VAP, Younkin and Long (2004) showed that the PSP infrared loss actually exhibits bimodal behavior in the pyrgeometer-pyranometer relationship, dependent on ambient relative humidity conditions, and confirmed the Philipona (2002) findings that the daylight pyranometer infrared loss is enhanced compared to that exhibited at night. Thus, the DiffCorr VAP produces an improved measure of downwelling diffuse shortwave irradiance over what the instrument itself is capable of making by correcting for the infrared loss inherent in the raw measurements.

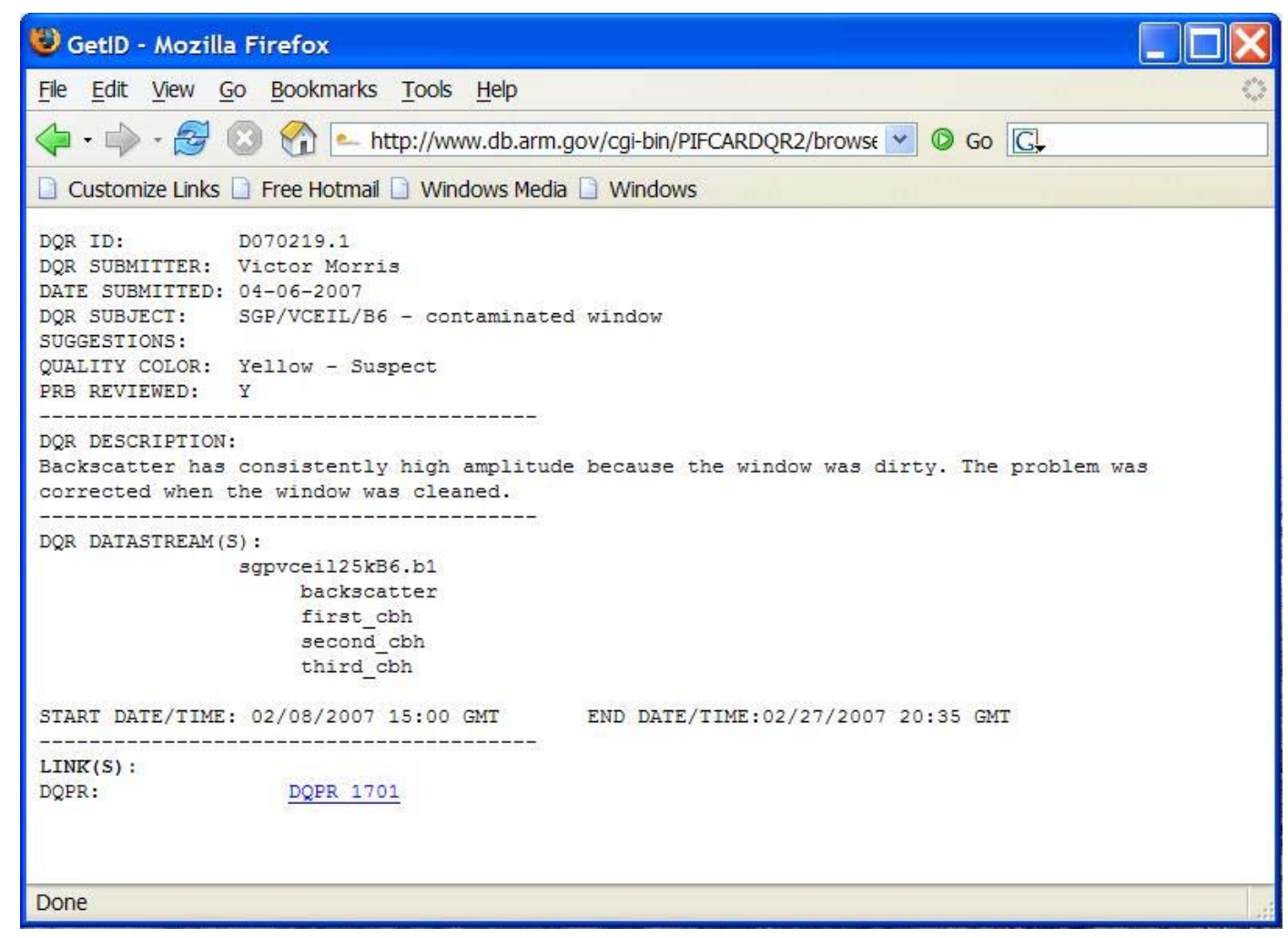

Figure 12: Data Quality Report D070219.1 issued to data users to alert them to the issue described in Figure 11. This report is attached to any data order containing this particular measurement and time period. 
Other VAPs have addressed measurement uncertainty. The Best Estimate Flux (BEFlux) VAP (Shi and Long 2002) was designed to produce the best possible measure of surface broadband irradiances for the SGP Central Facility. Instrumentation there includes three separate surface radiation systems located within a few meters of one another. The BEFlux VAP compares the sets of like measurements to test for consistency and then averages the two that agree best to produce a best estimate for that value if that agreement is determined to fall within typical limits established by the historical analysis of known good data. This assessment of historical data then serves as an indication of what range of uncertainty field operations contribute to overall measurement uncertainty. The results of this study are shown in Table 2 (after Shi and Long 2002) as the 95 percent cumulative frequency level of the absolute differences for all data that exhibited the best agreeing pair regardless of which particular instruments were used at any given time (best), the next best agreeing pair (typical), and the worst-agreeing pair (worst). These values, in addition to other factors affecting measurement accuracy (calibration; sensitivity drift between calibrations; contamination of the radiometer domes) can then be used for other single radiometer system sites to set limits on expected performance for quality assessment purposes. In this case, 'best' is the best that can be expected for long-term field measurements, 'typical' is what one might expect on average for ACRF sites, and 'worst' is what one has to consider as the possible operational portion of the total uncertainty of the data.

Table 2: Level at which 95 percent cumulative frequency of agreement was reached between ARM Southern Great Plains Climate Research Facility radiometer measurements (after Shi and Long 2002).

\begin{tabular}{|l|c|c|c|}
\hline Measurement: & Best & Typical & Worst \\
\hline Diffuse SW & $4.0 \pm 1.4$ & $9.0 \pm 3.1$ & $12.0 \pm 3.8$ \\
\hline Direct Normal SW & $6.3 \pm 3.3$ & $13.6 \pm 6.3$ & $15.0 \pm 6.7$ \\
\hline Downwelling LW & $3.1 \pm 0.4$ & $5.1 \pm 1.2$ & $7.1 \pm 1.4$ \\
\hline Upwelling SW & \multicolumn{3}{|c|}{$11.1 \pm 2.8$} \\
\hline Upwelling LW & \multicolumn{3}{|c|}{$9.6 \pm 3.0$} \\
\hline
\end{tabular}

The range of climatologically expected values also plays a role in quality assessment. The Quality Control of Radiation (QCRad) VAP (Long and Shi 2006) implements all that the ARM Program has learned in the field about the behavior of surface broadband radiometers and the assessment of their data quality, while at the same time providing a best estimate of their radiation values for data users. For instance, in the development of the DiffCorr VAP (Younkin and Long 2004), considerable effort was expended in the development of methods for testing downwelling longwave measurements, including the pyrgeometer case and dome temperatures and detector fluxes, to prevent the use of questionable pyrgeometer values when correcting for IR loss in the diffuse shortwave measurements. The international Baseline Surface Radiation Network (BSRN) group has implemented earlier work for automated quality assessment methodology (Long and Dutton 2002). The BSRN methodology, which not only sets climatological limits but also makes extensive use of cross comparisons based on known relationships between variables, has been expanded and improved upon in the QCRad VAP. While the BSRN method uses limits that encompass the entire range of climates from the equator to the poles, the QCRad methodology uses limits based on the particular climatology of a given site. The QCRad methodology 
includes additional tests based on knowledge gained through other VAP development efforts such as the aforementioned BEFlux and DiffCorr, and also the Shortwave Flux Analysis VAP (Long and Ackerman 2000; Long and Gaustad 2004). Thus, VAPs have played a role in not only testing measurements for quality but also in developing methods and expanding knowledge that can be used for improving the testing methodologies themselves.

Testing of measurements using limits and cross-comparisons for quality assurance is standard, but in practice, subtle measurement errors can be difficult to detect using such methods. Additionally, some measurements do not lend themselves to limits testing. In some cases, there is no better test for subtle measurement inaccuracies than by using the data in scientific research. One example of this has involved analysis of millimeter cloud radar data; its measured quantity is the reflected radiation from actively broadcast electromagnetic pulses. While the amount of power broadcast and returned can be monitored, there are many other factors involved in this complex instrument that can affect the data quality. The Active Remotely-Sensed Cloud Locations ARSCL VAP (Clothiaux et al. 2000; Clothiaux et al. 2001) uses cloud radar data as its primary input, and it is within the ARSCL processing that many of the cloud radar measurement problems have been revealed. The ARSCL output serves as input into the Baseline Cloud Microphysical Retrievals (MicroBase) VAP (Jensen and Johnson 2006), where again the results are scrutinized in the context of whether the retrievals are consistent with other measurements and are relevant to the physical circumstances in which they are imbedded. Such comparison of parameters in the context of the physical situation is a powerful tool for determining data quality to a degree not often possible for individual measurements or the retrievals themselves.

As an example of this, MicroBase output is one of the major inputs to the Broadband Heating Rate Profiles (BBHRP) VAP (Mlawer et al. 2002). BBHRP takes the output from several complex VAPs, including ARSCL and MicroBase, and uses it in detailed radiative transfer model calculations. The BBHRP output then is compared with surface and top-of-atmosphere irradiance measurements in a closure experiment framework. It has been through these ongoing model-measurement comparisons that a subtle problem with SGP Central Facility surface direct shortwave measurements was discovered. The comparison revealed a shift in model-measurement agreement statistics for the direct shortwave, which turned out to be caused by human error when two digits of the normal incidence pyrheliometer calibration factor were inadvertently transposed while being entered into a data logger. This human error resulted in a roughly two percent error in the direct shortwave measurements, which turns out to be within the stated uncertainty of the calibrations themselves (Stoffel 2005) and thus was not detectable by standard limits and cross-comparison testing.

In summary, the processing of VAPs has and will continue to serve a significant and valuable purpose in ACRF data quality assurance efforts. In addition, this processing allows for (1) determining measurement uncertainties and the characterization of instrument behavior, both of which are used to set testing limits in the first place; (2) developing new procedures to be used in testing; and (3) the improving the accuracy of the measured quantity itself by correcting for known errors due to the inherent physical characteristics of the measuring instruments. VAPs - by their combination of multiple independent measurements analyzed in innovative ways and by extension the very existence of the ACRF facilities that make these measurements possible - have been essential in revealing subtle measurement issues. These issues are difficult or impossible to detect using standard quality control methods, and as such have been invaluable in characterizing errors and ascertaining a best estimate of the "truth" with associated uncertainty. 


\section{Role of Field Campaigns in Improving Data Quality}

ACRF sites frequently host field campaigns to address specific scientific questions, augment routine data collections, and/or test and validate new instruments. These campaigns also are referred to within the ARM Program as intensive operational periods (IOPs). Through 2007, no less than 173 field campaigns have been carried out at the SGP site; 18 campaigns have been held at TWP sites; and 34 have been conducted at NSA sites. Additionally, 21 different campaign activities were held during the inaugural AMF deployment in Point Reyes, California, and succeeding deployments in Niamey, Niger, and Heselbach, Germany. A specific activity of some campaigns has involved application of observational strategies and instrument comparisons aimed at improving the accuracy and quality of key ACRF measurements. A few key campaigns are described here to show the quality and depth of the work that has been done, which in some cases has had community-wide ramifications on field measurement.

Given the importance of water vapor as a greenhouse gas and its role in the life cycle of clouds and precipitation, the transfer of latent and sensible heat, and atmospheric chemistry, the ARM Program has expended considerable observational effort, particularly at the SGP site, on the measurement of water vapor. Much progress has been made to this end through a series of water vapor IOPs, summarized by Revercomb et al. (2003). These campaigns included three water vapor IOPs held in September 1996, September/October 1997, and September/October 2000, respectively, a lidar IOP held in September/October 1999, and the ARM-First International Satellite Cloud Climatology Project (ISCCP) Regional Experiment (FIRE) Water Vapor Experiment (AFWEX), conducted with NASA in November/December 2000. Additionally, the Nauru-99 campaign verified microwave radiometer calibration accuracy in the tropical Pacific environment and compared humidity measurements from radiosondes (Westwater et al. 2003).

The 1996 and 1997 water vapor IOPs and the 1999 lidar IOP at the SGP site provided key information on the quality and accuracy of on-site water vapor instrumentation (Revercomb et al. 2003). Dualradiosonde launches revealed significant variability across and within calibration batches and showed that differences between any two radiosondes act as an altitude-independent scale factor in the lower troposphere, such that a well-characterized reference can be used to reduce the variability. An approach subsequently was adopted by the ARM Program to scale the radiosonde's moisture profile to agree with the precipitable water vapor observed by a microwave radiometer; this scaling significantly reduced the sonde-to-sonde variability by a factor of two (Turner et al. 2003). The first two water vapor IOPs also were able to verify that $60-\mathrm{m}$ tower-mounted in situ sensors can serve as an absolute measurement reference, and the site's unique Raman lidar can serve as a stable transfer standard; further IOP results found that the sensitivity of microwave radiometers was excellent over a wide range of integrated water vapor. The third water vapor IOP saw the fielding of further water vapor instrumentation to address leftover issues of absolute calibration.

Also beginning with the first water vapor IOP, verification of site moisture measurements was undertaken through laboratory intercomparison of in situ moisture sensors (including both capacitive chip and chilled mirror sensors) using Oklahoma Mesonet facilities. Tests were made both before and after the IOP, making it possible to detect both instrument problems prior to the IOP and instrument failure or drift during the IOP (Richardson et al. 2000). Consequences of this work were modifications to humidity 
sensor calibration procedures and the fielding of redundant humidity and temperature sensors to better detect sensor drift and calibration errors.

While the water vapor IOPs were concerned with characterization of water vapor in the lower troposphere, AFWEX was conducted to better characterize upper-tropospheric water vapor measurement (Ferrare et al. 2004). Results from the water vapor IOPs and AFWEX, as described in Soden et al. (2004), showed excellent agreement between satellite and Raman lidar observations of upper tropospheric humidity with systematic differences of about 10 percent; radiosondes, conversely, were found to be systematically drier by 40 percent relative to both satellite and lidar measurements. Existing strategies for correcting the sonde dry bias were found inadequate in the upper troposphere and an alternative method was suggested that considerably improved sonde measurement agreement with lidar observations; it was recommended as a strategy to improve the quality of the global historical record of radiosonde water vapor observations during the satellite era. Further work to characterize the accuracy of Raman lidar water vapor measurements, based on the results of the first two water vapor IOPs, is documented in Turner and Goldsmith (1999), while Ferrare et al. (2006) described evaluation of daytime measurements of water vapor and aerosols made by the Raman lidar during an aerosol IOP conducted in May 2003.

The Nauru-99 campaign provided a more subtle understanding of how field campaigns can contribute to data quality by asking how well the data collected accomplished their scientific intent. ACRF tropical equatorial sites make measurements representative of the surrounding oceanic area, which is by far the prevalent surface type. One goal of Nauru-99 was to investigate whether the small island of Nauru itself was influencing the measurements made there because of the cloud street phenomenon it produces; this ultimately was confirmed by the campaign. This campaign result then lead to a year-long Nauru Island Effects Study (NIES; Long 1998), in which a quantification of the island effect on measurements was accomplished, along with the development of a way to detect the effect's ongoing occurrence and estimate its influence on the data (McFarlane et al. 2005). NIES also produced a study that explained the mechanism of cloud street formation (Matthews et al. 2007). Thus, while quantification and detection of the Nauru Island effect is not data quality assessment in the traditional sense of diagnosing instrument performance, it is data quality assessment in the sense of quantifying how well the measurements that are taken address a scientific purpose. Here, the island effect is contaminating the goal of making measurements representative of the surrounding oceanic area.

Other important field characterization at the SGP site has been accomplished for measurements of atmospheric radiation. Examples include (1) the second ARM Enhanced Shortwave Experiment (ARESE-II) conducted in February/April 2000 (Michalsky et al. 2002), which focused on broadband shortwave calibration using ground-based and aircraft-mounted radiometers and a standard; (2) a diffuse horizontal shortwave irradiance IOP held in September/October 2001 (Michalsky et al. 2003) that focused attention on a nighttime offset by comparing diffuse irradiance measurements among most commercial pyranometers and some prototypes with the goal of reducing the uncertainty of shortwave diffuse irradiance measurements in lieu of a standard or reference for the measurement; and (3) the first international pyrgeometer and absolute sky-scanning radiometer comparison during September/October 1999 (Philipona et al. 2001), which was conducted to learn more about the reliability and consistency of atmospheric longwave radiation measurements and calculations and to determine their uncertainties, also in lieu of the existence of an absolute standard for the measurement. 
Additionally, much work has been done to improve the accuracy of the atmospheric emitted radiance interferometer's calibration. This was a focus of an extended range interferometer intercomparison IOP conducted at the NSA site from January 2004 through June 2006 (Turner et al. 2004a). Two instruments were deployed that were identical except that the temperatures of blackbodies used for their calibration were significantly different. This allowed for evaluation of the accuracy of the approach that the ARM Program was using to correct for the non-linear behavior of the interferometer detector. Additionally, during the spectral liquid and ice comparison IOP conducted at the SGP site in October 2003, a second interferometer was deployed running in a prototype "rapid-sampling" mode (i.e., sky samples every 20-30 s instead of every 7-8 min). This side-by-side comparison with the routine operational interferometer running a different temporal sampling strategy allowed scientists to assess the adequacy of a newly developed noise filter (Turner et al. 2006). On the strength of this experiment, the ARM Program was convinced to adopt the new rapid-sampling mode in all of its interferometers.

\section{Data Archival, Display, and Distribution}

The ACRF Data Archive (http://www.archive.arm.gov/) was established to store and distribute the data collected at ACRF sites. Its primary functions are to store and accurately represent the existence of data files, provide access to all requested files, and to present specific and complete quality information for all files; internal quality assurance of the data archiving operation itself is vital to the success of these functions. In this section, we focus first on how the Archive provides access to, displays, and distributes both measurement data and data quality metadata. Then we consider what is needed "behind the scenes" to accomplish these tasks: this makes clear the importance of applying in-house quality assurance procedures to the Archive's data processing infrastructure to ensure its fidelity in providing robust data that can be easily accessed and distributed to data users.

\subsection{Data Access and Distribution}

ACRF data are free for use by the public; data users that are interested in ordering data may explore the millions of files within the Archive's holdings using a web browser, then select a meaningful subset, see an overview of quality information, and order files. Searches can begin either from the ARM Program home page (http://www.arm.gov/) or at the Archive's web site (http://www.archive.arm.gov/) using a number of search options; these include the ARM Data Browser; a Catalog Interface; a Thumbnail Browser; a Web Shopping Cart; and an IOP Data Browser. Searches often begin by specifying location and date range, and after such highest-level choices have been made, lower-level subsets of choices are made in hierarchical fashion (e.g., by instrument or by measurement). If the Data Browser or Web Shopping Cart options are used, graphical displays can be requested as the user approaches or reaches an actual selection of files, and at such time summaries of quality assurance information become visible. When the subsets of files of interest have been defined, the files can be ordered. Automated processes then retrieve and stage the files and their associated DQRs, for retrieval by FTP. An email address and a phone number for User Services are provided for data users needing to order files by email, wanting to report problems with the website, or needing help.

\subsection{Information Display}

Several types of quality assurance information are offered or displayed during the user's process of selecting files to order. Quick looks, including thumbnail graphs of scientifically relevant measurements, 
let the user visually judge the overall nature and completeness of the actual data in the files before ordering them. Color tables of automated flagging results contained within each data file (comprising a day) also are displayed for each scientifically relevant measurement. An assigned color is a single classification of the preponderance of the file's quality control flag states for the measurement's samples within the day (classified as good - green; suspect - yellow; incorrect - red; missing - black; undetermined - grey; and review pending - white). Color-coding symbols are used to indicate whether DQRs exist for this measurement during the day. Finally, any DQRs relating to the files being considered can be listed by title, with a link provided to the actual report text. This varied quality information palette is provided to help the user confirm his/her selection or modify the selection to something more appropriate to his/her needs. Finally, the order can be placed and the user is later notified by email to retrieve the files by FTP. Figures 13 and 14 provide examples of thumbnail plots and color tables a data user might find when perusing data to order.

Along with the actual measurements contained in the data files, some quality information also is delivered in-file. The retrieved files contain the quality control flags that are the basis for the color summary presented by the Data Browser. The explanation of the flags is provided in the NetCDF file's metadata as Global Attributes. The flags are useful but do not capture all that a data user may need to know about quality; DQRs provide the means for documenting other quality issues or concerns that have become known through further human examination. Along with the requested files, any DQRs associated with the files are delivered as text in HTML format.

\subsection{Archiving}

The efficacy of access, distribution, and display depends in turn on the efficacy of many underlying Archive processing activities. These functions are accomplished by means of structured data stream/file naming conventions, the design of the Archive's metadata database, and intricate logic that relies on consistent metadata content for each data stream in the database. These naming conventions in turn have implications for the structure of the DQRs, and result in in-house quality assurance procedures that are run during the process of initial ingesting of data files into the Archive, as explained below.

Structured data stream naming conventions are fundamental to enabling the Archive to carry out its function. A data stream is a collection of successive daily files of a particular type. The leading fields in a NetCDF filename denote the site and the facility within the site, the instrument or VAP name and the data integration period (for some files), the data level (e.g., raw or processed), the date of the first measurements in the file, the time of these first measurements, and the file's format. The key to this convention is that the filename contains all the information needed to identify the location, the type of file, and the initial date/time of its contents. The first two of these fields define the data stream to which the file belongs. 


$$
\begin{aligned}
& \text { 07/01/2004 to } 00 \text { Customize view to } 30 \text { days } \\
& \mathrm{mm} / \mathrm{d} / \mathrm{d} / \mathrm{yyy} \quad \mathrm{mm} / \mathrm{dd} / \mathrm{yyyy}
\end{aligned}
$$

Previous 234567891011 Next

(Note: ALL - Select all files for entire date range and all datastreams; VIEW - Select all files for current displayed date range and datastreams. Clicking thumbnail

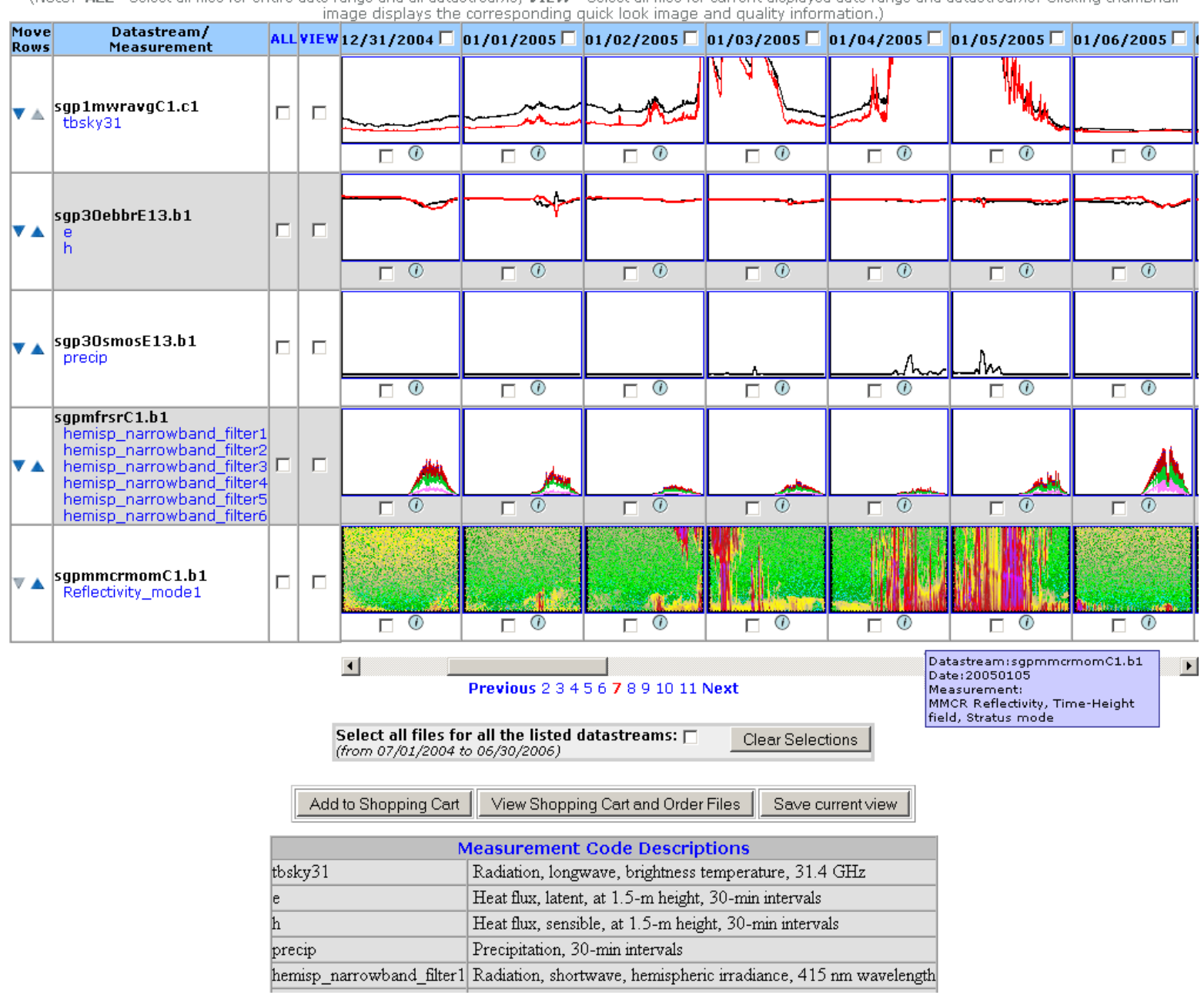

Figure 13: Example plots from several instruments as generated in the ARM Data Archive Thumbnail Browser, a user-customizable interface capable of concurrently displaying multiple measurements from multiple instruments. A mouse-over pop-up window provides details for one of the plots shown. Clicking a thumbnail provides full-size quick look plots and available data quality information. Only a sample of the measurement code descriptions available is shown. 
Measurements:

1) Precipitation, 30-min intervals

2) Wind speed, at $10-\mathrm{m}$ height, 30 -min intervals

3) Wind direction, at $10-\mathrm{m}$ height, 30-min intervals

4) Humidity, relative, at $2-m$ height, 30 -min intervals

5) Temperature, air, at 2-m height, 30-min intervals

6) Pressure, vapor, at $2-m$ height, $30-m i n$ intervals

7) Pressure, atmospheric, at $1-m$ height, 30-min intervals

8) Wind speed, vector-averaged, at $10-\mathrm{m}$ height, 30-min intervals

9) Wind speed, 30-min intervals, standard deviation

10) Wind direction, 30-min intervals, standard deviation

11) Humidity, relative, 30-min intervals, standard deviation

12) Temperature, air, 30-min intervals, standard deviation

Note: Colors inside the box represent auto quality check (Auto QC) colors and the symbols inside the box represent Data Quality Report (DQR) colors

\section{Legend (color:status):}

\begin{tabular}{|c|c|c|c|c|c|}
\hline : Missing & : Undetermined & : Review Pending & L: Good & : Suspect & : Incorrect \\
\hline \multicolumn{6}{|l|}{ Symbol } \\
\hline G: Green DQR & Y: Yellow DQR & R: Red DQR & & & \\
\hline
\end{tabular}

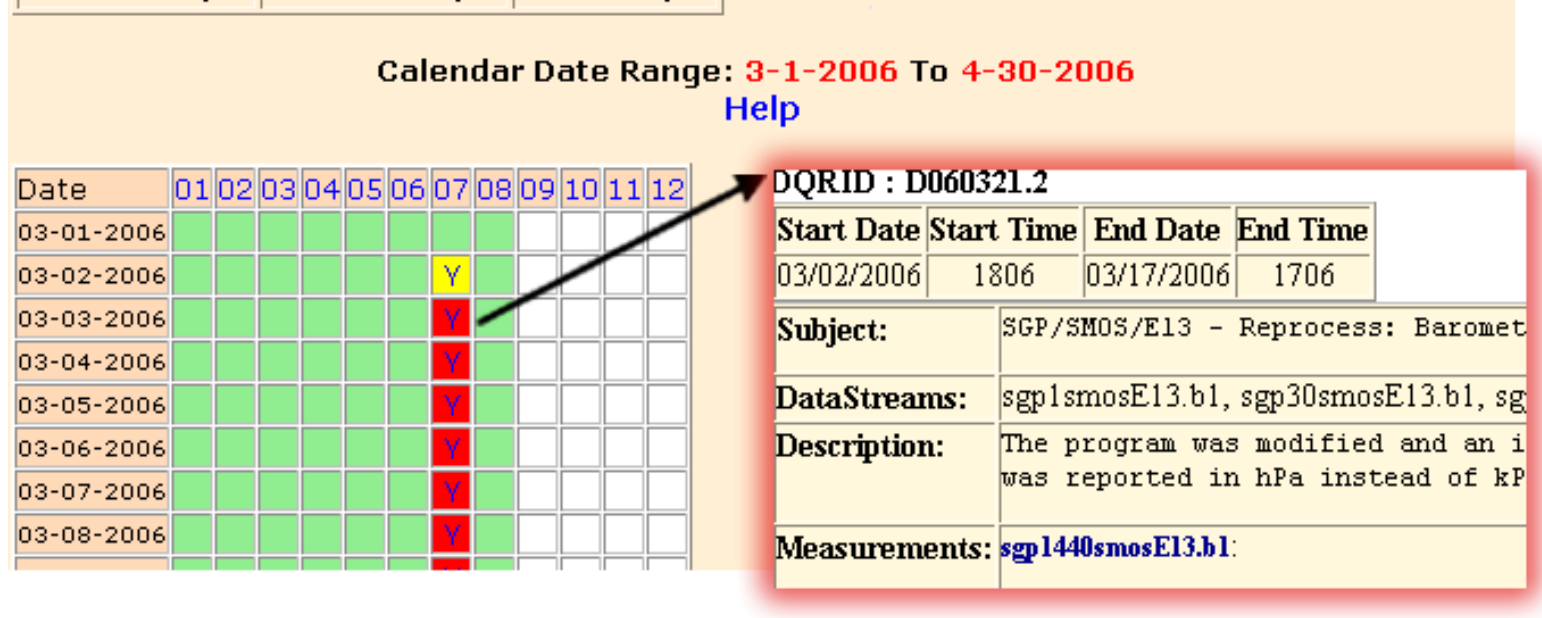

Figure 14: Example color table display obtained from the Data Archive Data Browser for data from a Surface Meteorological Observation Station. The color of a cell displays a summary of data existence and data quality status for a measurement on a particular day. "Y" symbols indicate that a more detailed text description of quality information (a DQR) exists for the atmospheric pressure measurement for those days. The lower-right inset shows part of the report that would be obtained by clicking on the "Y" symbol for March 3, 2006. 
The structured filenames then facilitate the organization and function of the Archive metadata database. Each filename has entries for its start date/time, end date/time, number of samples, file size, MD5 checksum (a type of electronic fingerprint for the file), a version number, and the date the file was received by the Archive. Many additional integrated metadata reference tables in the database then allow the filenames, based on the data streams to which they belong, to be grouped in different ways (e.g., space, time, instrument class, particular measurements) according to the needs of data users. For example, twelve instrument categories have been defined. Each data stream represented in the database is associated with one or more of these instrument categories. When data users select an instrument category while browsing, they are shown a list of instrument links, which in turn display a list of data streams available from each instrument.

\subsection{Metadata for Displaying Information About Data}

The information that populates these integrated metadata reference tables needs to be complete and consistent. Metadata completeness allows the user to find the same data stream from different web page starting points, and metadata consistency is needed for the ARM Program's web site information to agree with that shown when the Archive's holdings are browsed. A "birth of a data stream" process was devised to collect this needed metadata. Related tools enable updating the information when required. Having an assured mechanism to collect and update this information has recently enabled the integrated metadata to be shared by the various web sites and allows data ordering from various starting points. Furthermore, the integrated system can change and evolve as needed without introducing information synchronization issues.

\subsection{Integrating Data Quality Reports With Data}

The integrated metadata enable users to find and order data files, but DQRs are structured differently and require additional attention. The challenge of associating these reports with data files is complicated by the fact that a report may cover a period of weeks, months, or years, whereas a data file nominally covers one day. Furthermore, a sequence of like files constitutes a single data stream, but a report usually addresses issues contained in multiple data streams. The problem became one of how to manage the different granularity between data files and DQRs so that their overlap could be automatically determined and allow the reports to be correctly matched to a collection of requested files. The solution to this problem was to identify, within each report, all of the data streams included within its scope, and the exact date range for each data stream. This information was then entered into a DQR metadata database. Using this database in conjunction with the Archive database, the same logic that allows the Archive holdings to be displayed along many dimensions allows correct report/data file associations. A parallel emphasis on metadata is being extended to value-added processing data, field campaign data, and relevant external data from other agencies.

\subsection{Quality Assurance Procedures for File Processing}

To properly accomplish all of the tasks outlined in this section, the Archive must execute some quality assurance procedures of its own to make sure that file processing is conducted seamlessly. Some are directed at ensuring that the Archive does not lose or corrupt any of the thousands of files it is sent daily; others focus on those elements of file names and file contents that are stored in the Archive database, 
enabling the Archive to identify and deliver the correct subset of files as requested. These checks enable the Archive to store all files, protect them against corruption, display holdings in logical and useful ways for ordering, and provide all files (and only those files) needed to fulfill a request. Requiring the DQRs also to be specific with respect to dates, data streams, and measurements allows the Archive to provide the users with the information on data quality that is vital to ensuring proper understanding of data file contents. These procedures are executed as part of a ten-step process:

1. Analyze filename manifests and file checksums. The manifests and MD5 checksums are sent to the Archive along with the files. These are checked in the Archive's processing steps to ensure that all files sent are received and archived as sent. The checksum is stored in the Archive and can be used later to confirm the identity of the file with its original source.

2. Create two types of backup files. The primary backup is a copy on a separate system physically isolated from the main archival storage. A secondary backup exists because two copies of each file are kept in the main Archive library, a robotic tape library mass storage system, managed by the High-Performance Storage System developed by the U.S. Department of Energy and IBM (http://www.hpss-collaboration.org/hpss/index.jsp).

3. Reject duplicate files. To reject duplicate files, a check for file uniqueness compares each new file's MD5 checksum with the MD5 checksums of all currently archived files. If the checksum is identical to that of an existing file, the new file is rejected, because the new file's content is completely redundant.

4. Check the filename for consistency with the file's content. If the beginning date/time in the third and fourth fields of the structured filename does not agree with the initial date/time information in the contents of the file, resolution is needed.

5. Hold and investigate files outside of the normal time sequence. Substantially past-dated (out of sequence) files may contain corrupt time information. For example, the computer running the instrument and recording its data could have reset its clock to a date years before. Such substantially out-of-sequence files are moved aside and investigated, unless prior arrangements have been made (e.g., to accept reprocessed data from the past). Correct time information is vital to the usefulness of a file. Currently, the ACRF sites use GPS receivers to minimize the possibility of corruption of time information. Future-dated files, for reasons similar to those discussed here in connection with the sequence check, are further investigated and/or rejected as well.

6. Hold and investigate files not belonging to a known data stream. The importance of data stream metadata to the locating and delivery of files was discussed above. Holding unknown files until the metadata are provided ensures completeness of metadata and availability of files.

7. Assign version numbers. Version numbers allow an easy determination of whether prior instances of a file have been archived and make it possible to notify users that updated files exist. All versions of a file are kept unless deletion is specifically requested. Even deleted files can be retrieved in the rare cases when this is needed. 
8. Read date and number-of-samples information from the files. Once a file is opened, the date and time of the first and last samples in the file, and the number of samples, are determined and stored in the Archive database. This process also confirms that the file's basic format is valid.

9. Evaluate and report performance metrics. This higher-level check evaluates completeness. For each predictable data stream and day (i.e., file), the ratio of the number of samples for the day to the mode of the number of daily samples from the data stream, expressed as a percentage, is calculated. Data streams with intrinsically variable numbers of samples, such as balloon-borne sondes, are excluded from this analysis. The mean of these daily completeness metrics is tabulated monthly; the target expectation is greater than 95 percent. Problematic situations are investigated. This check also helps maintain the reliability of the automated instrumentation. Metrics are reported quarterly to DOE.

\subsection{Data Usage and Publication Statistics}

One measure of the value of ACRF data are data usage statistics. Another measure is the number of peerreviewed publications that have used the data for analysis, and the related number of times these publications have been cited by others.

Before November 2007, the Data Archive had collected more than 114 TB of data in 8.3 million files. Researchers had requested more than 18 million files $(83 \mathrm{~TB})$ from routine data streams stored at the Archive. The Archive has also distributed (by way of user FTP access) more than 1.7 million files (1,640 GB) of IOP data (IOP datasets are generally more concise than the routine ACRF data streams). The Archive has a cumulative "registered user base" of 3,600 individuals. In a typical month, $100-120$ users submit 400-600 requests for data.

As for publications, the number of peer-reviewed papers published by ARM Program Science Team members and anyone else that has used ACRF data through February 2008 is 1975.

\section{Data Stream Reprocessing}

The ACRF Reprocessing Team is tasked with reprocessing data to fix known problems when clear corrections are available. Examples of correctable problems include calibration errors or offsets, metadata coding errors, and updates to remote sensing retrieval processes. Reprocessing helps produce a consistent data format across sites and time to increase the usability of data for both data users and as input to value-added processing algorithms. A reprocessing task can apply corrections for a few days to a single data stream, or can result in the wholesale, end-to-end reprocessing of an entire class of data. The result of reprocessing is a dataset of greater quality with fewer caveats for the data user.

Reprocessing tasks are largely identified when engineering and/or operations change requests are made (see Section 13) and during problem resolution processes. When a correctable data quality problem is identified, a reprocessing task is submitted to the reprocessing database and assigned an appropriate priority. Reprocessing can be an involved and time-consuming process. Therefore, a DQR often is required to alert data users of the quality problem until the reprocessed data become available.

Before a reprocessing task is undertaken, problem reports and DQRs associated with the data stream to be corrected are reviewed to identify other data quality problems that could be corrected simultaneously. 
The existing DQRs also are pre-reviewed for opportunities to merge documentation of like-quality problems into a single consolidated quality report. Additionally, data stream structural changes through time are identified so that these also can be addressed, if appropriate, to produce data of a consistent format. These steps can be thought of as addressing the reprocessing of the metadata at the same time the data they represent are reprocessed.

After the reprocessing has been performed and before the data are released to the Archive, the reprocessed dataset must be thoroughly reviewed to verify that the reprocessing was properly accomplished. A series of tests are performed, and at any point in the verification process the failure of a test will result in the data being returned to the reprocessing center for additional processing or correction. These are described next.

First, a completeness check is performed. An automated tool is used to compare the original dataset and the reprocessed dataset, and brief reports are produced showing data gaps filled, new data gaps created, differences in the ways files are split within a single day, and differences in the number of records within same-named files. Each discrepancy is carefully examined and reconciled to ensure that new problems have not been introduced by the reprocessing.

Second, the NetCDF headers for the reprocessed data are compared to each other to identify metadata changes throughout the reprocessing period. The NetCDF headers of the reprocessed data on the temporal boundaries of the reprocessing also are compared with the NetCDF headers of the data. This is done immediately before and after the reprocessing period to ensure there are no unintended differences. Again, any differences (e.g., between calibration coefficients or between serial numbers) are thoroughly examined and reconciled or the reprocessed data are returned for additional correction.

Third, the reprocessed data are spot checked using a plotting tool to confirm the intended corrections have been applied and that no unintended changes have occurred to variables that should not have been modified by the reprocessing. For short reprocessing tasks encompassing a few days, each reprocessed day and each variable are compared to the original data. For larger reprocessing tasks, at least one day of reprocessed data in each month is compared to the originally processed data for the primary variables modified during reprocessing, and a random handful of days are checked for all variables. Additionally, the days at the temporal borders of the reprocessing are checked carefully for intended or unintended modifications in all variables. Additionally, several days of data at the temporal borders of the data are plotted to ensure continuity with the data immediately before and after the reprocessing period. If there is any question about the veracity of the reprocessing, the instrument mentor, algorithm developer, and/or value-added processing translator are asked to review a sample of the reprocessed data.

The fourth and final step of reprocessing is a post-review of all relevant problem reports, DQRs, and metadata. This task is critical to ensuring that valid advisory information is provided to data users. Recall earlier that before reprocessing, problem reports and DQRs associated with the data stream were carefully screened to determine if the documented problems could be 'fixed' through the reprocessing request. After the reprocessing, these reports are reexamined. DQRs that have been addressed by the reprocessing effort either are removed from the data system or are modified to indicate reprocessing has been completed. Remaining valid DQRs are sanitized and/or merged to reflect accurately the reprocessed dataset and to communicate succinctly to the data user all known data quality concerns. 
Only after successfully passing these checks are the data cleared for archival. Internal metadata and public data quality displays housed at the Archive, including thumbnail plots and color-coded indications of quality, are revised and stored when the new data are archived. A reprocessing notice is prepared, which documents that the reprocessing took place, and the notice is sent to all previous requestors of the data to alert them to the availability of the reprocessed data. Such data reprocessing increases the value of the data made available to users through elimination of known but correctable quality concerns, which ultimately improves the usability of both the data and its data quality documentation.

\section{Engineering and Operations Management}

The ACRF engineering and operations infrastructures implement formal processes and procedures and establish responsibilities timelines to identify negative systems performance, establish root causes, approve resources to correct problems, and develop modifications or new solutions. The bottom line of these key infrastructure activities is to tie together the entire quality assurance infrastructure to ensure optimal instrument and systems performance, with the ultimate goal of providing the best data possible to researchers.

\subsection{Engineering Change Processes}

Engineering activities include data system development and modification; instrument system development and modification; value added product development and maintenance; data ingest development and maintenance; communications development; and general site engineering. Once a fundamental instrument or system performance issue has been identified and diagnosed, an engineering change can be requested. Issues related to the performance of an instrument or computer system or to the logical state of a measurement and its data quality may lead to the redesign of an existing system. An engineering change request system was developed to track and manage such changes, serving also as the starting point for adding a new instrument capability, data product, or system functionality. Proposed engineering tasks are initiated and managed through specific engineering design processes; engineering change process flow, culminating in operations change process flow, is illustrated in Figure 15.

For engineering tasks seeking a fundamental change or new capability, the engineering process begins with an Engineering Change Request (ECR). An ECR describes the reason for a need and indicates any known costs and/or impacts to current operations or systems, and contains detail on requirements definition, analysis, design, documentation, testing, training, and delivery. An Engineering Review Board meets every Monday to review and either approve or reject ECRs, and assigns priority to approved requests. When priority is assigned, an ECR is considered in the overall context of the ACRF infrastructure workload so that the programmatic impact of performing ECR-specified work is understood and communicated. Once approved, the ECR becomes an Engineering Change Order (ECO). The ECO documents, among other things, estimated project duration, task status, project impacts, requirements and design reviews, and at the end of the process, a readiness review. To close an ECO, all of the requirements as defined must be met and approved. In most cases, an ECO is completed by the issuance of a Baseline Change Request (BCR; see Operations change processes below) to implement the change operationally. For engineering tasks requiring little or no design work, or that need to address a pressing operational issue, a simplified Engineering Work Request (EWR)/Engineering Work Order (EWO) process is used instead. Nevertheless, roles, responsibilities, and tracking methods are defined to facilitate understanding, priority, impact, and status of tasks. 


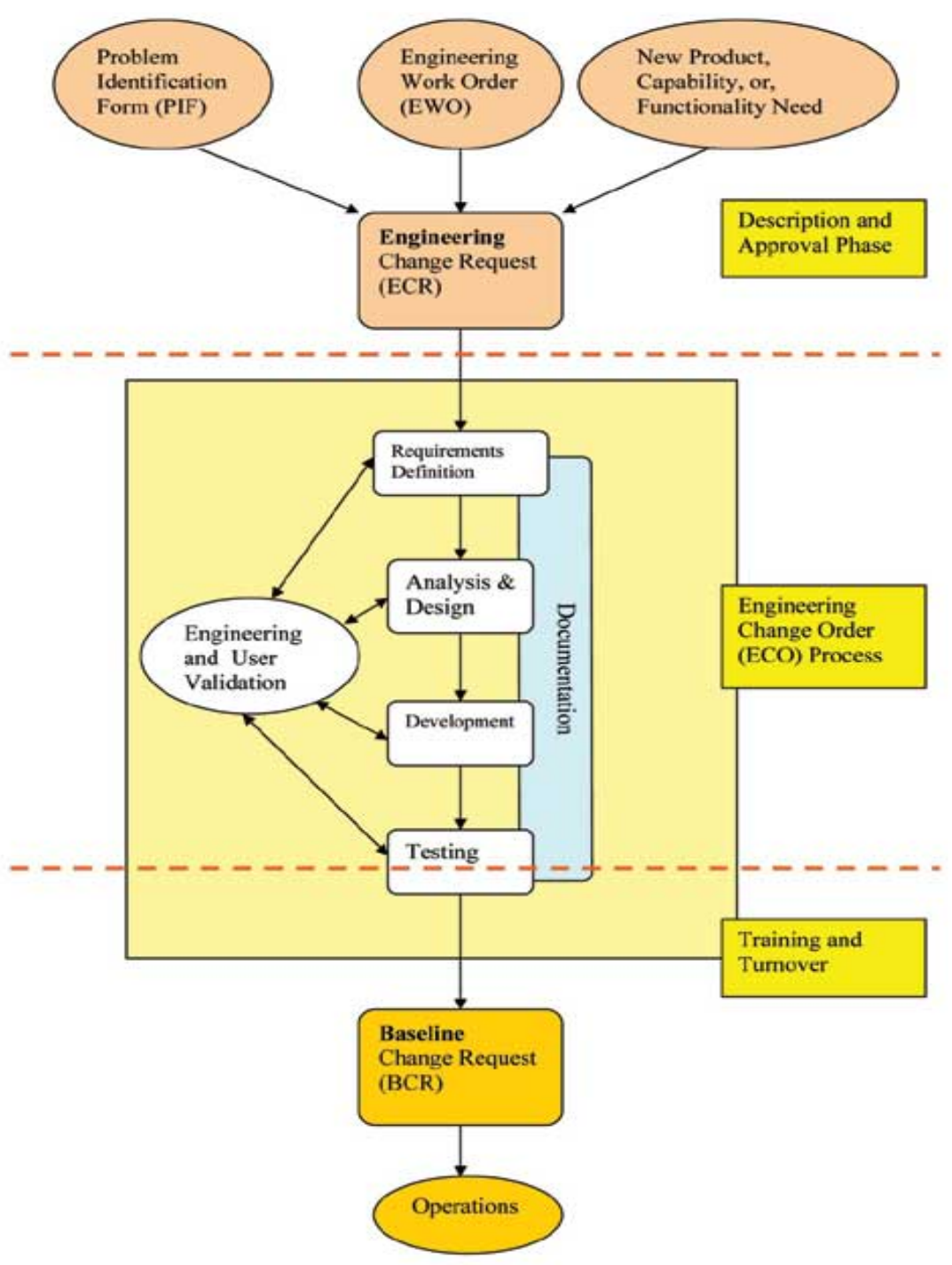

Figure 15: The ACRF engineering and operations change process flow.

An Engineering Task Tracking Tool helps manage all engineering processes. The Engineering Team uses it to perform resource loading, track and communicate status, and schedule and set priorities. Tracking ranges from daily (for emergency priority projects) to twice-yearly (for routine priority projects) actions. The ACRF Infrastructure Management Board reviews on a weekly basis a summary report of all engineering tasks to ensure the right balance of tasks is undertaken. Resources within the Engineering Team may be reassigned as needed to support programmatic priorities. 


\subsection{Operations Change Processes}

Once an engineering solution has been developed and successfully tested, a Baseline Change Request (BCR) is issued to establish ACRF operations configuration control and to formally request and document the implementation of a change (see Figure 15). BCRs are required for changes to instruments, data systems, data processes, data streams, measurement methods, and facilities, and helps ensure that all components of the infrastructure are consulted before implementing any change. Because seemingly minor changes can have significant repercussions, no changes to an operational instrument, computer, facility, or other system, can be made without an approved BCR. The BCR process allows the Operations Team to determine the resources required to make the change and to prioritize activities based on importance, impact, and projected cost. A priority level is assigned from emergency to routine, which sets limits on allowable review periods ( 24 hours to 30 days). Daily oversight is provided by a BCR administrator.

The $\mathrm{BCR}$ process not only documents a proposed change and reviewer comments, but also assigns a signal point of contact that is responsible for overseeing the proposed change to completion. A searchable database captures reviewer and coordination comments and updates, and specifies a completion date. Once the implementation activity has been completed, only the assignee can recommend that the BCR be closed. A BCR is usually left open for several weeks after the work completion to assure documentation of any unanticipated impacts.

\section{Future Directions in ACRF Data Quality Assurance}

The ACRF data quality assurance program continually evolves as new technologies arise and as the legacy dataset grows. This section describes a number of ways in which the data quality assurance process is being improved as of the beginning of 2008 .

\subsection{Using Historical ACRF Measurements to Improve Working Quality Control Limits and to Detect Trends}

Given that, about 15 years of continuous data have now been amassed for some ACRF measurements, a wealth of samples valid for statistical analysis now exist. Thus, data now are being mined to obtain appropriate data ranges by site and various time ranges (Moore et al. 2007). A new system will statistically review the historical data to both improve working quality control limits and to allow better detection of slow but consistent trends in data seen when, for example, a calibration drifts. Objectives of this work include the identification of more appropriate quality control limits for data inspection purposes, including time-varying (e.g., monthly or seasonal) and site-specific quality control limits, and providing new ways of visualizing data. A schematic view of this process is shown in Figure 16.

This analysis system intends to generate long time-series plots, frequency distributions, and other relevant statistics for scientific and engineering data for most data streams. Frequency distributions categorized by month or season will be used to establish valid data ranges specific to those time domains, keeping in mind that statistics alone are not sufficient for establishing limits and valid data ranges, since an understanding of both the physics of the atmosphere with respect to the quantity being measured and also the measuring instrument must be well understood. Such limits should improve problem detection 
capability and perhaps provide the ability to identify limits that can distinguish between a performance warning and a performance failure. Two known cases in which a consideration of physical understanding has proven useful in enhancing statistical information are described below.

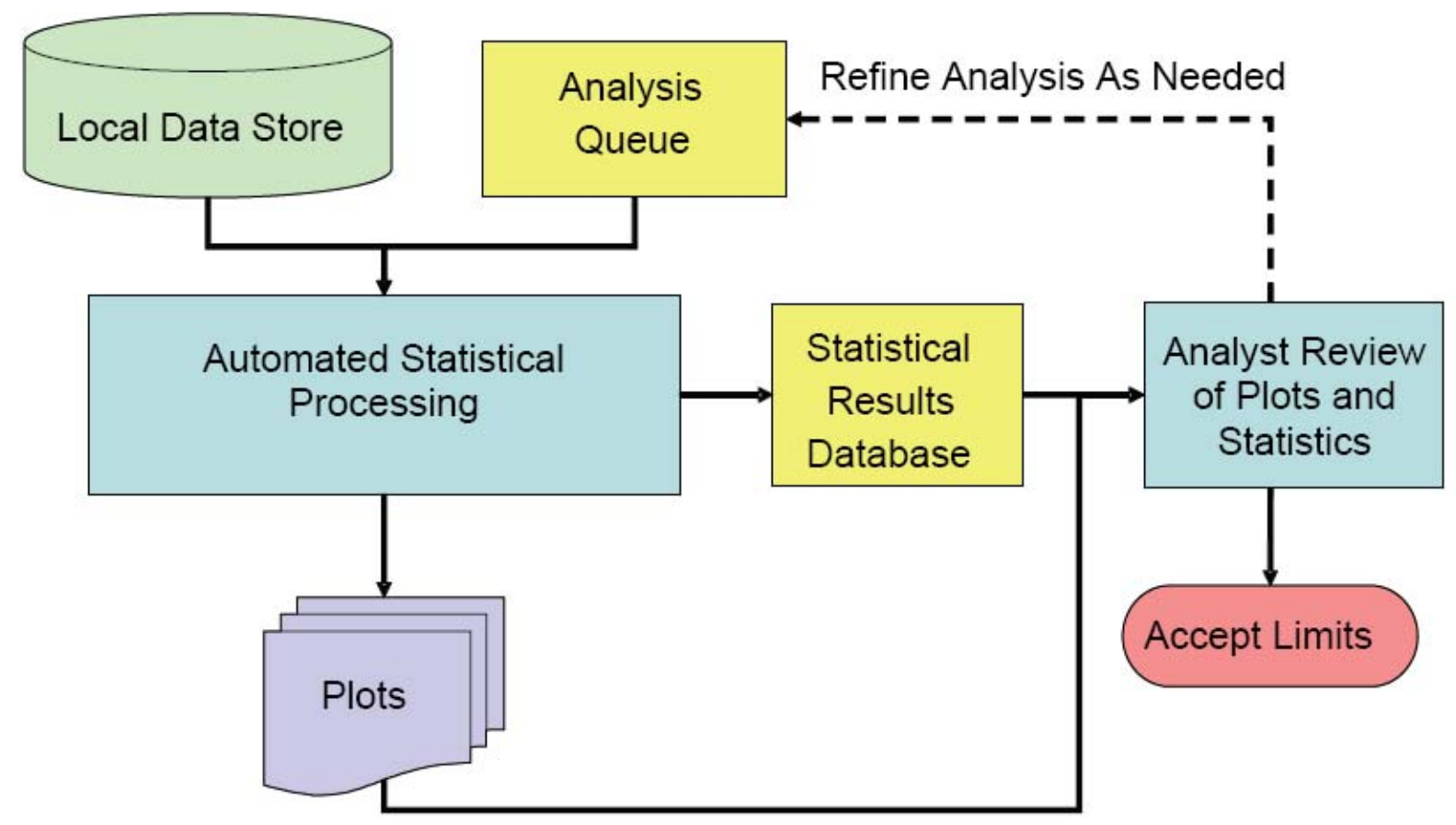

Figure 16: Statistical analysis system block diagram, running from left to right and top to bottom. Historical data would be subjected to statistical processing, the results of which would be perused by an analyst for validity. The result would be refined data quality checking limits for various time aggregations and locations.

One example is included in the QCRad VAP, described in Section 9. In it, the correlation between ambient air temperature and upwelling and downwelling longwave radiation is used to set limits on acceptable longwave values based on the statistical analysis of the relationship as appropriate for the climate regime (Long and Shi 2006). This testing can detect some types of data abnormalities that mere limits on the acceptable range of longwave values cannot. Another example of the application of physical understanding in the QCRad VAP is the use of ambient air temperature to determine what solar zenith angle-dependent maximum allowable upwelling shortwave limit choice should be used: one suitable for snow covered ground where surface albedo is relatively large, or, one more typical for non-snow conditions? Statistical analysis can be used to set seasonal limits, but these might not work well for occurrences of early or late season snowfall events, or may require an exaggerated date range to include these rare events. When the ground is covered with snow, virtually all of the radiative energy input to the surface goes into the water phase change (i.e., melting the snow) rather than the raising of the temperature of the surface air itself. Thus, surface temperature, and the air above the surface, will remain near or below freezing until a significant amount of the snow has melted and the underlying less-reflective surface is uncovered. We have set a snow-covered surface air temperature limit based on climatological 
analyses (related to surface type and roughness) and when the air temperature falls above this value the non-snow surface albedo limits are used in data testing; otherwise, snow-covered limits are used. This 'active' limit determination has the advantage of using more appropriate limits based on actual conditions. This can include unseasonably warm days during normally cold months, rather than just typical seasonal climate statistics. As these examples show, both physical understanding and climatological statistics play an important role in our quality assessment efforts.

In the analysis system being constructed, statistics and proposed limits will be stored in a relational database for easy reporting, refining, and for use by other processes. The system will include a feedback mechanism to help keep data quality analysts and instrument mentors in agreement regarding validation checks. Web-based applications to allow an analyst request of a unique data analysis and to view the results will be developed, allowing the creation of statistics or parametric analyses over any custom time range (e.g., day, month, or year) series of years. An example of how data mining could be used to improve valid range-testing limits is shown in Figure 17, while Figure 18 shows an example of how such mining can be used to detect an abnormal longer-term trend in a data stream.
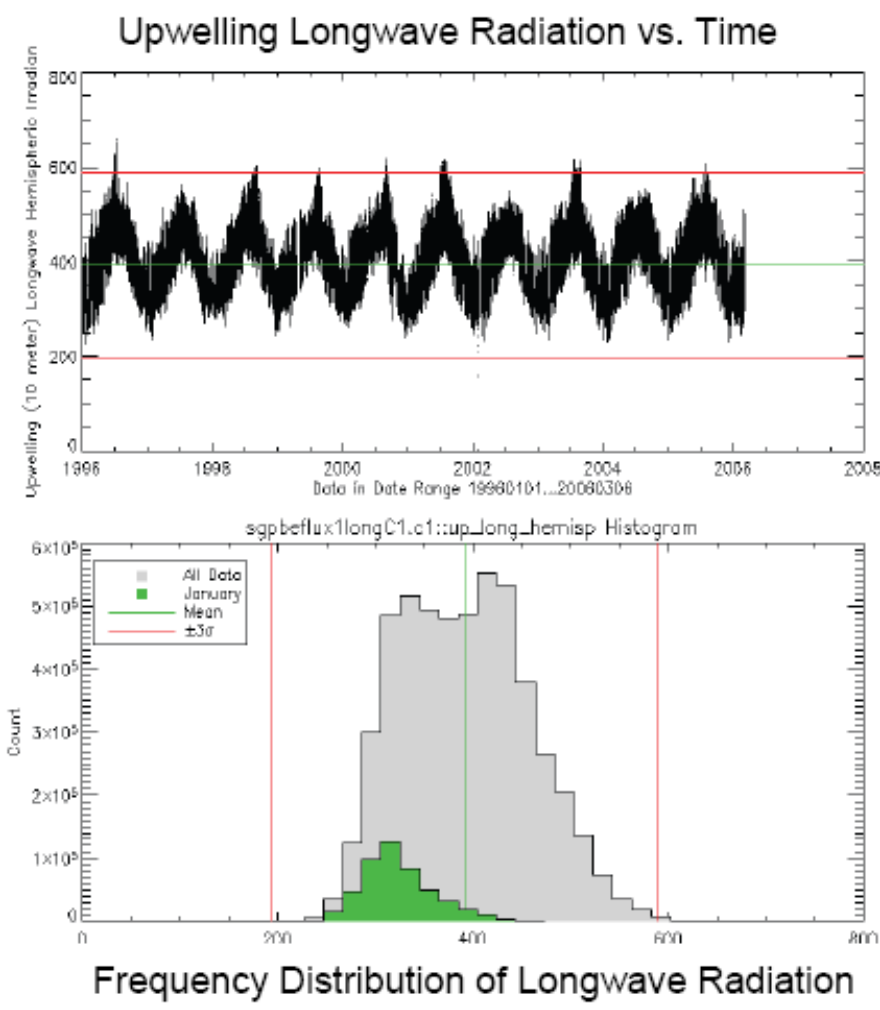

Figure 17: Upwelling longwave radiation exhibits a strong seasonal dependence, as seen in the timeseries and frequency distribution plots. The distribution colored green represents values measured in January for each of the ten years analyzed. The gray area represents all months. The mean and three standard deviation values are shown for all months. As shown, precise limits of a valid data range in January would be more restrictive than those for the entire year. 

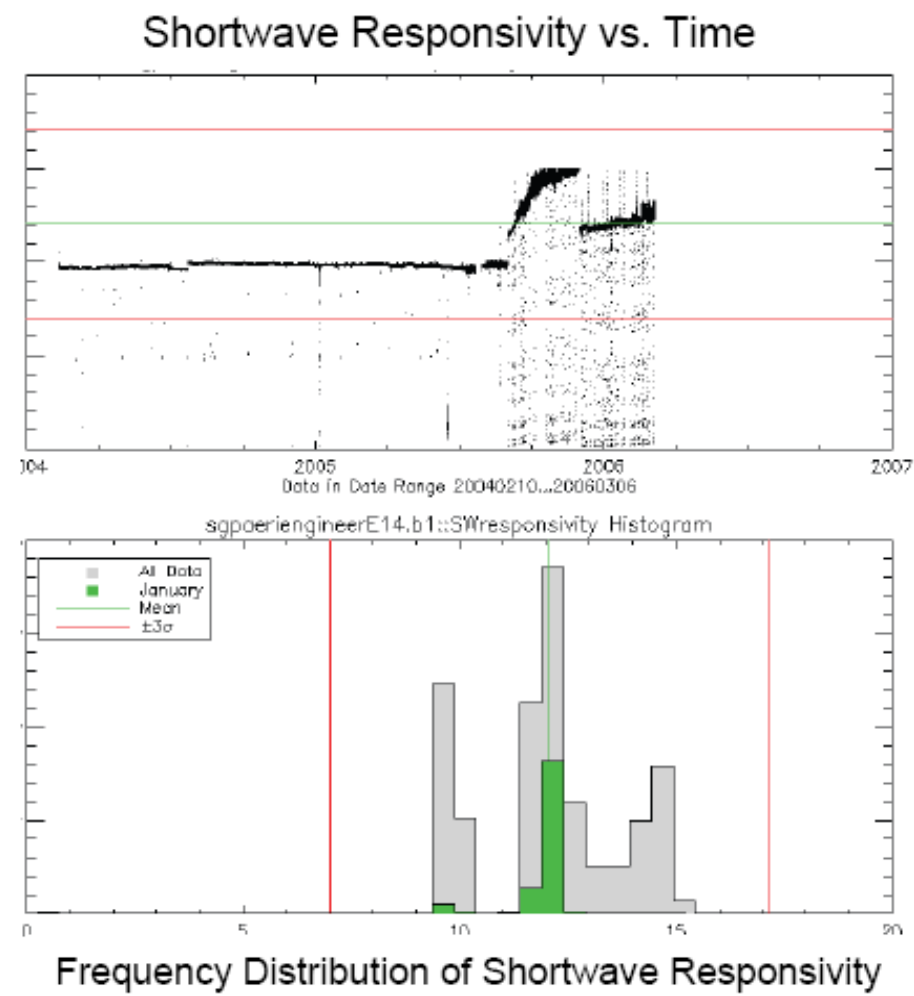

Figure 18: Multi-modal distributions signify trend shifts that may warrant investigation of possible data quality issues. Here, a significant shift is detected in a diagnostic engineering parameter within the Atmospheric Emitted Radiance Interferometer during the second half of 2005. Mean and 3 standard deviation values are shown for all months, which are shaded gray in the histogram. January values are shown as green.

\subsection{A New Data Model for Providing Data and Statistics to Users}

Similarly, providing the users of ACRF data with information that better serves their needs is an important aspect of general data quality. Existing thumbnails and quick looks are helpful for identifying data characteristics on a daily basis but do not readily reveal longer-term patterns nor provide any summary of information "learned" from the measurements. As the ACRF data collection period approaches 15 years at some sites, and spatial coverage has extended to include tropical and Arctic regions as well as intermediate biomes, a more integrative approach to presenting and providing ACRF data is timely.

The Data Archive is developing a new data model that will eclipse, but not entirely replace, the current approach of displaying and providing data centered on daily instrument-based files. User input, especially from the climate modeling community, is being actively sought and incorporated into the development of this hierarchical model. As this is written in late 2007, our expectation is that only the core measurements from top-level data streams and VAPs will be included. The data user ultimately will begin a data search by selecting a location and a variable, much as is currently done, but then will be able to view a series of statistical data summaries. These summaries will include time scales ranging from the 
full period of record, through annual and seasonal levels, down to individual months. At each desired time range, the user will be able to see graphical and numerical statistical summaries. The available summaries (in graphical and tabular format) will depend on the type of the measurement. These may include simple types of statistics like mean, median, or more complex summaries like a probability distribution function. In addition, when a suitable period of interest has been identified, the user will be able to order the data comprising the summary in a chosen format (NetCDF, ASCII, Excel, or XML) or request access to original NetCDF data files stored in the Archive.

Conditional selection of data is expected to be a unique optional (and later-developed) feature for this method of data access. This capability will allow the user to ask for specific data fields when conditions are met for other data fields. For example, the user can check for cloud cover and temperature and then ask for specific radiation variables during cool, overcast conditions. The result will be that users will no longer need to download large quantities of files and/or data volumes and subsequently perform data reductions at their home institutions to obtain the data they really need.

\subsection{Storing and Organizing Documentation on Measurements for Data Quality Purposes}

Since Data Quality Office analysts inspect on average 5,000 measurement variables per analyzed day, they must have a good understanding of instrument performance and data expectations when analyzing diagnostic plots. This requires an understanding of many broad meteorological concepts as well as important nuances of individual instruments. Information describing instrument measurement characteristics, if it existed at all, was stored in numerous locations, making ready access difficult. To gather and organize this information, the Data Quality Office has implemented a new Wiki (a Hawaiian word meaning 'quick') system that provides easy information access to data analysts and provides them the ability to add quickly, in an uncomplicated manner, new knowledge about instruments and data as it is learned. The "DQ Wiki" can be accessed from the DQ HandS home page (http://dq.arm.gov/).

A Wiki is a collaborative platform designed to allow multiple users the ability to edit web pages from any computer. It is organized in an open format viewable from a web browser and is easily updatable by any qualified, registered user. Changes made are viewable instantaneously without the assistance of a central web designer, allowing both the rapid addition of new information and the updating of outdated information, while preserving revision history. An example of a Wiki platform that has gained wide popularity is Wikipedia (www.wikipedia.org). ${ }^{1}$ While the Data Quality Office does not intend to create documentation this substantial, or allowing the public to edit the information, the same potential exists for creating and displaying a wealth of programmatic data quality guidance. There are several different Wiki collaboration platforms to choose from, with the Twiki ${ }^{2}$ open-source platform ultimately selected (Kehoe et al. 2007). Figure 19 shows an example of guidance that has been prepared and stored in the DQ Wiki showing an instrument operating in an acceptable manner.

\footnotetext{
${ }^{1} \mathrm{http}: / /$ en.wikipedia.org/wiki/Wikipedia (last accessed December 19, 2006).

${ }^{2} \mathrm{http}: / /$ www.twiki.org/ (last accessed December 19, 2006).
} 


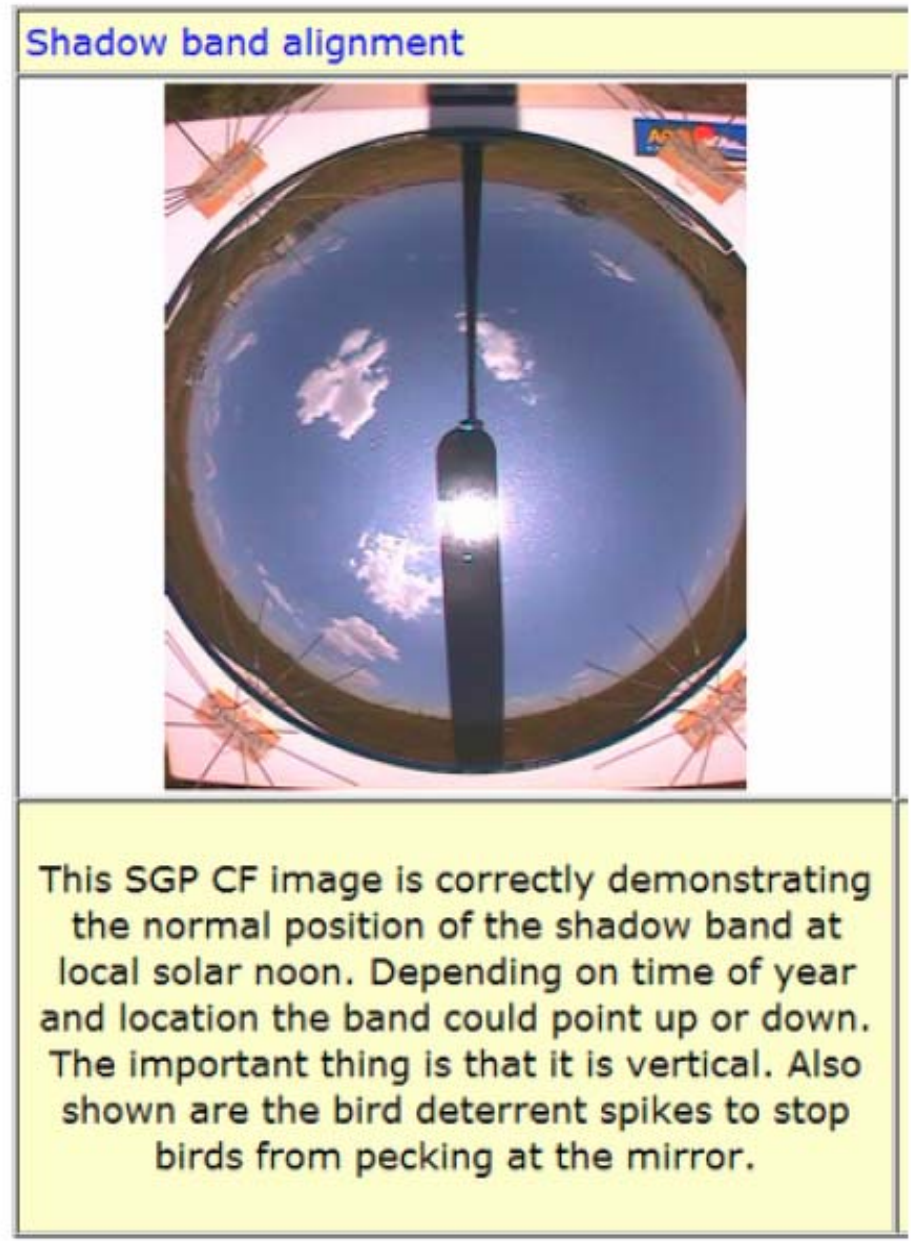

Figure 19: A data quality Twiki example of a Total Sky Imager shadowband correctly shading the sun at local solar noon; local solar noon is an optimal time to check the alignment of the shadowband. This 'optimal' image then can be compared to real-time examples by data quality analysts as a pattern recognition technique.

Basic instrument and data quality documentation and guidance have been gathered from each instrument mentor. This information has been transformed into a Wiki page for each instrument, including specific examples of good data and known problems. By having a repository of examples and accompanying explanations, analysts are able to quickly gain pattern-recognition knowledge and use it to scan plots to locate suspect data, allowing them to more easily and accurately identify problems. This greatly decreases the time spent inspecting data and leads to quicker problem identification, which leads to quicker problem reporting and, in theory, problem resolution. The DQ Wiki is allowing for open exchanges of ideas and information on data quality, and has both streamlined the process to train new analysts and helped establish and propagate institutional knowledge. 


\subsection{Automated Data Stream Quality Processing Modules}

Presently, the hourly processing of automated quality control information is limited to checking for violations of simple range (minimum and maximum) and maximum rate of change (delta) limits. The Data Quality Office has implemented more sophisticated instrument mentor-recommended automated checking algorithms for some instruments, but these results are not coded into the NetCDF data files and as such are not readily available to data users.

To rectify this, a plan is being developed to incorporate more sophisticated checking algorithms within the data processing infrastructure. This higher-order data quality processing would occur after a complete 24-hour set of data have been collected from an instrument; if additional data quality issues are identified by this processing, the data quality information within the file will be revised. The file would then be delivered both to the Data Quality Office for diagnostic display of its data quality attributes in DQ HandS and to the Data Archive for public distribution. Figure 20 shows a flow diagram of the proposed change to the present automated data quality-processing path.

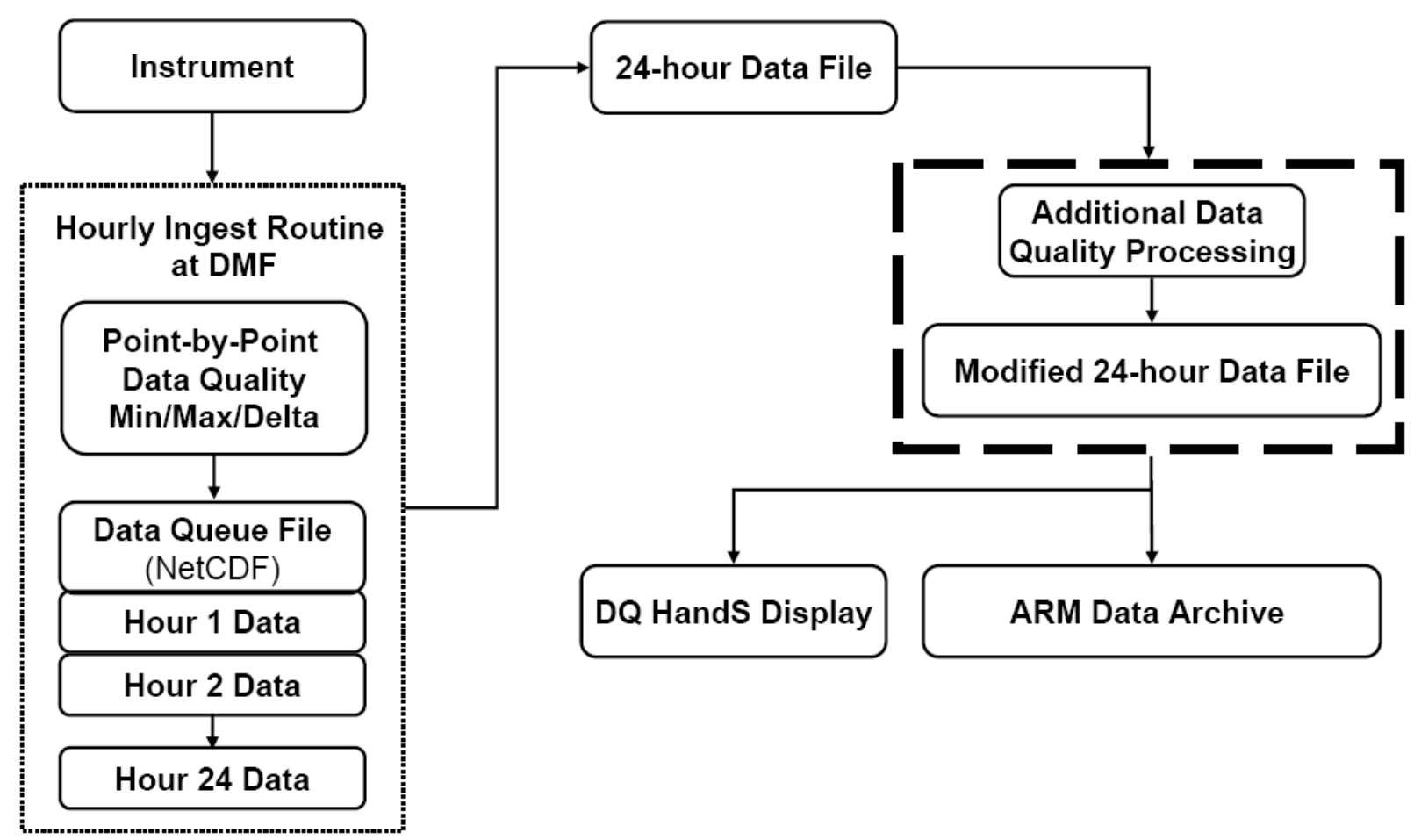

Figure 20: Proposed revision to the data quality flag processing path (inside large-dashed box on the right), allowing for additional and/or more sophisticated automated data quality processing at the end of a 24-hour data collection cycle. The current extent of automated data quality processing is shown within the dotted box to the left. 


\subsection{Operations Status System Database}

To better track and report the status of ACRF instruments and their subcomponents at widely distributed locations, operations staff recently completed the first development phase of a comprehensive Operations Status System (OSS; http://oss.arm.gov/oss.php). By serving as a central collection point for all ACRF instrument status information, the OSS enables timely and cost-effective decisions affecting site operations, particularly with respect to quickly remedying instrument performance issues, and in doing so has become a key component of the quality assurance process.

In the past, each ACRF locale operated and maintained individual databases to track site-specific activities. However, some of these activities - such as monitoring the operational state of an instrument system, or documenting preventative and corrective maintenance, shipping and receiving, inventory, and calibrations - are common across all ACRF sites. In addition, the site-specific databases lack consistent time stamps for tracking these activities and for measuring the length of time a system or component spends in a given state. Given this, and knowing that these activities have a huge impact on budget planning and operational efficiency, a programmatic need was identified to standardize the cross-site elements of operations databases into a common system.

The OSS tracks the various states of instrument, computer, and infrastructure systems, and the subcomponents that make up those systems, and as such now serves as an ACRF-wide inventory tracking system. Each OSS state corresponds to an event; the nine operational states possible and the events they describe are shown in Table 3. Search capabilities allow OSS components to be found by variables such as name, serial number, property number, model number, current state, and current location.

Table 3: Possible Operations Status System states.

\begin{tabular}{|l|l|}
\hline \multicolumn{1}{|c|}{ State } & \multicolumn{1}{c|}{ Event Description } \\
\hline IN-OK & On line and operating as expected \\
\hline IN-VERIFICATION NEEDED & $\begin{array}{l}\text { On line, operational, appears to be operational, but needs } \\
\text { verification of data quality }\end{array}$ \\
\hline IN-NOT OK & Should be on line, but is not and troubleshooting is needed \\
\hline OUT-SPARE & Not on line and is a spare \\
\hline OUT-REPAIR & Not on line because out for repair \\
\hline OUT-CALIBRATION & Not on line because out for calibration \\
\hline OUT-OTHER & Not on line because of planned removal \\
\hline OUT-DECOMMISSIONED & Not on line because no longer used \\
\hline SHIPPED-REPAIR & A component has been shipped to the vendor for repairs \\
\hline SHIPPED-CALIBRATION & A component has been shipped to the vendor for calibration \\
\hline SHIPPED-BETWEEN SITES & A spare component is en route between sites \\
\hline
\end{tabular}


OSS data are stored in a MySQL ${ }^{1}$ open source relational database. A schema diagram summarizing the database structure is shown in Figure 21. OSS systems ${ }^{2}$ deployed at an ACRF site facility are composed of installed components. The current state of every system and component is based on its latest event. Over time, any system or component may have many events. The event states and time stamps for a given system or component are constantly summarized in a state report which contains statistical information that can be used to develop diagnostic metrics such as 'mean up time', 'mean down time,' 'mean time between repairs,' and 'mean-time to repair.' Having access to current instrument status, metrics, and operational histories allow site managers, in an objective manner, to promptly identify any necessary actions and consider future budget expenditures. Components that are not installed may be unavailable due to repair or calibration, available as spares, or decommissioned if no longer in use. A history of each component's location and installation status is maintained. Component location history updates occur any time a component is installed, removed, or relocated. Since movement can affect state, every component location history change has a corresponding event. OSS provides reference capabilities to those event documents.

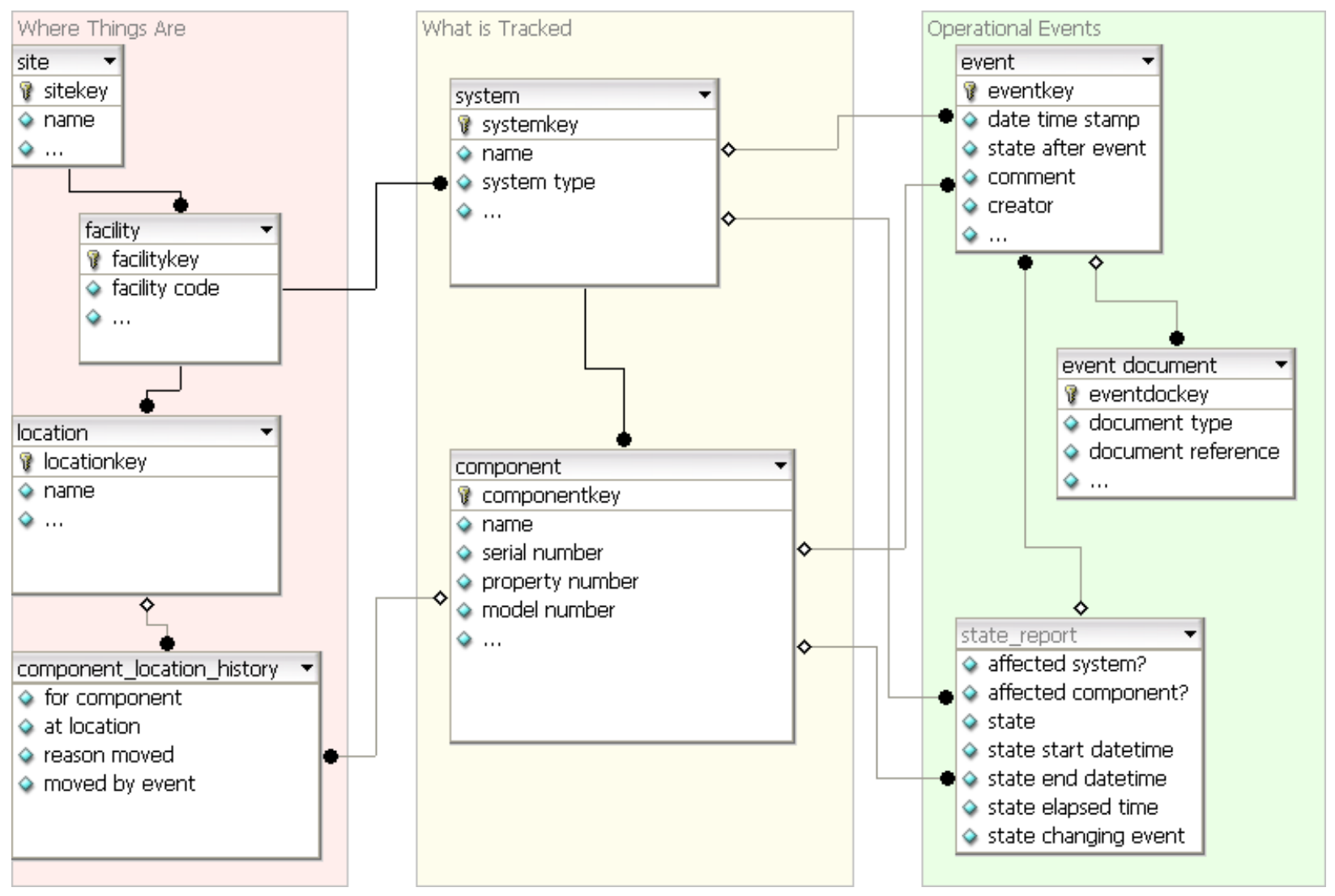

Figure 21: Operations Status System database schema in summarized form.

\footnotetext{
${ }^{1}$ http://www.mysql.com/ (last accessed August 2, 2007)

${ }^{2}$ OSS database entities are represented here in bold text.
} 
The next OSS development phase will allow existing common web-based reporting systems to automatically create or pre-fill ${ }^{1}$ OSS events. Future enhancements will automate OSS inventory updates when instrument system maintenance occurs and allow site operators to directly store information in OSS that is now entered into site-specific databases. This will save site operators entry effort, reduce transcription errors, provide an automatic link back to the report documenting the event, and allow OSS information to become available sooner, while allowing site operators to retain capabilities that meet unique site requirements. Finally, other ACRF reporting tools may want or need access to OSS data. For example, "web services" 2 could be developed to allow other web sites, web applications, or software systems to request and present interesting OSS data; this could facilitate the display of an instrument's current OSS state and recent events on the ARM Instrument Pages (http://www.arm.gov/instruments/) and possibly in the DQ HandS system.

\section{Summary}

The ACRF data quality assurance system starts with instrument selection and ends with data dissemination, and contains many important steps in between. ACRF instruments have been selected to satisfy specific measurement requirements identified by the ARM-funded Science Team as necessary to achieve the scientific goals of the program, which include improving the treatment of clouds and atmospheric radiation within general circulation models. An instrument mentor serves as the technical point of contact for each instrument and develops a fundamental statement of expectations for the instrument's performance. These expectations, which include performance attributes such as accuracy, precision, and response time, are documented on public web pages so data users can determine the suitability of the measurements for their scientific application. The mentor also provides ACRF site operators with detailed guidance for deploying the instrumentation, prepares the documentation, and provides the training needed to permit on-site technicians to operate, maintain, diagnose, and repair the instrument. Mentors also prepare data quality inspection and assessment guidance for Data Quality Office analysts and prepare monthly data analysis retrospectives describing instrument performance. Importantly, mentors are part of the problem resolution process when instrument performance deviates from expectations, as evidenced through anomalous data quality.

ACRF site operators and technicians conduct preventative and corrective instrument and site maintenance, and collect and store information on field procedures and the metadata describing the results of their efforts. They also perform bench and in-field calibration checks. As an example, the Radiometer Calibration Facility was established to provide calibrations traceable to the World Radiometric Reference for all of the program's broadband shortwave radiometers; it can accommodate up to 100 broadband radiometers per calibration period. Site and instrument maintenance also includes a continuous quality field assessment that provides for improvements in instrument and site performance through yearly audits that include inspections and observations of site grounds, instruments, peripheral equipment, maintenance procedures, and technician proficiency.

\footnotetext{
${ }^{1}$ Pre-filled events would be reviewed and completed as necessary by site operations personnel for inclusion as an OSS event.

${ }^{2}$ http://en.wikipedia.org/wiki/Web_service (last accessed August 2, 2007)
} 
A data collection and processing infrastructure was devised to efficiently transport the data generated by instruments in the field to a central distribution point. Through several iterations and significant efforts to establish Internet connectivity to each field site, the ACRF data system has developed an efficient and integrated data flow. All data from the field sites are centrally processed on an hourly basis, accomplished using satellite networking, specialized data movement processes, and a tight configuration management process.

Data collected by field instrumentation must be documented such that users can readily identify whether there are known problems. Data quality inspection and assessment activities have evolved over the 15-year life of the ARM Program, culminating in the formation of a Data Quality Office in July 2000. It has since coordinated the data quality program, including the development of comprehensive inspection, assessment, and reporting tools, and data checking protocols, based on the best of what had been produced by the various players in data quality up to that time, and has played a key role in ensuring consistent application of data quality protocols across ACRF sites. Instrument mentors, as the technical authorities for the instruments, continue to provide in-depth instrument-specific perspectives on data quality and are crucial to resolving problems and identifying long-term data trends. Site scientists, as authorities on the locale and the site's scientific mission, continue to provide a broad perspective on data quality spanning the full range of instrumentation and oversee problem resolution. They also may perform targeted research on topics related to site data quality issues, and have the vital role of interacting with the scientific community to plan and conduct field campaigns at their sites, which have at times have identified previously-unknown data quality issues.

The quality of ACRF instrument-level measurements has been further improved through the processing and analysis of higher-order, value-added data products. These products often provide sophisticated interpretations of measurement-level information that are impossible to make through routine data quality analysis. In addition, many field campaigns have involved application of observational strategies and instrument comparisons aimed specifically at better measurement characterization; these have led to the improved accuracy and therefore more robust data quality of key ACRF measurements.

To be useful to the user community, data must not only be of high quality, but they also must be easy to access and obtain, and they must be sufficiently easy to work with. The ACRF Data Archive was established to not only efficiently store and provide access to the data collected by field instrumentation, but also to present intuitive, specific, and complete quality information for all data files. Data stream reprocessing is crucial to ensure that known, correctable problems are removed, helping to produce a consistent data format across sites and time to increase the usability of data. The anticipated result of reprocessing is a dataset of greater quality with fewer obstacles for the data user. In addition, engineering and operations management processes help ensure optimal instrument and systems performance and the application of fundamental changes in a structured, documented manner.

Future directions in ACRF data quality assurance intend to produce more precise automated data checking limits and facilitate better detection of slowly developing data trends, incorporate more sophisticated data checking algorithms at the file-creation level, and produce more thorough and detailed guidance for data quality analysts. A new data model will allow users ordering data at the Data Archive to obtain more information at the time of acquisition about long-term patterns in data as well as summary statistics of information gleaned from the measurements, while a new Operations Status System will allow for better tracking of ACRF instruments and their subcomponents. 
The processes that have been developed for the ACRF data quality assurance system represent a possible framework for use in other instrumentation-diverse networks; we offer them here to the data collection community to highlight the myriad aspects that go into producing a robust, high-quality dataset suitable for scientific research. We also invite community appraisal of these processes, which can be made by contacting the lead author directly or by submitting a comment through the ARM Program's webpage at http://www.arm.gov/about/contactus.stm.

\section{Acknowledgments}

Support for the ARM Climate Research Facility Data Quality Office at the University of Oklahoma and for this manuscript is provided by DOE Grant DE-AC05-76RL01830. Argonne National Laboratory's work is sponsored by the Office of Biological and Environmental Research, Office of Science, U.S. Department of Energy, under contract number DE-AC02-06CH11357. The contributions of S. W. Christensen and R. A. McCord were supported by the U.S. Department of Energy, Office of Science, Biological and Environmental Research (BER) programs. Though many have contributed over the years to our data quality assurance efforts, the lead author wishes to acknowledge two original members of the Southern Great Plains Site Scientist Team, Jeanne Schneider and Mike Splitt, who pioneered data quality efforts at the first data collection site near Lamont, Oklahoma.

\section{References}

Ackerman, TP, and GM Stokes. 2003. "The Atmospheric Radiation Measurement Program. Physics Today 56(1):38-44.

Augustine, JA, JJ DeLuisi, and CN Long. 2000. "SURFRAD - A national surface radiation budget network for atmospheric research." Bulletin of the American Meteorological Society 81(10):2341-2357.

Bahrmann, CP, and JM Schneider. 1999. "Near real-time assessment of SWATS data quality, resulting in an overall improvement in present-day SWATS data quality." Proceedings, Ninth Atmospheric Radiation Measurement (ARM) Science Team Meeting, San Antonio, Texas, May 18-20. Available at http://www.arm.gov/publications/proceedings/conf09/extended abs/bahrmann_cp.pdf. Accessed June 4, 2008.

Blough, DK. 1992. "Real-time statistical quality control and ARM." Transactions, $46^{\text {th }}$ Annual ASQC Quality Congress, May 18-20, Nashville, Tennessee. American Society for Quality Control, Milwaukee, Wisconsin, pp. 484-490.

Burns, SP, J Sun, AC Delany, SR Semmer, SP Oncley, and TW Horst. 2003. "A field intercomparison technique to improve the relative accuracy of longwave radiation measurements and an evaluation of CASES-99 pyrgeometer data quality." Journal of Atmospheric and Oceanic Technology 20(3): 348-361.

Cess, RD, TT Qian, and MG Sun. 2000. "Consistency tests applied to the measurement of total, direct and diffuse shortwave radiation at the surface." Journal of Geophysical Research-Atmospheres

105(D20): 24881-24887. 
Clothiaux, EE, TP Ackerman, GG Mace, KP Moran, RT Marchand, MA Miller, and BE Martner. 2000. "Objective determination of cloud heights and radar reflectivities using a combination of active remote sensors at the ARM CART sites." Journal of Applied Meteorology 39(5):645-665.

Clothiaux, EE, MA Miller, RC Perez, DD Turner, KP Moran, BE Martner, TP Ackerman, GG Mace, RT Marchand, KB Widener, DJ Rodriguez, T Uttal, JH Mather, CJ Flynn, KL Gaustad, and B Ermold. 2001. The ARM Millimeter Wave Cloud Radars (MMCRs) and the Active Remote Sensing of Clouds (ARSCL) Value Added Product (VAP). DOE Tech. Memo. ARM VAP-002.1, U.S. Department of Energy, Washington, D.C., available at http://www.arm.gov/publications/tech_reports/armvap-002-1.pdf. Accessed June 4, 2007.

Dabberdt WF, TW Schlatter, FH Carr, EWJ Friday, D Jorgensen, S Koch, M Pirone, FM Ralph, JZ Sun, P Welsh, JW Wilson, and XL Zou. 2005. "Multifunctional mesoscale observing networks." Bulletin of the American Meteorological Society 86(7): 961-982.

Delamere, JS, HA Eide, H Lindquist, R Storvold, P Utley, K Stamnes, CR Turney, KB Widener, and B Zak. 1999. "The first year of operation of the North Slope of Alaska/Adjacent Arctic Ocean ARM site: An overview of instrumentation, data streams, and data quality assurance procedures." Proceedings, Ninth Atmospheric Radiation Measurement (ARM) Science Team Meeting, March 22-26, 1999, San Antonio, Texas, U.S. Department of Energy, Washington, D.C. Available at http://www.arm.gov/publications/proceedings/conf09/extended abs/delamere1 js.pdf. Accessed June 4, 2008.

Dutton, EG, JJ Michalsky, T Stoffel, BW Forgan, J Hickey, DW Nelson, TL Alberta, and I Reda. 2001. "Measurement of broadband diffuse solar irradiance using current commercial instrumentation with a correction for thermal offset errors." Journal of Atmospheric and Oceanic Technology 18(3): 297-314.

Federal Coordinating Council for Science, Engineering, and Technology (FCCSET). 1990. Committee on Earth and Environmental Sciences. Our Changing Planet: The FY 1991 Research Plan of the U.S. Global Change Research Program. Office of Science and Technology Policy, Washington, D.C.

Ferrare, R. A., E. V. Browell, S. Ismail, S. Kooi, L. H. Brasseur, V. G. Brackett, M. B. Clayton, J. D. W. Barrick, G. S. Diskin, J. E. M. Goldsmith, B. M. Lesht, J. R. Podolske, G. W. Sachse, F. J. Schmidlin, D. D. Turner, D. N. Whiteman, D. Tobin, L. Miloshevich, H. E. Revercomb, B. B. Demoz, and P. Di Girolamo, 2004: Characterization of upper- troposphere water vapor measurements during AFWEX using LASE. Journal of Atmospheric and Oceanic Technology 21(12): 1790-1808.

Ferrare, R, D Turner, M Clayton, B Schmid, J Redemann, D Covert, R Elleman, J Ogren, E Andrews, JEM Goldsmith, and H Jonsson. 2006. "Evaluation of daytime measurements of aerosols and water vapor made by an operational Raman lidar over the Southern Great Plains." Journal of Geophysical Research-Atmospheres 111(D5): Art. No. D05S08.

Fiebrich, CA, and KC Crawford. 2001. "The impact of unique meteorological phenomena detected by the Oklahoma Mesonet and ARS Micronet on automated quality control." Bulletin of the American Meteorological Society 82(10): 2173-2187. 
Fiebrich, CA, JE Martinez, JA Brotzge, and J. B. Basara. 2003. “The Oklahoma Mesonet's skin temperature network." Journal of Atmospheric and Oceanic Technology 20(11):1496-1504.

Fiebrich, CA, DL Grimsley, RA McPherson, KA Kesler, and GR Essenberg. 2006. "The value of routine site visits in managing and maintaining quality data from the Oklahoma Mesonet. Journal of Atmospheric and Oceanic Technology 23(3):406-416.

Gracio, DK, LD Hatfield, KR Yates, JW Voyles, JL Tichler, RT Cederwall, MJ Laufersweiler, MJ Leach, and P Singley. 1996. "Data systems for science integration within the Atmospheric Radiation Measurement Program." In $12^{\text {th }}$ International Conference on Interactive Information Processing Systems (IIPS) for Meteorology, Oceanography, and Hydrology, January 28-February 2. Atlanta, Georgia, American Meteorological Society, Boston, Massachusetts, pp. 327-336.

Hollinger, SE, and RA Peppler. 1995. "Automated weather station characterization and documentation." In Proceedings of the First International Water Resources Conference, August 14-18, San Antonio, Texas, published by the American Society of Civil Engineers, New York, 2:1147-1151.

Ivanova, K, EE Clothiaux, HN Shirer, TP Ackerman, JC Liljegren, and M Ausloos. 2002. "Evaluating the quality of ground-based microwave radiometer measurements and retrievals using detrended fluctuation and spectral analysis methods." Journal of Applied Meteorology 41(1):56-68.

Jensen, M, and K Johnson. 2006. Continuous Profiles of Cloud Microphysical Properties for the Fixed Atmospheric Radiation Measurement Sites. Atmospheric Radiation Measurement Program Technical Report DOE/SC-ARM/P-0609, available at http://www.arm.gov/publications/programdocs/doe-sc-arm-p06-009.pdf. Accessed June 4, 2008.

Kehoe, KE, RA Peppler, KL Sonntag, and ST Moore. 2007. "Storing and organizing ARM Program measurements documentation for data quality purposes." Preprints, $14^{\text {th }}$ Symposium on Meteorological Observation and Instrumentation, January 14-18, San Antonio, Texas, American Meteorological Society, Boston Massachusetts, CD-ROM JP1.12. http://ams.confex.com/ams/pdfpapers/118999.pdf. Accessed June 4, 2008.

Lambert, WC, FJ Merceret, GE.Taylor, and JG Ward. 2003. "Performance of five 915-MHz wind profilers and an associated automated quality control algorithm in an operational environment." Journal of Atmospheric and Oceanic Technology 20(11):1488-1495.

Long, CN. 1998. Nauru Island Effect Study (NIES) IOP Science Plan. ARM Technical Document $D O E / S C-A R M-0505$, available at http://www.arm.gov/publications/programdocs/doe-sc-arm-0505.pdf. Accessed June 4, 2008.

Long, CN, and TP Ackerman. 2000. "Identification of clear skies from broadband pyranometer measurements and calculation of downwelling shortwave cloud effects." Journal of Geophysical Research-Atmospheres 105(D12):15609-15626.

Long, CN, and EG Dutton. 2002. BSRN Global Network recommended QC Tests, V 2.0. BSRN, available at http://ezksun3.ethz.ch/bsrn/admin/dokus/qualitycheck.pdf. Accessed June 4, 2008. 
Long, CN, and KL Gaustad. 2004. The Shortwave (SW) Clear-Sky Detection and Fitting Algorithm: Algorithm Operational Details and Explanations. ARM TR-004.1, available at http://www.arm.gov/publications/tech_reports/arm-tr-004-1.pdf. Accessed June 4, 2008.

Long, CN, and Y Shi. 2006. The QCRad Value Added Product: Surface Radiation Measurement Quality Control Testing, Including Climatology Configurable Limits. ARM TR-074, available at http://www.arm.gov/publications/tech_reports/arm-tr-074.pdf. Accessed June 4, 2008.

Macduff, MC, and RC Eagan. 2005. "ACRF data collection and processing infrastructure." ARM TR046 Preprints, $21^{\text {st }}$ International Conference on Interactive Information Processing Systems (IIPS) for Meteorology, Oceanography, and Hydrology, January 9-13, San Diego, California, American Meteorological Society, Boston, Massachusetts CD-ROM, J17.1. Available at http://www.arm.gov/publications/tech_reports/arm-tr-046.pdf Accessed June 4, 2008.

Martinez, JE, CA Fiebrich, and MA Shafer. 2004. "The value of a quality assurance meteorologist." Preprints, $14^{\text {th }}$ Conference on Applied Climatology, Seattle Washington, American Meteorological Society, Boston, Massachusetts CD-ROM, 7.4. Available at http://ams.confex.com/ams/pdfpapers/69793.pdf Accessed June 4, 2008.

Martinez, JE, CA Fiebrich, and RA McPherson. 2005. "The value of weather station metadata." Preprints, $15^{\text {th }}$ Conference on Applied Climatology, Savannah, Georgia, American Meteorological Society, Boston, Massachusetts CD-ROM, J3.1. Available at http://ams.confex.com/ams/pdfpapers/91315.pdf Accessed June 4, 2008.

Mather, JH, TP Ackerman, WE Clements, FJ Barnes, MD Ivey, LD Hatfield, and RM Reynolds. 1998. "An atmospheric radiation and cloud station in the tropical western Pacific." Bulletin of the American Meteorological Society 79(4):627-642.

Matthews, S, JM Hacker, J Cole, J Hare, CN Long, and RM Reynolds. 2007. "Modification of the atmospheric boundary layer by a small island: Observations from Nauru." Monthly Weather Review 135(3):891-905.

McFarlane, SA, CN Long, and DM Flynn. 2005. "Impact of island-induced clouds on surface measurements: Analysis of the ARM Nauru Island Effect Study data." Journal of Applied Meteorology 44:(7)1045-1065.

Meek, DW, and JL Hatfield. 1994. "Data quality checking for single station meteorological databases." Agricultural and Forest Meteorology 69(1-2):85-109.

Meyer, SJ, and KG Hubbard. 1992. "Nonfederal automated weather stations and networks in the United States and Canada: A preliminary study." Bulletin of the American Meteorological Society 73(4):449-457. 
Michalsky, J, P Kiedron, J Berndt, T Stoffel, D Myers, I Reda, J Treadwell, A Andreas, S Asano, A Uchiyama, A Yamazaki, M Haeffelin, T Tooman, R McCoy, A Bucholtz, BC Bush, SK Pope, AS Leitner, and FPJ Valero. 2002. "Broadband shortwave calibration results from the Atmospheric Radiation Measurement Enhanced Shortwave Experiment II." Journal of Geophysical Research-Atmospheres 107:(D16): Art. No. 4287.

Michalsky, JJ, R Dolce, EG Dutton, M Haeffelin, G Major, JA Schlemmer, DW Slater, JR Hickey, WQ Jeffries, A Los, D Mathias, LJB McArthur, R Philipona, I Reda, and T Stoffel. 2003. "Results from the first ARM diffuse horizontal shortwave irradiance comparison." Journal of Geophysical Research-Atmospheres 108(D3): Art. No. 4108.

Miller, NE, JC Liljegren, TR Shippert, SA Clough, and PD Brown. 1994. "Quality measurement experiments within the Atmospheric Radiation Measurement Program." Preprints, Fifth Symposium on Global Change Studies, Nashville, Tennessee, American Meteorological Society, Boston, Massachusetts, pp. 35-39.

Mlawer, EJ, JS Delamere, SA Clough, MA Miller, KL Johnson, TR Shippert, CN Long, RG Ellingson, MH Zhang, RA Ferrare, and RT Cederwall. 2002. "The Broadband Heating Rate Profile (BBHRP) VAP." In Proceedings, 12th ARM Science Team Meeting, April 8-12, St. Petersburg, Florida, available at http://www.arm.gov/publications/proceedings/conf12/extended_abs/mlawer-ej.pdf. Accessed June 4, 2008.

Moore, ST, RA Peppler, KE Kehoe, and KL Sonntag. 2007. "Analysis of historical ARM measurements to detect trends and assess typical behavior." Preprints, $16^{\text {th }}$ Conference on Applied Climatology, January 14-18, San Antonio, Texas, American Meteorological Society, Boston, Massachusetts CD-ROM, P2.6. Available at http://ams.confex.com/ams/pdfpapers/119946.pdf. Accessed June 4, 2008.

Ohmura, A, EG Dutton, B Forgan, C Fröhlich, H Gilgen, H Hegner, A Heimo, G König-Langlo, B McArthur, G Müller, R Philipona, R Pinker, CH Whitlock, K Dehne, and M Wild. 1998. "Baseline Surface Radiation Network (BSRN/WCRP): New precision radiometry for climate research." Bulletin of the American Meteorological Society 79(10):2115-2136.

Peppler, RA, and ME Splitt. 1997. "SGP Site Scientist Team data quality assessment activities." Proceedings, Seventh Atmospheric Radiation Measurement (ARM) Science Team Meeting, March, San Antonio, Texas, U.S. Department of Energy, pp. 403-406. Available at http://www.arm.gov/publications/proceedings/conf07/extended_abs/peppler_ra.pdf Accessed June 4, 2008.

Peppler, RA, DL Sisterson, and PJ Lamb. 1999. Site Scientific Mission Plan for the Southern Great Plains CART Site, July-December 1999. ARM-99-002, U.S. Department of Energy, Washington, D.C. Available at http://www.ipd.anl.gov/anlpubs/1999/12/34541.pdf Accessed June 4, 2008.

Peppler, RA, KE Kehoe, KL Sonntag, ST Moore, and KJ Doty. 2005. "Improvements to and status of ARM's Data Quality Health and Status System." Preprints, $15^{\text {th }}$ Conference on Applied Climatology, Savannah, Georgia, American Meteorological Society, Boston, Massachusetts CD-ROM, J3.13. 
Philipona, R. 2002. "Underestimation of solar global and diffuse radiation measured at Earth's surface." Journal of Geophysical Research-Atmospheres 107(D22): Art. No. 4654.

Philipona, R, EG Dutton, T Stoffel, J Michalsky, I Reda, A Stifter, P Wendling, N Wood, SA Clough, EJ Mlawer, G Anderson, HE Revercomb, and TR Shippert. 2001. "Atmospheric longwave irradiance uncertainty: Pyrgeometers compared to an absolute sky-scanning radiometer, atmospheric emitted radiance interferometer, and radiative transfer model calculations." Journal of Geophysical Research-Atmospheres 106(D22):28129-28141.

Reda, I, J Hickey, C Long, D Myers, T Stoffel, S Wilcox, JJ Michalsky, EG Dutton, and D Nelson. 2005. "Using a blackbody to calculate net longwave responsivity of shortwave solar pyranometers to correct for their thermal offset error during outdoor calibration using the component sum method." Journal of Atmospheric and Oceanic Technology 22(10):1531-1540.

Revercomb, HE, DD Turner, DC Tobin, RO Knuteson, WF Feltz, J Barnard, J Bösenberg, S Clough, D Cook, R Ferrare, J Goldsmith, S Gutman, R Halthore, B Lesht, J Liljegren, H Linné, J Michalsky, V Morris, W Porch, S Richardson, B Schmid, M Splitt, T Van Hove, E Westwater, and D Whiteman. 2003. "The ARM Program's water vapor intensive observation periods-Overview, initial accomplishments, and future challenges." Bulletin of the American Meteorology Society 84(2):217-236.

Richardson, SJ. 1995. "Automated temperature and relative humidity calibrations for the Oklahoma Mesonetwork." Journal of Atmospheric and Oceanic Technology 12(4):951-959.

Richardson, SJ, ME Splitt, and BM Lesht. 2000. "Enhancement of ARM surface meteorological observations during the fall 1996 water vapor intensive observation period." Journal of Atmospheric and Oceanic Technology 17(3):312-322.

Schroeder, JL, WS Burgett, KB Haynie, I Sonmez, GD Skwira, AL Doggett, and JW Lipe. 2005. "The West Texas Mesonet: A technical overview." Journal of Atmospheric and Oceanic Technology 22(2):211-222.

Shafer, MA, CA Fiebrich, DS Arndt, SE Fredrickson, and TW Hughes. 2000. "Quality assurance procedures in the Oklahoma Mesonetwork." Journal of Atmospheric and Oceanic Technology 17(4):474-494.

Shi, Y, and CN Long. 2002. Best Estimate Radiation Flux Value Added Product: Algorithm Operational Details and Explanations. ARM TR-008, available at http://www.arm.gov/publications/tech_reports/armtr-008.pdf. Accessed June 4, 2008.

Sisterson, DL, JJ Teske, DK Breedlove, RA Peppler, and CP Bahrmann. 1999. "Maintaining continuous operation of complex instruments at the SGP CART site." Proceedings, Ninth Atmospheric Radiation Measurement (ARM) Science Team Meeting, San Antonio, Texas, available at http://www.arm.gov/publications/proceedings/conf09/extended_abs/sisterson_dl.pdf. Accessed June 4, 2008. 
Soden, BJ, DD Turner, BM Lesht, and LM Miloshevich. 2004. "An analysis of satellite, radiosonde, and lidar observations of upper tropospheric water vapor from the Atmospheric Radiation Measurement Program." Journal of Geophysical Research-Atmospheres 109(D4): Art. No. D04105.

Splitt, ME. 1996. "Data quality display modules - assessment of instrument performance at the Southern Great Plains Cloud and Radiation Testbed site." In Proceedings of the Sixth Atmospheric Radiation Measurement (ARM) Science Team Meeting, March, San Antonio, Texas, pp. 301-303. Available at http://www.arm.gov/publications/proceedings/conf06/extended abs/splitt me.pdf Accessed June 4, 2008.

Stamnes, K, RG Ellingson, JA Curry, JE Walsh, and BD Zak. 1999. "Review of science issues, deployment strategy, and status for the ARM North Slope of Alaska-Adjacent Arctic Ocean climate research site." Journal of Climate 12(1):46-63.

Stoffel, T. 2005. Solar Infrared Radiation Station (SIRS) Handbook. ARM TR-025, available at http://www.arm.gov/publications/tech_reports/handbooks/sirs_handbook.doc. Accessed June 4, 2008.

Stokes, GM, and SE Schwartz. 1994. "The Atmospheric Radiation Measurement (ARM) Program: Programmatic background and design of the cloud and radiation test bed." Bulletin of the American Meteorological Society 75(7):1201-1221.

Tucker, DF. 1997. "Surface Mesonets of the western United States. Bulletin of the American Meteorological Society 78(7):1485-1495.

Turner, DD, and JEM Goldsmith. 1999. "Twenty-four-hour Raman lidar water vapor measurements during the Atmospheric Radiation Measurement Program's 1996 and 1997 water vapor intensive observation periods." Journal of Atmospheric and Oceanic Technology 16(8):1062-1076.

Turner, DD, BM Lesht, SA Clough, JC Liljegren, HE Revercomb, and DC Tobin. 2003. "Dry bias and variability in Vaisala RS80-H radiosondes: The ARM experience." Journal of Atmospheric and Oceanic Technology 20(1):117-132.

Turner, DD, HE Revercomb, RO Knuteson, RG Dedecker, and WF Feltz. 2004a. An Evaluation of the Nonlinearity Correction Applied to Atmospheric Emitted Radiance Interferometer (AERI) Data Collected by the Atmospheric Radiation Measurement Program. ARM TR-013, available at http://www.arm.gov/publications/tech_reports/arm-tr-013.pdf. Accessed June 4, 2008.

Turner, DD, DC Tobin, SA Clough, PD Brown, RG Ellingson, EJ Mlawer, RO Knuteson, HE Revercomb, TR Shippert, and WL Smith. 2004b. "The QME AERI LBLRTM: A closure experiment for downwelling high spectral resolution infrared radiance." Journal of the Atmospheric Sciences 61(22):2657-2675.

Turner, DD, RO Knuteson, HE Revercomb, C Lo, and RG Dedecker. 2006. "Noise reduction of Atmospheric Emitted Radiance Interferometer (AERI) observations using principal component analysis." Journal of Atmospheric and Oceanic Technology 23(9):1223-1238. 
U.S. Department of Energy (DOE). 1990a. Executive Summary: Atmospheric Radiation Measurement Program Plan. DOE/ER-0442, DOE, Washington, D.C.

U.S. Department of Energy (DOE). 1990b. Atmospheric Radiation Measurement Program Plan. DOE/ER-0441, DOE, Washington, D.C.

U.S. Department of Energy (DOE). 1991a. Executive Summary: Identification, Recommendation, and Justification of Potential Locales for ARM Sites. DOE/ER-0494T, DOE, Washington, D.C.

U.S. Department of Energy (DOE). 1991b. Identification, Recommendation, and Justification of Potential Locales for ARM Sites. DOE/ER-0495T, DOE, Washington, D.C.

Weber, BL, DB Wuertz, DC Welsh, and R McPeek. 1993. "Quality controls for profiler measurements of winds and RASS temperatures.” Journal of Atmospheric and Oceanic Technology 10(4):452-464.

Westwater, ER, BB Stankov, D Cimini, Y Han, JA Shaw, BM Lesht, and CN Long. 2003. "Radiosonde humidity soundings and microwave radiometers during Nauru99." Journal of Atmospheric and Oceanic Technology 20(7):953-971.

Younkin, K, and CN Long. 2004. Improved Correction of IR Loss in Diffuse Shortwave Measurements: An ARM Value Added Product. ARM TR-009, available at http://www.arm.gov/publications/tech_reports/arm-tr-009.pdf._Accessed June 4, 2008. 